\section{Cahiers de Narratologie}

Analyse et théorie narratives

$20 \mid 2011$

Voix off et narration cinématographique

\title{
Empty Quarter (Une Femme en Afrique) de Raymond Depardon : l'image d'une voix off
}

\section{Cyril Laverger}

\section{(2) OpenEdition}

Journals

Édition électronique

URL : http://journals.openedition.org/narratologie/6310

DOI : 10.4000/narratologie.6310

ISSN : 1765-307X

Éditeur

LIRCES

Référence électronique

Cyril Laverger, «Empty Quarter (Une Femme en Afrique) de Raymond Depardon : I'image d'une voix off », Cahiers de Narratologie [En ligne], 20 | 2011, mis en ligne le 26 août 2011, consulté le 22 avril 2019. URL : http://journals.openedition.org/narratologie/6310; DOI : 10.4000/narratologie.6310

Ce document a été généré automatiquement le 22 avril 2019

Article L.111-1 du Code de la propriété intellectuelle. 


\title{
Empty Quarter (Une Femme en Afrique) de Raymond Depardon: l'image d'une voix off
}

\author{
Cyril Laverger
}

1 Célèbre photographe reporter, puis réalisateur de courts et longs métrages documentaires à partir de la fin des années soixante, Raymond Depardon tourne son premier long métrage de fiction ${ }^{1}$ durant sept mois en 1984-1985. Empty Quarter (Une Femme en Afrique) ${ }^{2}$ relate une relation amoureuse nourrie d'expériences autobiographiques. Il explique ainsi ce recours à la fiction : "Après Faits divers, j'ai eu l'impression - pas une impression, une certitude - que je ne voulais pas continuer dans l'escalade de films à sensations. Je pensais que j'avais atteint le maximum dans le regard sur les autres et qu'il était temps - momentanément même - de tourner un film complètement différent à partir d'expériences personnelles ou d'une fiction. Tout de suite après Faits divers, le Centre National de la Photographie m'avait commandé les Années déclic qui était un film autobiographique, donc il n'y avait pas d'autre solution que la fiction. Depuis une dizaine d'années déjà j'avais l'idée de ce film racontant l'histoire d'un photographe, sa rencontre avec une femme, loin de Paris, dans une espèce de temps suspendu ${ }^{3} \ldots$ ".

2 Le personnage féminin est interprété par Françoise Prenant; elle effectue également le montage de ce film avec Jacques Kebadian ${ }^{4}$.

3 Le titre provient sans doute d'un auteur apprécié par Depardon, Wilfred Thesiger, et d'un de ses livres: Across the Empty Quarter. Il s'agit aussi de la dénomination anglaise d'un immense désert de la péninsule arabique; sans doute Empty Quarter définit-il ici tout autant le désert traversé par les protagonistes que la géographie des sentiments et la philosophie de la vie : un cœur vide à remplir, une compréhension de soi et des autres à (re)construire.

4 Raymond Depardon opte pour un dispositif narratif radical : ne jamais voir et entendre le personnage masculin qui vit cette aventure; seule sa voix off et les regards-caméra des 
autres protagonistes le font exister. Sans se présenter totalement comme un journal intime filmé à la manière de, par exemple, Joseph Morder, Lionel Soukaz, Alain Cavalier ou, plus encore, Stephen Dwoskin, Empty Quarter est une fiction extrêmement attentive au réel, à la vérité nue.

5 Cette présence de la voix off, sans jamais voir le personnage dont elle émane, ouvre des réflexions multiples. Pour les étayer, il est nécessaire à présent d'examiner les rapports qu'entretient cette voix off avec l'environnement sonore d'une part, et l'environnement visuel d'autre part. A savoir, sons in, hors-champ ${ }^{5}$ et off; cadrage, montage, récit, etc. Au fil du film, ces rapports se développent et définissent le statut de cette voix off, avant de le perturber insensiblement.

Description de certaines données :

7 Empty Quarter dure 83 minutes et 12 secondes. Il comporte 183 plans fixes et 26 plans en mouvement (hors caméra fixe dans un véhicule en mouvement), dont 7 plans en caméra portée épaule et 19 plans en panoramique.

\begin{tabular}{|l|l|l|}
\hline Données voix ${ }^{6}$ & Voix off homme & Voix in/hors-champ femme \\
\hline Durée & $19 \min 52 \mathrm{~s}$ & 8 min $24 \mathrm{~s}$ \\
\hline Nombre d'interventions & 49 & 28 \\
\hline Écart moyen entre les interventions & 1 min $15 \mathrm{~s}$ & 2 min $40 \mathrm{~s}$ \\
\hline Durée des interventions & de $3 \mathrm{~s}$ à $56 \mathrm{~s}$ & de $2 \mathrm{~s}$ à 2 min $30 \mathrm{~s}$ \\
\hline Durée moyenne des interventions & $24,3 \mathrm{~s}$ & $20,2 \mathrm{~s}$ \\
\hline Nombre de plans concernés & 59 & 28 \\
\hline
\end{tabular}

\section{Points d'ancrage}

\section{Ancrage progressif de subjectivité}

8 Après un générique de trois cartons noirs et caractères blancs ${ }^{7}$, le premier plan institue plusieurs facteurs définissant la dimension réaliste/fictive d'une part, et subjective d'autre part. Ce plan nocturne d'un endroit urbain dans lequel on entraperçoit une circulation automobile et, principalement, piétonne, instaure d'emblée une certaine exigence de vérité. La bande son est au diapason de l'image : un chant religieux lointain apparemment musulman et quelques bruits de véhicules accompagnent discrètement cette image ${ }^{8}$. Cette esthétique met ainsi en place un propos contemplatif par la durée du plan, sa fixité et l'absence d'action proprement dite. La carence d'indices nourrissant un quelconque exotisme superficiel prépare parfaitement l'esprit du récit qui s'ouvre; rien d'autre qu'un lieu anonyme aux accents culturels islamisants (quelques femmes voilées circulent dans cette semi-obscurité). 


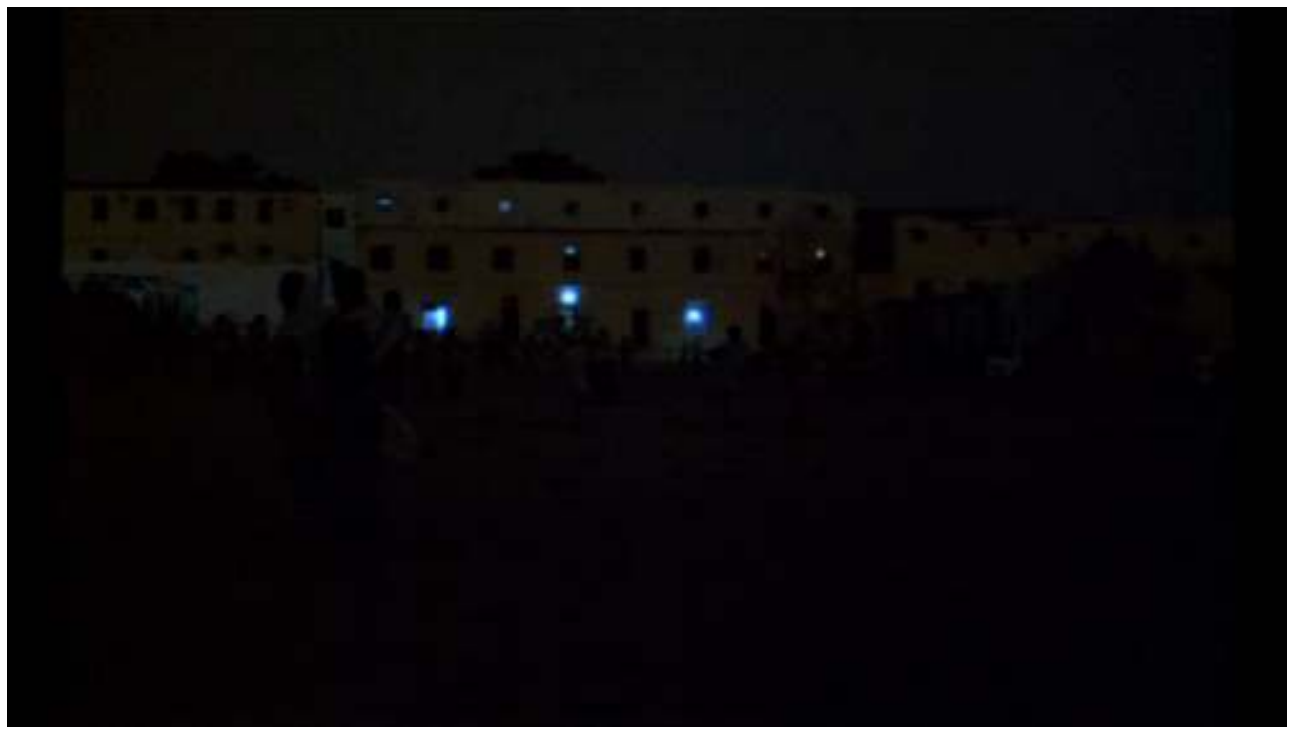

Plan $1-15 \mathrm{~s} / 1 \mathrm{~min} 34^{9}$

[«Empty Quarter (Une Femme en Afrique)», production : Double D Copyright Films / FR3 films production. Tous droits réservés.]

9 La voix off démarre près d'une minute après le début de ce plan: «C'est le mois de décembre ; j'attends de repartir pour un autre pays ; je suis au bord de la Mer Rouge, à Djibouti. »

10 Elle remplit son premier «devoir»: apporter des indications spatio-temporelles. Elle annonce aussi le discours à la première personne. De la sorte, la narration s'ancre initialement dans la subjectivité. Elle apparaît comme une "voix-Je ${ }^{10}$ " par sa qualité sonore : mate, grande proximité, niveau dominant distinctement l'ambiance extérieure. La voix est assez grave et neutre ; les couleurs du « jeu » semblent en être exclues : sans ostentation, sans modulation marquée, la vérité s'installe.

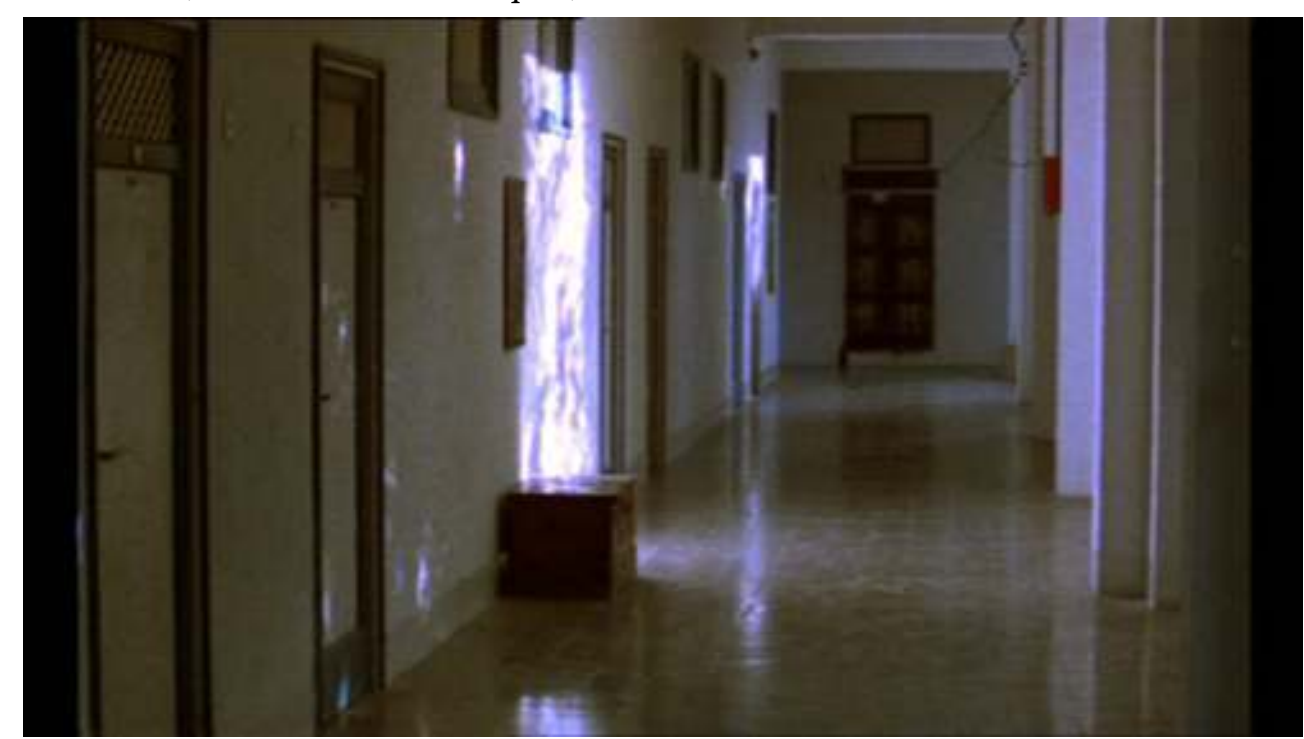

Plan 2 - $1 \min 34 / 2 \min 19$

[«Empty Quarter (Une Femme en Afrique)», production : Double D Copyright Films / FR3 films production. Tous droits réservés.]

11 Le plan 2 émerge d'un fondu au noir et sonore. Intérieur jour, clarté, couloir vide, gazouillis d'oiseaux hors-champ, lointain brouhaha: une véritable mise en lumière 
s'opère. Après la mise en situation générale du premier plan, les indices culturels ne sont plus convoqués. L'ambiance visuelle et sonore instille calme, neutralité, attente, vide; virginité d'un espace que seule la venue d'une personne permettrait de connoter. Pourtant, ce couloir restera vide pendant toute la durée du plan. Cette présence virtuelle est alors confiée à la voix off qui intervient rapidement, au bout de seulement quatre secondes : «Ce matin, j'ai rencontré une femme dans le hall de l'hôtel; elle venait voir si elle avait du courrier. Elle est en voyage comme moi depuis longtemps. Nous étions plutôt intimidés tous les deux. J'ai compris qu'elle attendait une lettre de quelqu'un qui doit venir la rejoindre. J'ai compris aussi qu'elle avait quelques difficultés. Je lui ai proposé de partager ma chambre. C'est une grande chambre, elle a accepté; maintenant je l'attends ».

12 Alors que le premier plan avait laissé, durant une minute, le spectateur « seul », cette soudaineté de la voix off marque une sorte de précipitation du narrateur soulignant son désir de nous évoquer sa rencontre avec cette femme. Par les éléments de son discours, la voix off s'approche d'une voix intérieure, d'une pensée d'un personnage présent horschamp qui observerait ce couloir ; l'image nous place dans la situation décrite au début et à la fin du texte : clarté et sonorité matinales, attente. Les pronoms personnels employés (je, elle, nous) nourrissent aussi l'implication du narrateur. La voix exprime des actions qui s'enchaînent et se conjuguent à la première personne du pluriel l'espace d'un instant, avant de s'achever sur une action à la première personne du singulier à laquelle le dispositif voix-image invite le spectateur à participer: «maintenant je l'attends». De plus, l'ambiance des chants d'oiseaux accompagne parfaitement la prémisse sentimentale.

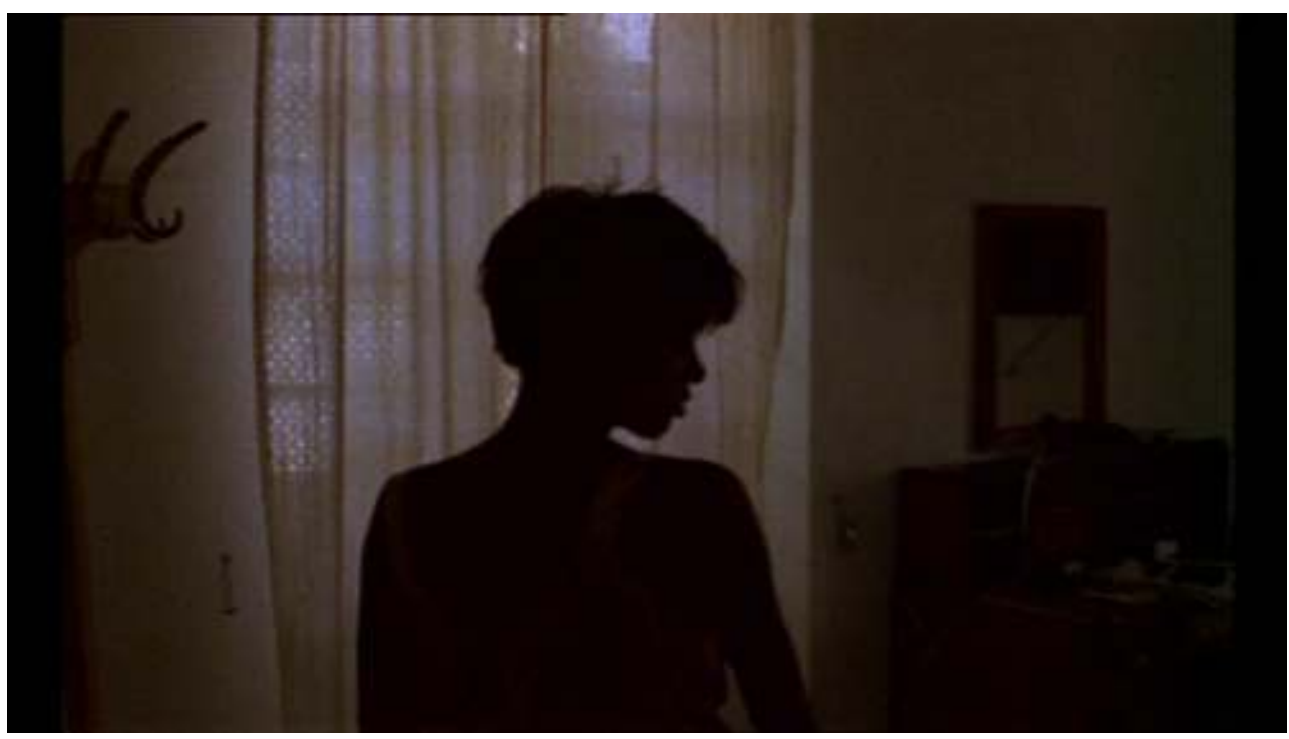

Plan $3-2 \min 19 / 3 \min 07$

[«Empty Quarter (Une Femme en Afrique) », production : Double D Copyright Films / FR3 films production. Tous droits réservés.]

Ce troisième plan propose la première apparition du personnage féminin dans un contrejour énigmatique propre à aiguiser la curiosité. La silhouette dessinée laisse deviner un corps jeune. Jusque-là, la voix off n'avait fourni aucune précision descriptive à son égard. L'absence de la voix off sur ce plan 3 et la présence de sons ambiants (sons directs, très vraisemblablement) créent une immersion dans le réel, sans distanciation. Par ailleurs, le son hors-champ de la manipulation d'un interrupteur débusque discrètement une présence : la lumière artificielle survient et indique que cette personne (l'homme de la 
voix off sans nul doute ${ }^{11}$ ) désire implicitement mieux la voir et, incidemment, mieux nous la montrer - en plus de permettre à cette femme de mieux y voir. A peine la lumière estelle faite que la jeune femme « s'évade » de cette prise de possession visuelle en allant sur la terrasse, passant ainsi derrière le voilage qui la masque et l'enveloppe un instant avec légèreté et sensualité, doublant l'espoir de mieux l'observer avec le désir fantasmatique de repousser ce contact. Un son hors-champ, une fois de plus, signifie cet état : après les gazouillis romantiques du plan 2, un triple coup de klaxon ${ }^{12}$ survient au moment même où elle apparaît sur la terrasse, comme pour saluer sa beauté.

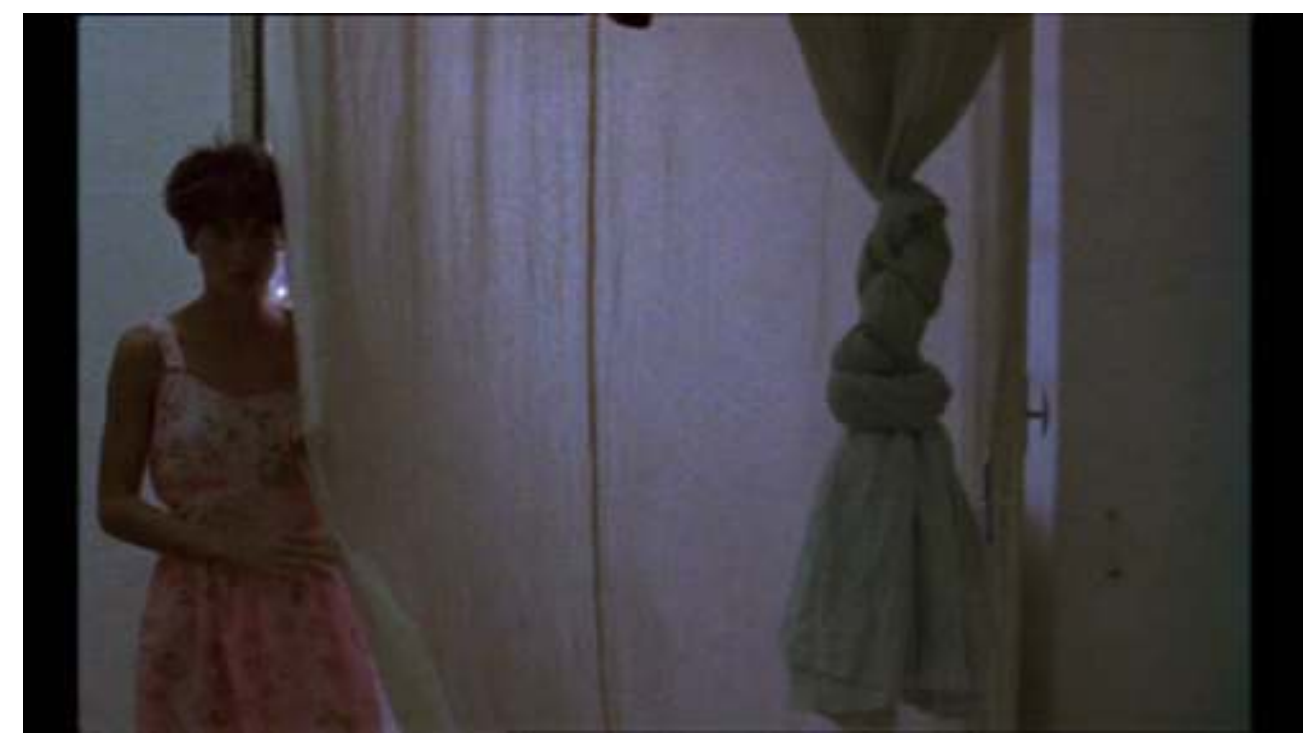

Plan 4 - 3 min 07/ 3 min 25

[«Empty Quarter (Une Femme en Afrique) », production : Double D Copyright Films / FR3 films production. Tous droits réservés.]

14 Par ce premier regard-caméra ${ }^{13}$, ce plan scelle définitivement le lien entre le personnage féminin et la caméra qui prend ainsi le statut de regardant, intimement lié à la voix off. Il n'est pas anodin que ce regard-caméra apparaisse fugitivement quand elle revient de son escapade sur la terrasse et qu'elle se dégage du voilage dans une luminosité pas encore très franche: cela affirme son "angélisme" et expose la timidité de la première rencontre, initialement évoquée par la voix off du plan $2^{14}$.

15 Ces quatre premiers plans établissent donc un ancrage progressif de subjectivité. Tout d'abord par la voix off: de la stricte neutralité situationnelle à l'implication personnelle, la voix off se définit comme une " voix-Je »; ensuite par le bruitage : l'interrupteur atteste la présence hors-champ du potentiel propriétaire de la voix off; enfin par l'image : le regard-caméra débusque le personnage masculin. En jouant sur les mots, «quelqu'un nous est/a démasqué/s » dans ces deux derniers plans.

Quelle est donc la nature de cette familiarité qu'entretiennent voix off et caméra? Le strict point de vue subjectif est-il revendiqué? L'homme n'étant ni visible, ni explicitement audible dans l'espace observé et suggéré, et les plans étant parfaitement fixes, le point de vue ne peut être qualifié de purement subjectif. Comme, par la suite, le personnage masculin ne sera jamais vu et entendu par le spectateur, cette subjectivité est imparfaite. Cette caméra fixe est une sorte de poste d'observation quasi mental qui donne à voir l'objet de la pensée et d'un vécu. Pour l'associer et la dissocier de l'expression "regard-caméra», ce point de vue pourrait être dénommé "regard-de-caméra», la caméra devenant l'excroissance visuelle altruiste de la « voix-Je ». 


\section{Point de vue et point d'écoute}

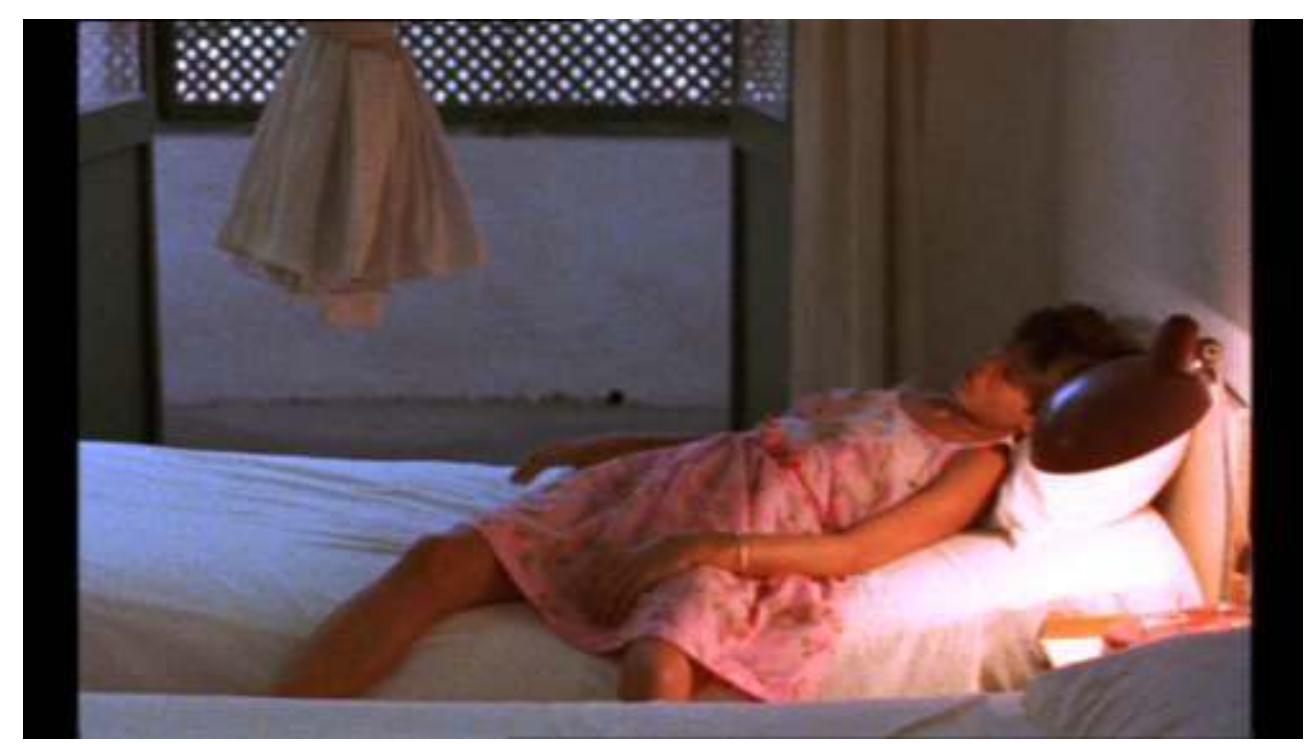

Plan $5-3 \min 25 / 4 \min 07$

[«Empty Quarter (Une Femme en Afrique)», production : Double D Copyright Films / FR3 films production. Tous droits réservés.]

Comme avec le deuxième plan, la voix off arrive rapidement : «Je lui donne le lit du côté de la fenêtre. Je suis content qu'elle soit là ; je ne suis plus tout seul. Je la regarde. Au fond, j'la connais pas. Elle s'installe dans la chambre; est-ce que c'est moi qui compte ou bien est-ce que ça l'arrange d'être sur place pour attendre son courrier? J'arrête de penser à ça. »

18 Un élément nouveau survient alors; pour la première fois, cette jeune femme s'exprime, alors qu'elle balance nonchalamment la moustiquaire nouée au-dessus d'elle. Sa voix apparaît deux secondes après la voix off : «C'est bien ici. Le patron de l'hôtel, il va rien dire?»

D'une part, la voix off lui a laissé le champ sonore libre, puisqu'aucun chevauchement des deux voix n'a lieu à ce moment-là; la voix de l'homme respecte donc cette nouvelle dimension de la personnalité du personnage féminin. Après le corps, la voix - et tout ce dont elle est chargée: timbre, expression, âge, émotion, sensualité,...- capte notre attention. D'autre part, c'est aussi le premier élément sonore véritablement in, c'est-àdire dont la source est ostensiblement dans le champ. Il n'est pas anodin que cette jonction audio-visuelle intervienne avec cette femme, qui devient ainsi non seulement le vecteur de la connexion entre image et son, mais aussi le seul personnage vivant pleinement devant nous - contrairement à la voix off irrémédiablement handicapée par le manque de corps. Après être apparue progressivement, le réalisateur confère à cette femme une voix pour achever sa présentation. Enfin, ses paroles semblent en accord partiel avec la voix off: à « je suis content qu'elle soit là » (off), elle a l'air de répondre un peu plus loin «c'est bien ici » (in); deux indices de satisfaction, mais qui ne fonctionnent pas sur le même mode émotionnel - décalage initial qui stigmatise le nœud de l'intrigue sentimentale. 


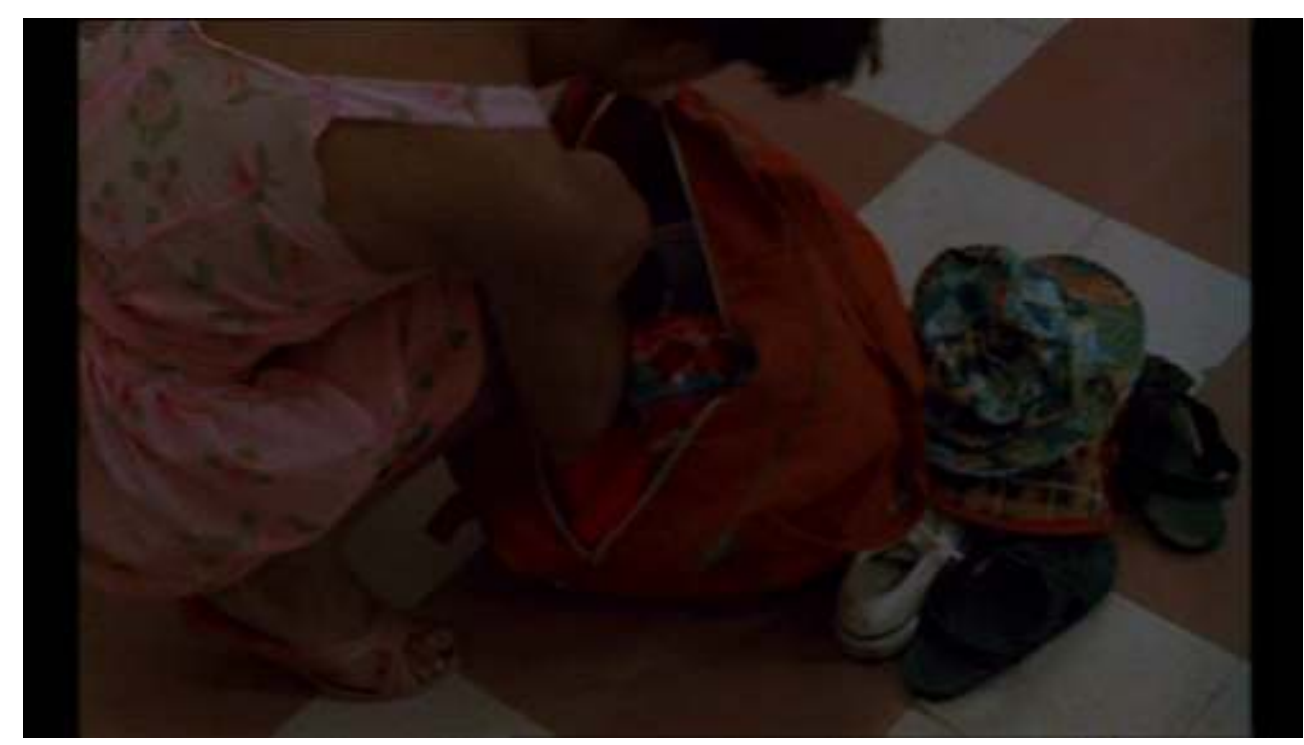

Plan $6-4 \min 07 / 4 \min 35$

[«Empty Quarter (Une Femme en Afrique)», production : Double D Copyright Films / FR3 films production. Tous droits réservés.]

20 Le plan suivant donne à entendre de nouveau la femme alors qu'elle entre dans le champ, s'accroupit et tente de faire fonctionner un petit appareil à cassette audio extrait de son sac. Elle est vue de dos et dit : «oh, ça marche plus !».

21 Ainsi, immédiatement après sa voix in, son visage est partiellement masqué et sa bouche non visible. Cette position de trois quarts dos et le fait qu'elle parle durant ce plan, augmentent d'un degré encore le potentiel point de vue subjectif du film : elle est vue et entendue sans qu'elle soit donnée à voir par un cadrage plus frontal; elle est donc observée. En mettant en marche son appareil et en quittant le champ en l'emportant, elle provoque l'apparition de l'air d'un opéra de Rossini (l'Italienne à Alger) qui emplit l'espace sonore et va jouer de façon marquée l'un des rôles traditionnels dévolu au son : le raccord avec le plan suivant. En effet, le plan 7 montre la jeune femme déjà assise sur son lit en train de déballer quelques affaires; la musique emballe l'ellipse alors que les 
enchaînements précédents ne "trichaient » pas et suggéraient concrètement un temps amputé.

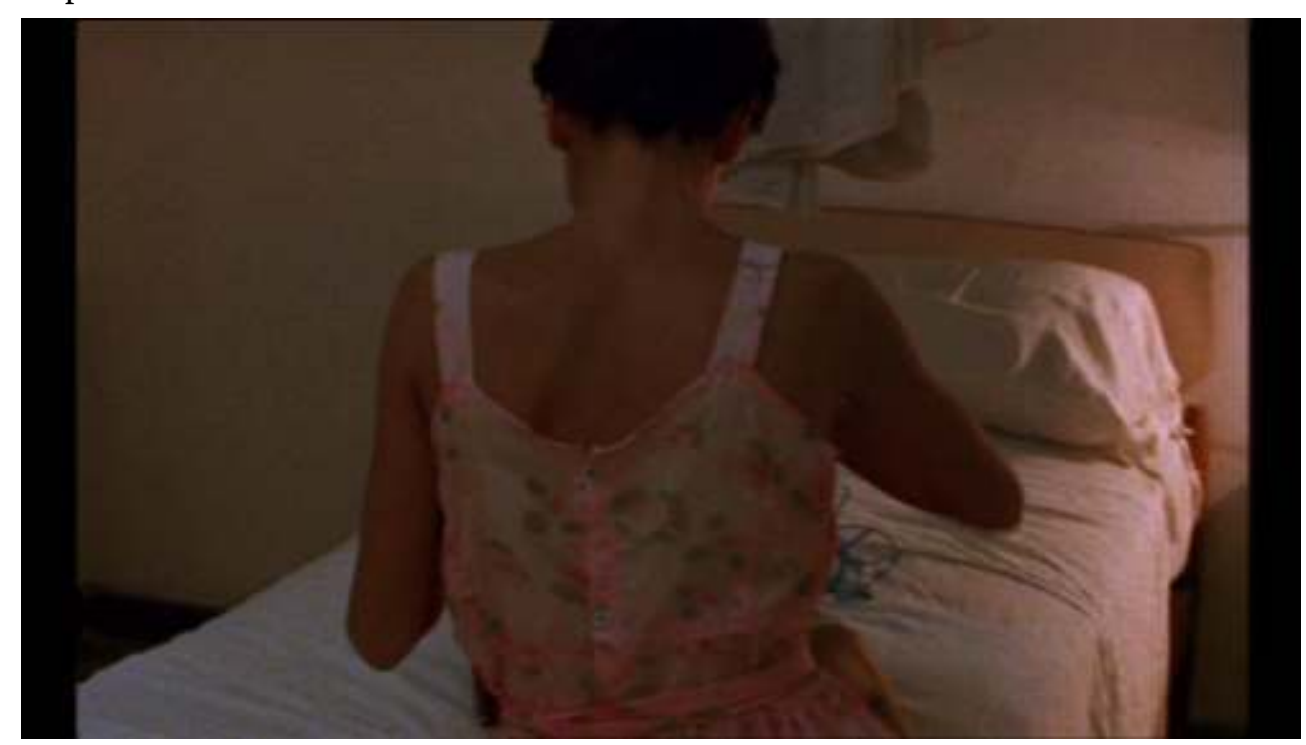

Plan $7-4 \min 35 / 4 \min 58$

[«Empty Quarter (Une Femme en Afrique) », production : Double D Copyright Films / FR3 films production. Tous droits réservés.]

Pourtant, cette musique va progressivement baisser de volume jusqu'à disparaître avant la fin du plan. Puisqu'il est fortement improbable qu'il s'agisse d'une agonie sonore ${ }^{15}$, par ce procédé inhabituel, le réalisateur souhaite probablement désamorcer l'enchaînement classique précédent afin de placer le spectateur dans une perspective esthétique moderne plus apte à accompagner et traduire le point de vue qu'il nous propose.

Le plan suivant présente un ventilateur au plafond cadré en plan moyen et en contreplongée ; seul le son qu'il produit est présent. Cette stricte simplicité nourrit à nouveau le synchronisme image et son: tout est aussi réel et immédiatement évident que ce ventilateur. Les approximations et ajustements entre image et bande son observés précédemment relèvent de ce fait du point de vue particulier adopté. 


\section{Point de vue et point de désir}

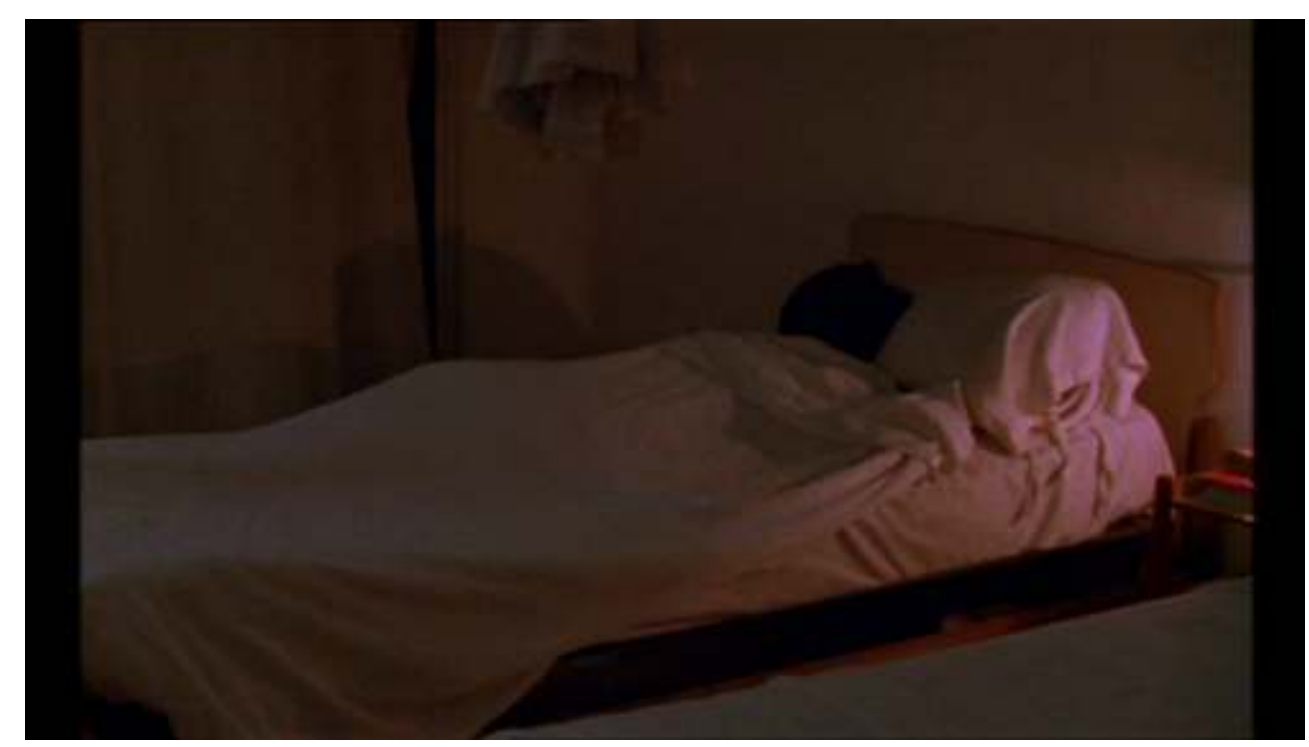

Plan $10-5 \min 13 / 5 \min 26$

["Empty Quarter (Une Femme en Afrique) », production : Double D Copyright Films / FR3 films production. Tous droits réservés.]

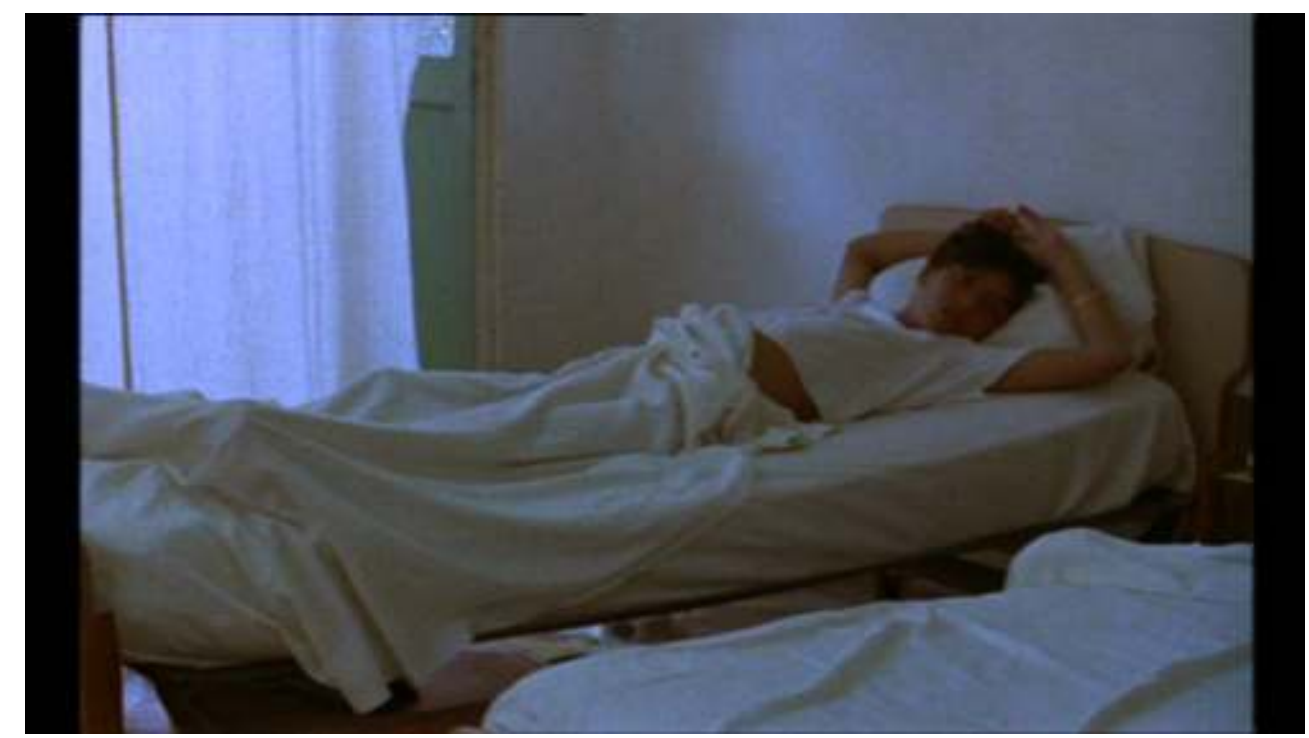

Plan $11-5 \min 26 / 6 \min 42$

[«Empty Quarter (Une Femme en Afrique)», production : Double D Copyright Films / FR3 films production. Tous droits réservés.]

Les deux plans suivants affirment un peu plus le regard "voyeur » : ces deux cadrages quasi identiques annoncent en effet une observation longue et renouvelée (nuit/jour - veille/lendemain/autre jour?). Voix in et voix off interviennent successivement quelques secondes après le début du plan 11 :

Voix in femme :

Bonjour ami du jour!

Voix off homme : 
Je n'ai pas connu beaucoup de femmes. J'ai voyagé, travaillé, je n'avais pas le temps. Je n'en reviens pas qu'il y en ait une avec moi, dans la même chambre depuis déjà un certain temps. La nuit, je l'écoute qui respire. J'ai peut-être envie d'être malheureux et quelque chose me dit qu'avec elle je vais l'être et je suis en train de m'installer là-dedans ; c'est déjà commencé.

La voix off de l'homme prend ici un statut plus réflexif, et se rapproche ainsi du statut du journal intime. Cette distanciation se met en place grâce à plusieurs aspects de son contenu: une première partie est dévolue à une constatation sur son rapport aux femmes ; puis il exprime une satisfaction inespérée ; enfin, il conclut sur une anticipation quasi mélancolique mêlée d'un certain masochisme. La distance avec le «vu » est donc plus avérée et le décalage temporel entre la réflexion et l'image l'atteste : « La nuit, je l'écoute qui respire » aurait naturellement pu être placé sur le plan nocturne précédent.

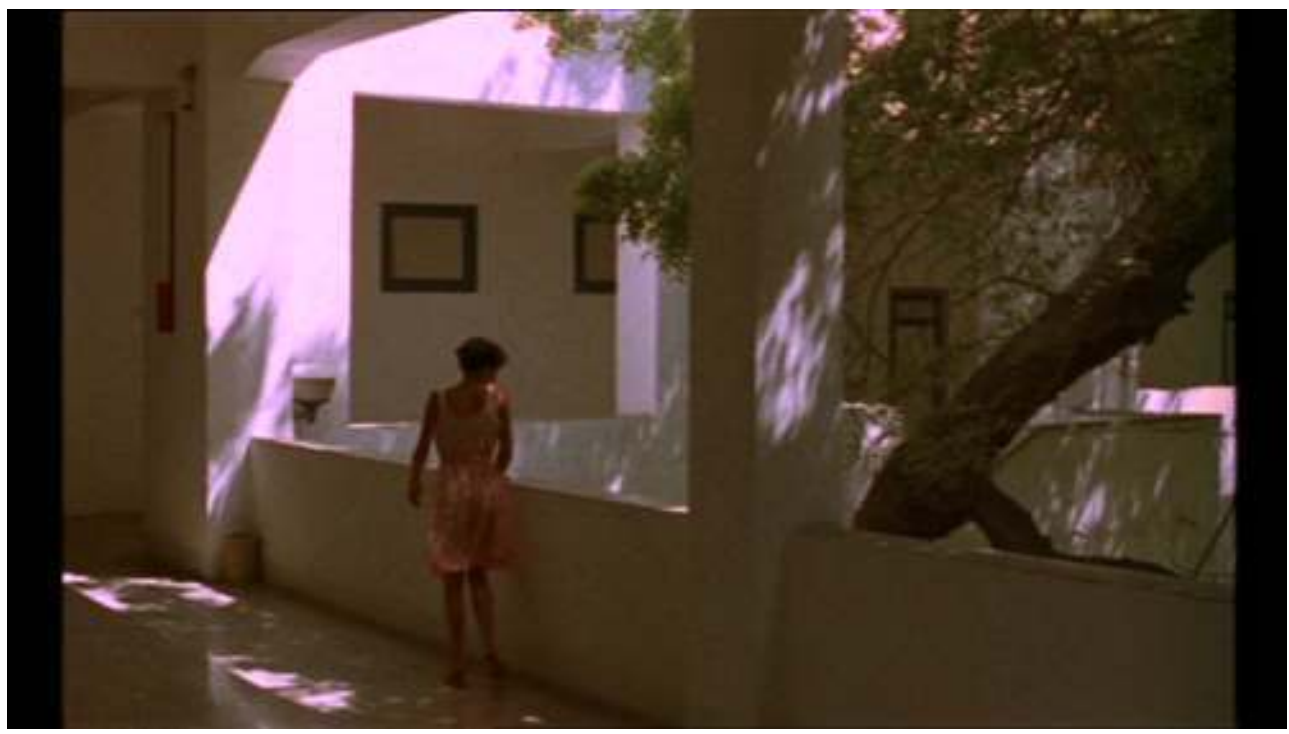

Plan $12-6 \min 42 / 7 \min 29$

[«Empty Quarter (Une Femme en Afrique)», production : Double D Copyright Films / FR3 films production. Tous droits réservés.]

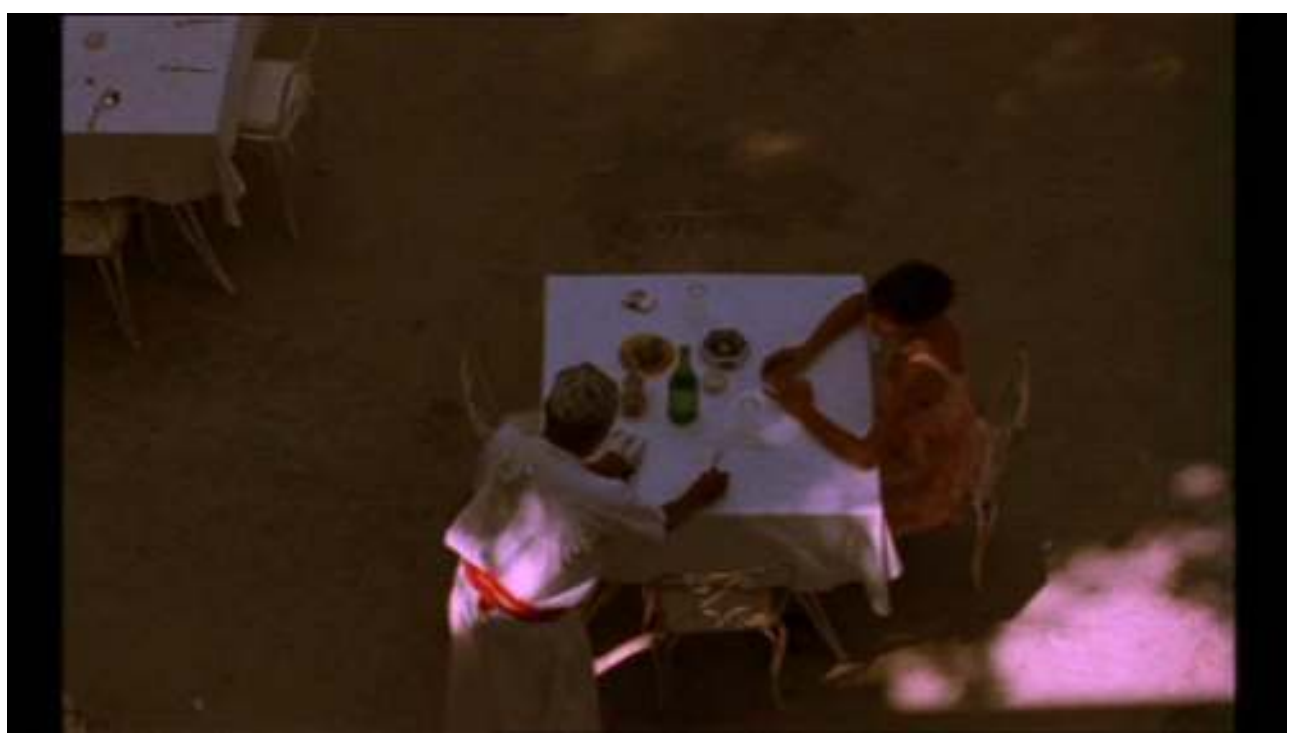

Plan $13-7$ min 29/8 min 01

[«Empty Quarter (Une Femme en Afrique) », production : Double D Copyright Films / FR3 films production. Tous droits réservés.] 
Les jours passent. Nous restons enfermés dans cet hôtel et on dirait même qu'il n'y a que nous deux comme clients. Parfois, je crois que nous venons à peine de nous rencontrer. Parfois, j'ai l'impression que nous nous connaissons depuis toujours. \{plan 12\} Je crois bien que je suis en train de devenir amoureux d'elle. J'essaye d'imaginer le moment où on va commencer à s'embrasser, le premier baiser qu'elle me donnera à moins qu'elle ne veuille jamais.

La voix off des plans douze et treize achève d'unir la voix masculine à la voie amoureuse grâce à plusieurs phases: l'usage du pronom «nous » d'abord, puis l'emploi du terme " amoureux » ensuite, et, enfin, la projection dans un futur sensuel. Bien sûr, il s'agit toujours - pour l'instant - d'une voie en sens unique.. ! Par ailleurs, ce sont les premiers plans où cette femme est observée à l'extérieur, en plans de demi-ensemble. Conjugués avec le texte de la voix off, ces plans accompagnent parfaitement le voyeurisme et l'observation distanciée. De plus, la présence du personnage masculin dans un horschamp indéfini spatialement est attestée dans le plan treize puisqu'un serveur installe un deuxième couvert à la table où se trouve la jeune femme.

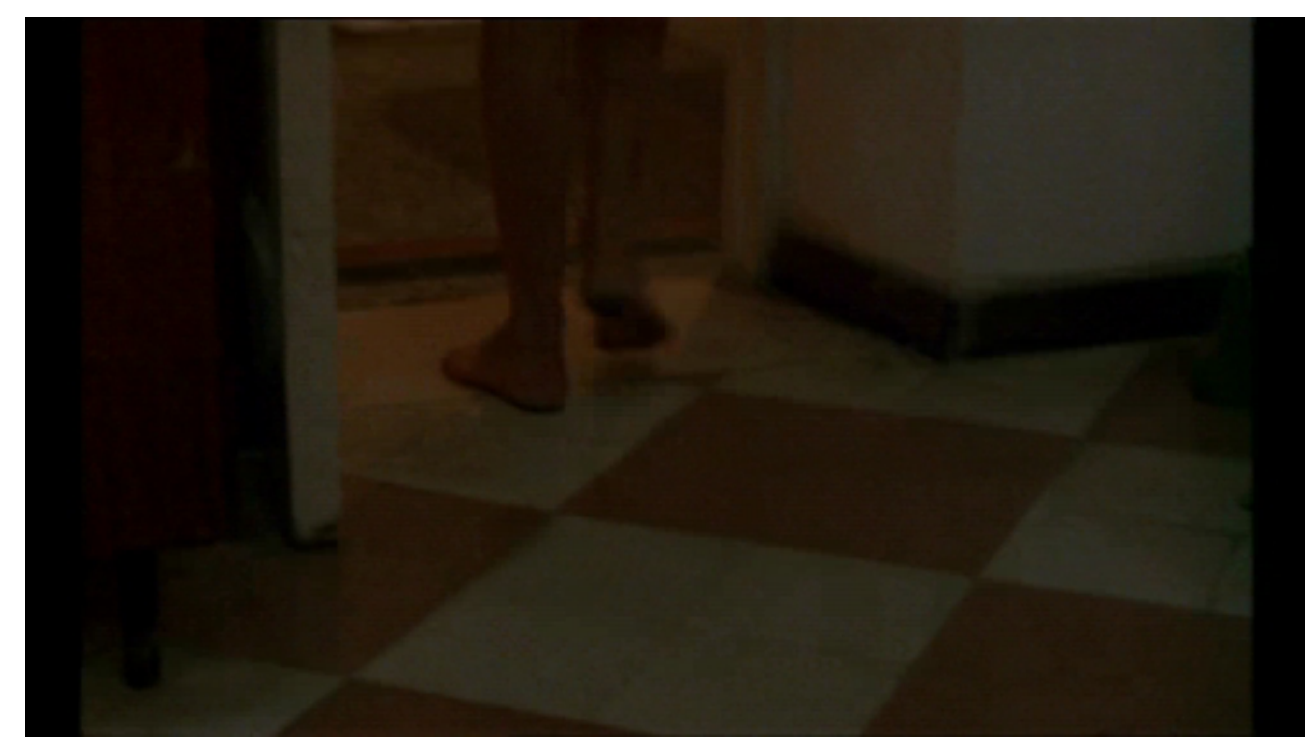

[«Empty Quarter (Une Femme en Afrique)», production : Double D Copyright Films / FR3 films production. Tous droits réservés.] 


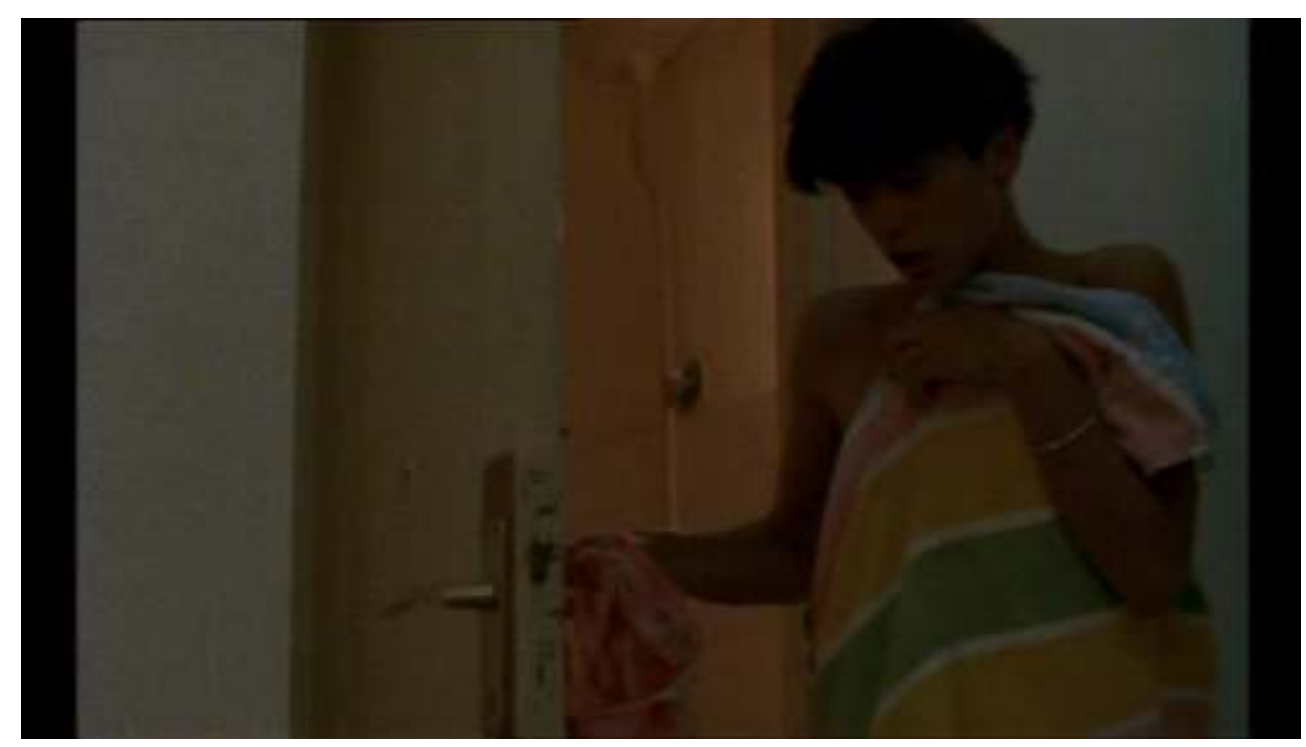

[«Empty Quarter (Une Femme en Afrique)», production : Double D Copyright Films / FR3 films production. Tous droits réservés.]

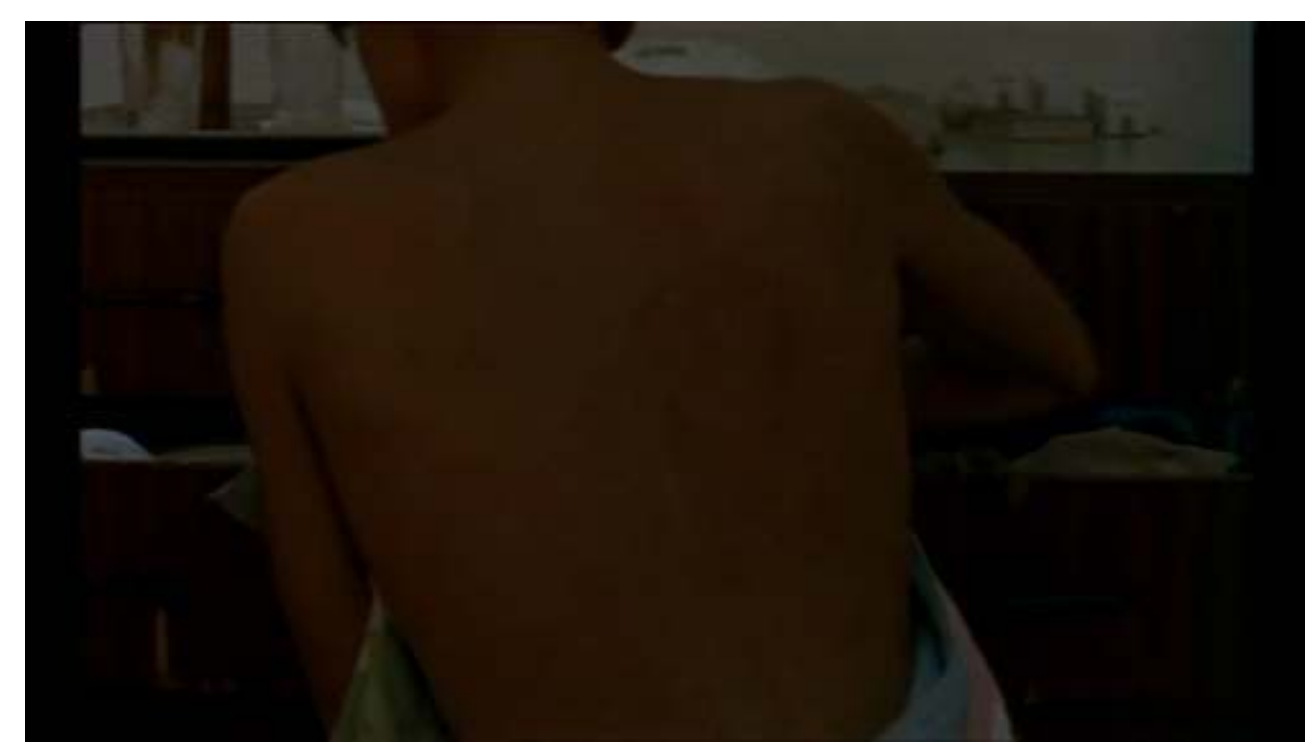

Plan 15 - 8 min 14/9 $\min 11$

[«Empty Quarter (Une Femme en Afrique)», production : Double D Copyright Films / FR3 films production. Tous droits réservés.]

29 Ce quinzième plan offre le premier mouvement de caméra: un panoramique accompagnant les déplacements du personnage féminin. Apparaît aussi le premier chevauchement des voix off et in :

Je me suis jamais senti comme ça dans une ville étrangère. Je n'ai jamais vécu comme ça, assez bien. Il y a des moments où on parle, [j'pense à rien moi] des moments où on se tait. J'apprends à la regarder. Mon regard ne se lasse pas. C'est comme si mes yeux étaient devenus une partie d'elle, un prolongement de son corps à elle.

Ce premier mouvement de caméra ${ }^{16}$, par son amplitude et son statut de poursuite, oriente le dispositif un peu plus vers le point de vue subjectif; surtout que le plan débute sur les pieds en plan rapproché, puis cadre la porte de la salle de bain fermée, comme un regard observateur qui se focalise et attend. Le voyeurisme est clairement affirmé : il est dit 
( «J'apprends à la regarder. Mon regard ne se lasse pas. ») et montré (on la voit revenir de la salle de bain le dos dénudé). Mais le choix d'un panoramique plutôt que d'une caméra portée crée cet étrange écart entre le strict point de vue subjectif immersif et le semisubjectif plus distancié. Ce film ne cesse d'évoluer entre ces deux options, en oscillant constamment entre leurs limites faisant ainsi fluctuer insensiblement la définition de la place de la caméra. La voix off ne fait d'ailleurs que confirmer cet état instable: elle se situe entre la réflexion a posteriori et l'affirmation voyeuriste en phase avec l'image. Le chevauchement avec la voix in de la jeune femme participe aussi à créer cette distance.

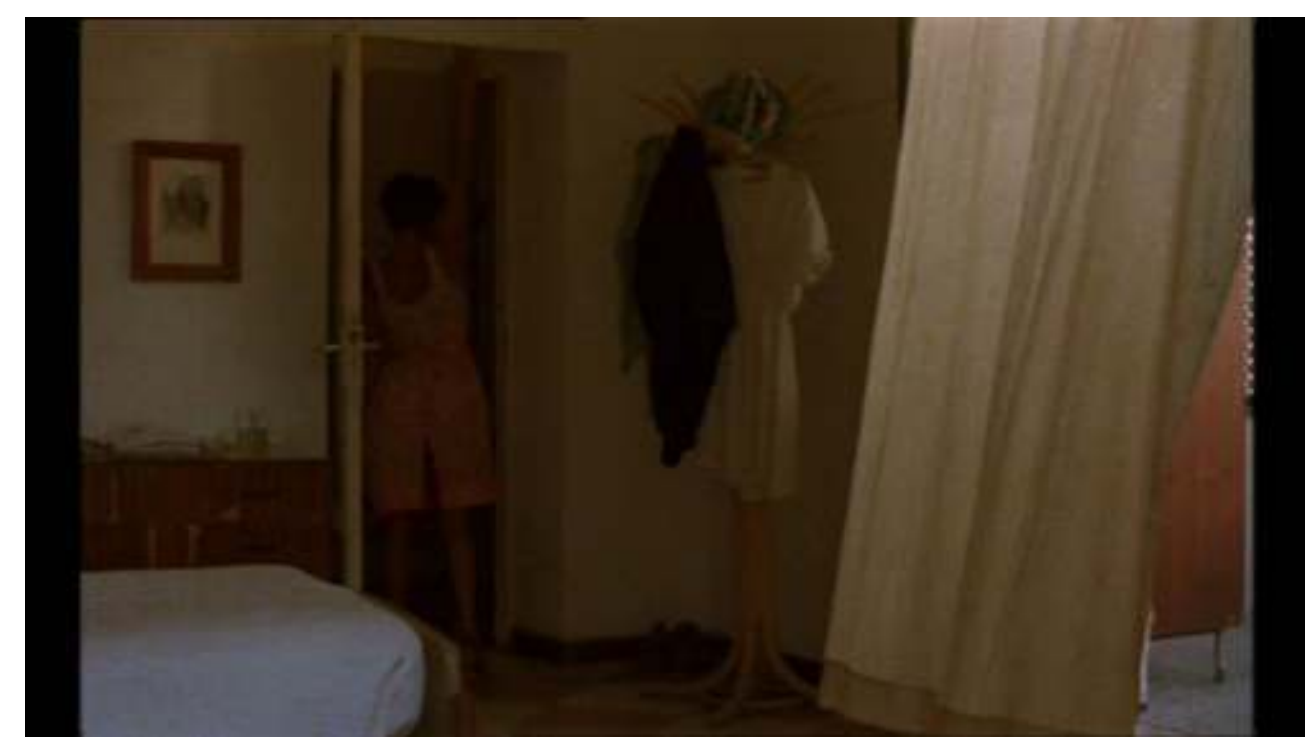

Plan $25-13 \min 11 / 14 \min 18$

[«Empty Quarter (Une Femme en Afrique) », production : Double D Copyright Films / FR3 films production. Tous droits réservés.]

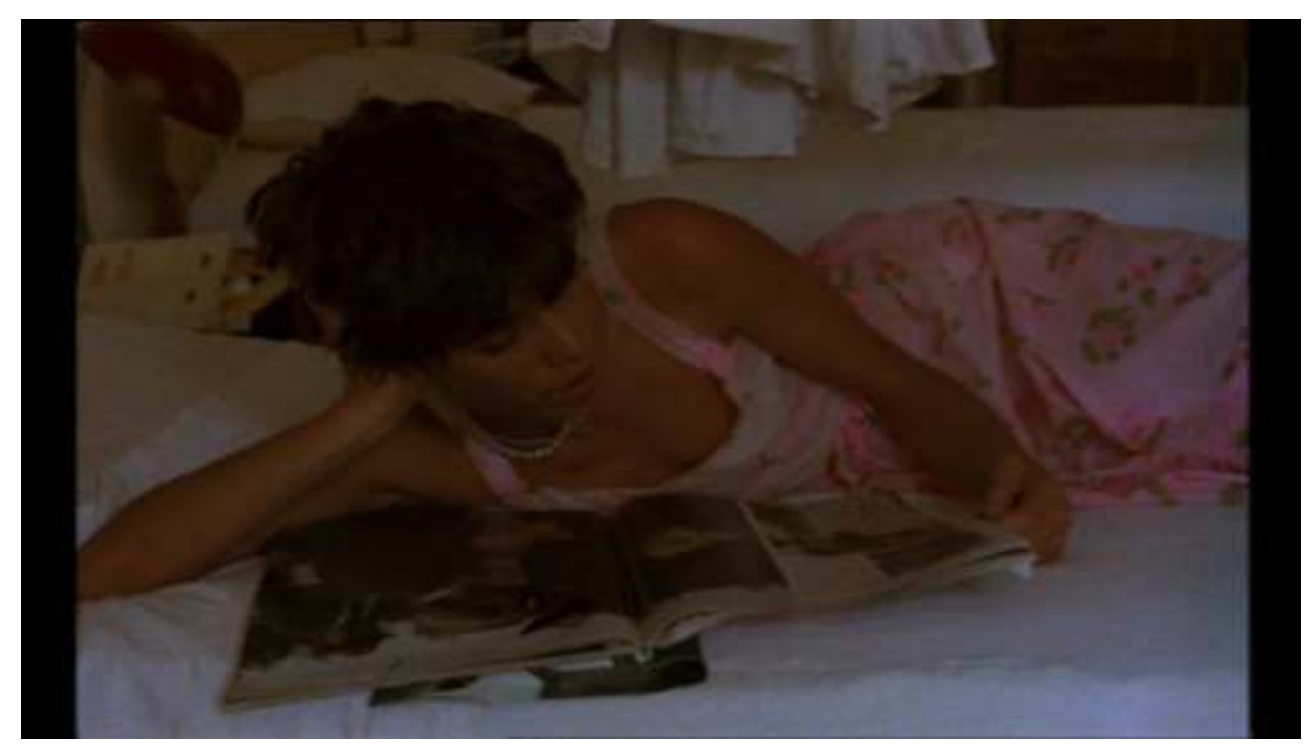

[«Empty Quarter (Une Femme en Afrique)», production : Double D Copyright Films / FR3 films production. Tous droits réservés.] 


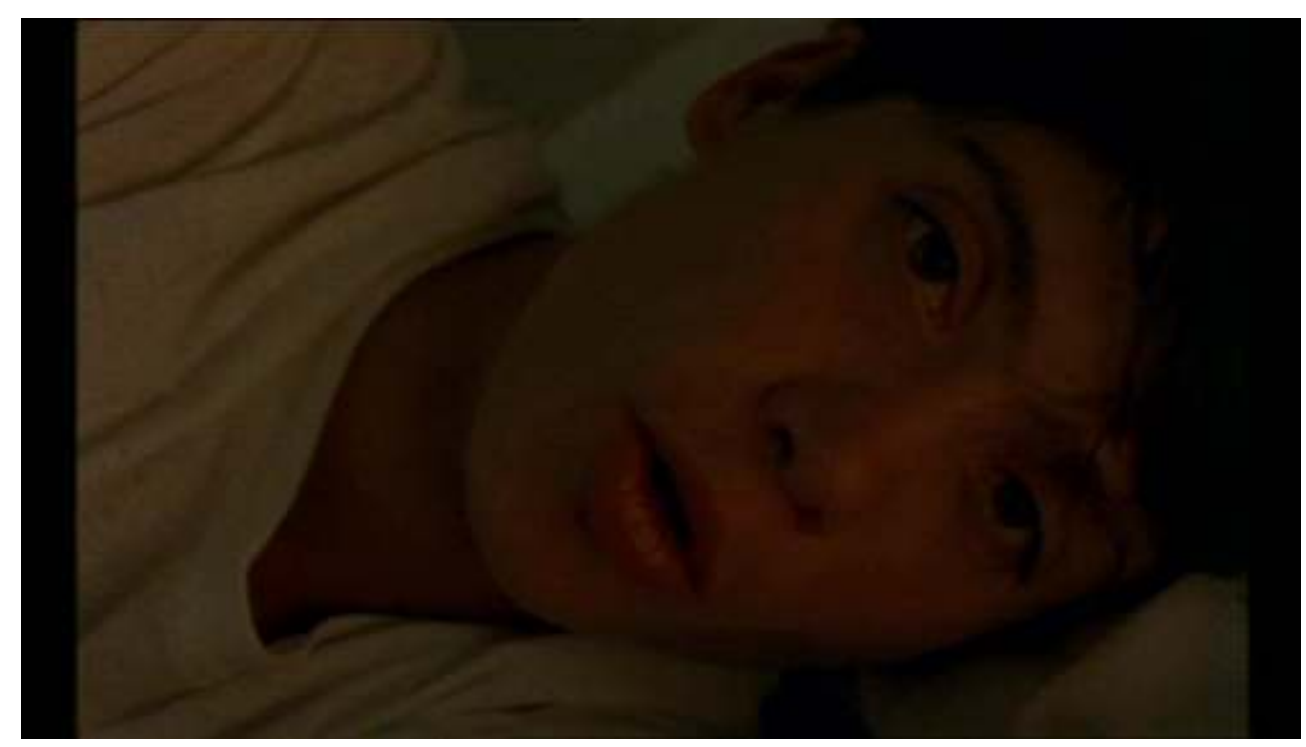

Plan 27 - 14 min 45/17 $\min 21$

[«Empty Quarter (Une Femme en Afrique)», production : Double D Copyright Films / FR3 films production. Tous droits réservés.]

31 Le plan 25 offre à nouveau un ample panoramique sur le déplacement de la femme, accompagné par la voix off qui expose explicitement son désir :

(...) Souvent pendant que je la regarde, je commence à bander, elle ne s'en rend pas compte (...)

Le plan 26 cadre fixement en plan rapproché la jeune femme allongée sur le carrelage, alors qu'un voilage la caresse au gré du vent. Le plan 27 cadre pour la première fois la femme en gros plan avec un regard-caméra particulièrement présent, d'autant plus que le plan dure plus de deux minutes et demie. Alors qu'elle évoque plusieurs souvenirs, la voix off est au diapason de la proximité et de l'intimité de ce plan :

C'est la première fois que je suis aussi près d'elle. Elle m'émeut. (...) je pourrais lui toucher les lèvres (...) l'approcher, être encore plus près.

Enfin, le plan s'arrête en cut alors que son regard est toujours grand ouvert vers la caméra. Ces éléments démontrent, en plus du voyeurisme déjà évoqué, un point de vue érotisant (plan 26 notamment) et une recherche d'intimité vécue et fantasmée («je pourrais lui toucher les lèvres, être encore plus près » etc.). Le point de vue se confond ici totalement avec un " point de désir », une fixation du désir. 


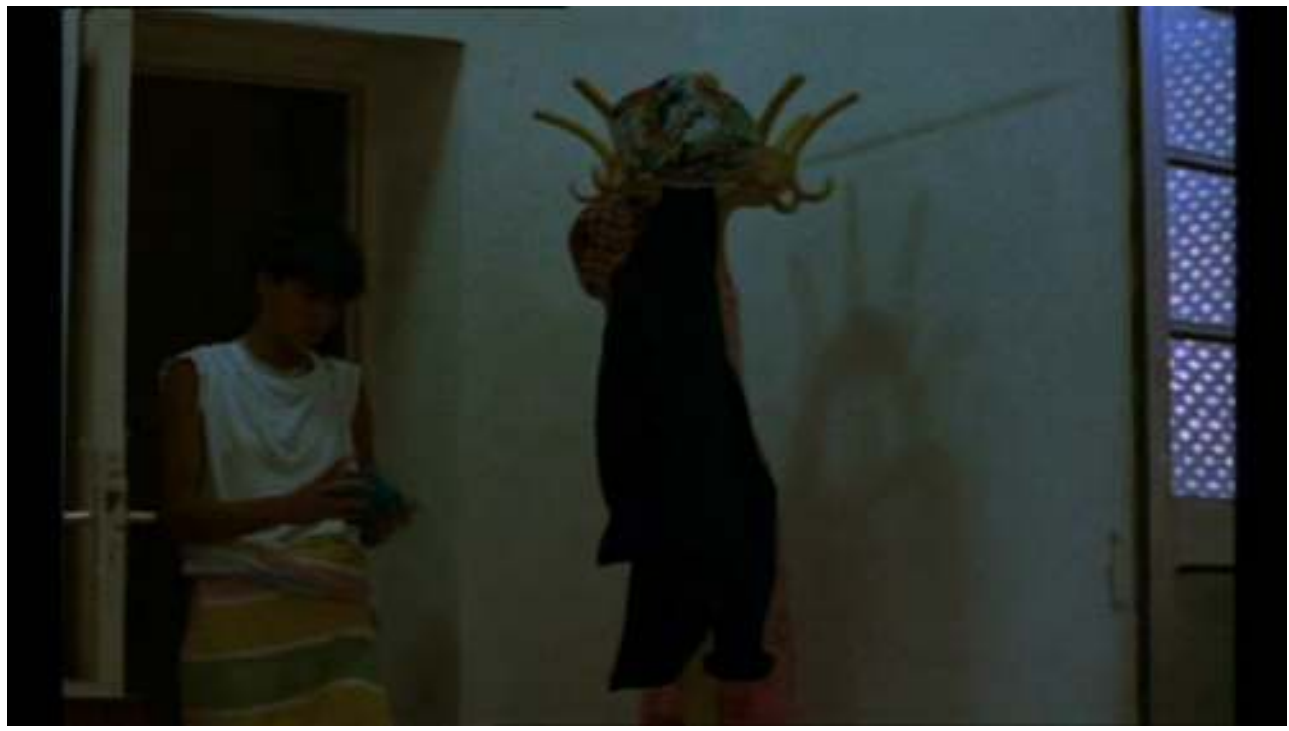

[«Empty Quarter (Une Femme en Afrique)», production : Double D Copyright Films / FR3 films production. Tous droits réservés.]

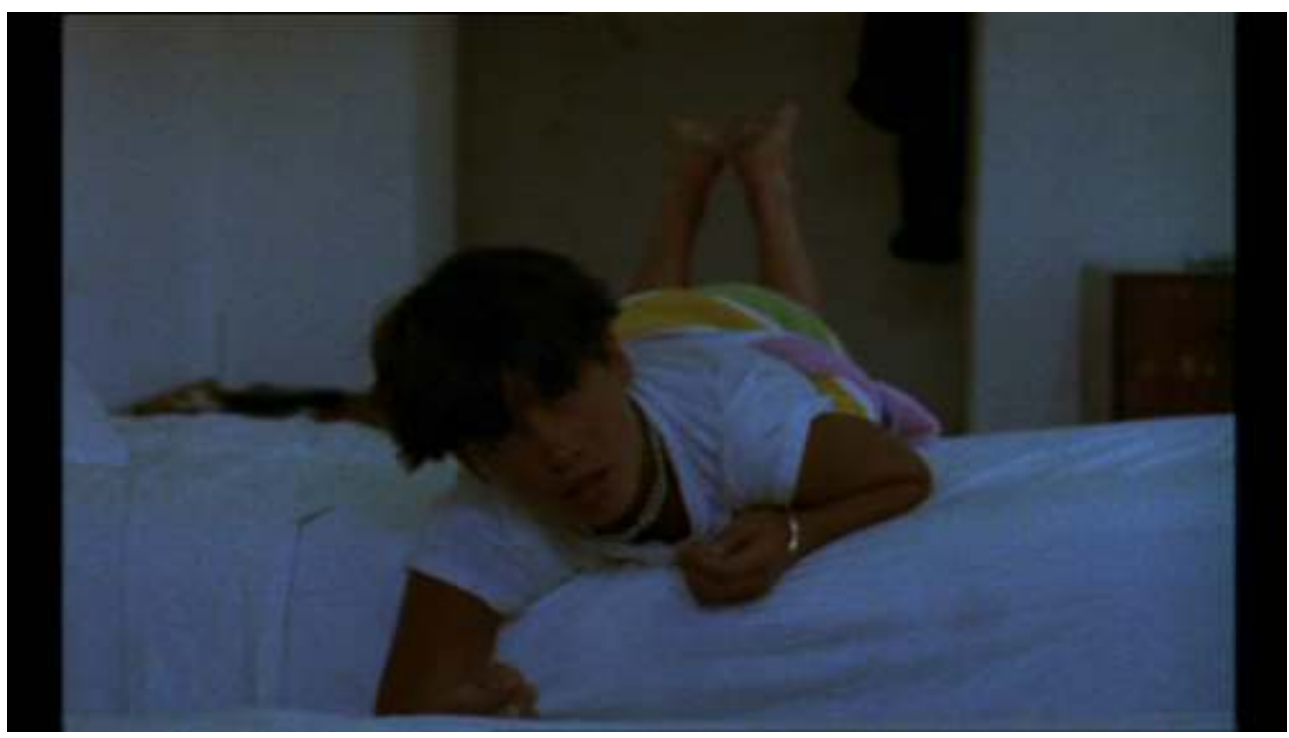

Plan 30 - 17 min 40/19 min 28

[« Empty Quarter (Une Femme en Afrique)», production : Double D Copyright Films / FR3 films production. Tous droits réservés.] 


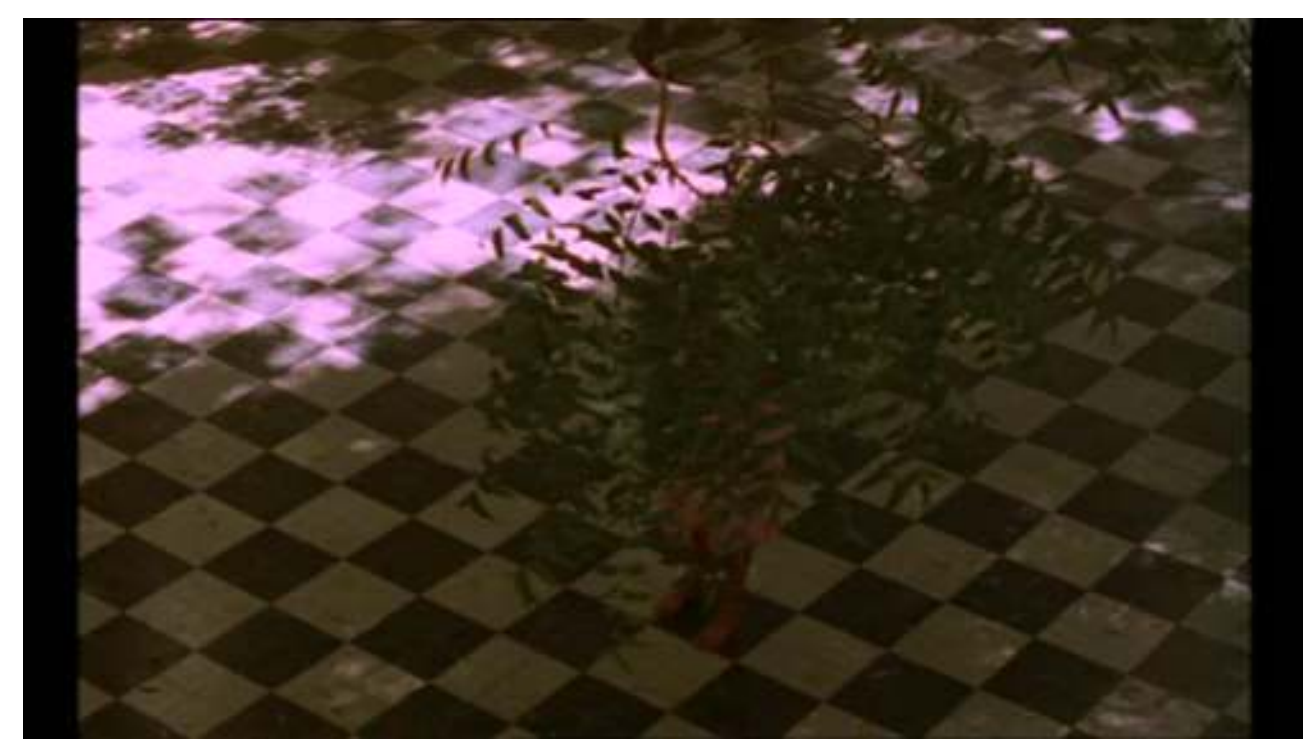

Plan 31 - $19 \min 28 / 20 \min 20$

[«Empty Quarter (Une Femme en Afrique)», production : Double D Copyright Films / FR3 films production. Tous droits réservés.]

Le plan 30 propose encore un panoramique de suivi du personnage féminin, un regardcaméra et un chevauchement abondant des voix off et in : elle ne cesse de parler sans que la voix off lui fasse de la place; le temps de la découverte respectueuse et admirative est en partie achevé, ce qui atteste une accoutumance au cours d'une période assez longue ${ }^{17}$. D'ailleurs, qu'en est-il du temps qui passe? Après l'indication calendaire initiale («C'est le mois de décembre ») le temps n'est plus marqué ; jours et nuits se succèdent et certaines habitudes se sont installées sans heurts : la gêne du début s'est dissipée, le dénudement discret s'immisce dans les allers et venues, les regards-caméra sont francs et soutenus... autant d'indices de l'habitude. Après l'émotion amoureuse et érotique clairement déclarée dans le plan 27, la voix off fait part d'un doute profond :

Peut-être même qu'elle me déteste. Elle reste ici parce que ça l'arrange (...) Je n'aime pas la voix qu'elle prend (...) J'aime ses yeux, le regard qu'elle a et sa bouche aussi et son profil quand elle penche la tête. Même quand je crois qu'elle me déteste, je trouve qu'elle est attendrissante (...)

Ici, le temps n'a plus vraiment d'importance : la pensée de l'homme vagabonde au gré de ses réflexions et la voix off en est la caisse de résonnance.

Le plan suivant filme en panoramique le déplacement extérieur de la jeune femme en plan de demi-ensemble. La voix off commente directement cette action alors que la femme est cachée par un feuillage à la fin du plan. Cette voix off acquiert ici un statut particulier: elle décrit quelque chose d'à peine visible dans une position proche d'un poste d'observation. Raymond Depardon l'énonce d'ailleurs ainsi : «C'est pas un plan subjectif, mais c'est quand même un plan de regard; il y a du voyeurisme ${ }^{18}$.» C'est en effet bel et bien de regard qu'il s'agit et la voix off serait donc l'expression sonore de ce regard, en admettant que ce regard regarde «à distance », « reconstitue» des bribes de moments vécus dans un contexte en partie fantasmatique. 


\section{Points de déconnexion}

37 Après cette mise en place/en phase des points de vue et d'écoute, le film déroule son itinéraire sentimental et géographique (vers Adiss-Abeba) dans une certaine harmonie, équilibrée par le voyage ( J'ai toujours pensé qu'un voyage ça se fait seul. Avec elle je change d'avis ; elle voyage bien. » plan 49)

\section{Penser/parler}

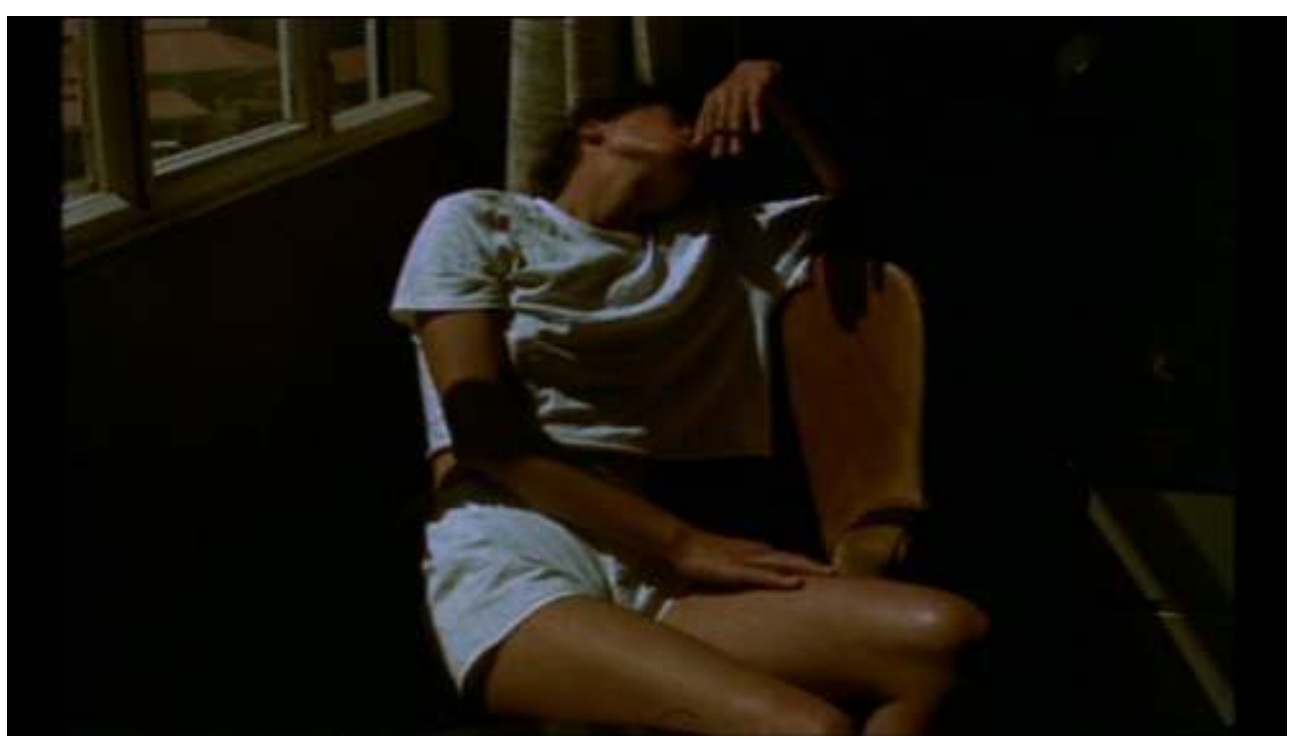

Plan 67 - 35 min 31/36 min 09

[«Empty Quarter (Une Femme en Afrique) », production : Double D Copyright Films / FR3 films production. Tous droits réservés.]

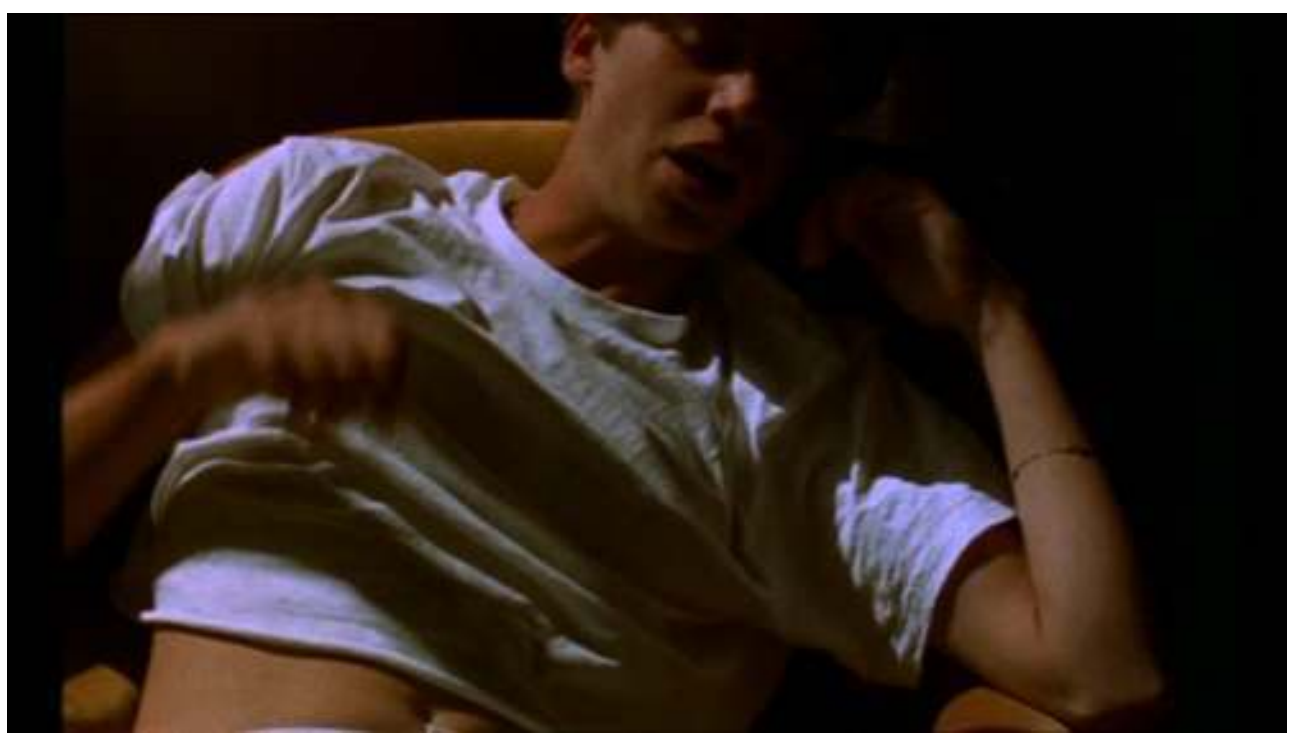

Plan 68 - 36 min 09/36 min 34

[«Empty Quarter (Une Femme en Afrique)», production : Double D Copyright Films / FR3 films production. Tous droits réservés.] 
Apparu lors du plan précédent (66), le son émis par une radio, sans doute hors-champ, propage la voix d'un animateur puis d'une chanson durant ces deux plans ${ }^{19}$. La voix off intervient une vingtaine de secondes après le début de ce plan :

Je ne me souviens plus des mots. J'me souviens d'autre chose, de la lumière. Il y avait du soleil ce jour-là. Elle était belle ; j'aurais dû me taire. Le plan suivant en raccord dans l'axe avec ellipse ostensible (changement de position du personnage) donne à entendre la voix in de la jeune femme :

J'suis fatiguée. J'ai envie de dormir.

La continuité sonore de la radio et l'ellipse visuelle trahissent un temps qui dérape au diapason de la mémoire. La voix off le confirme : elle évoque un souvenir et des regrets. Le raccord dans l'axe et la position alanguie de la jeune femme soulignent une fois de plus l'insistance du regard voyeur. La voix off fait part ici d'un constat paradoxal : «j'aurais dû me taire "... alors que cet homme ne s'est jamais fait entendre au spectateur et que, dans le même temps, sa voix off est récurrente. Ainsi, les phrases prononcées face à elle et jamais données à entendre sont, d'une certaine manière, décrites par défaut comme étant inutiles, déplacées, gênantes; d'autant plus ici que ce constat s'effectue au moment où elle souhaite dormir, ne plus rien entendre. Le paradoxe est d'autant plus saisissant que la timidité et la maladresse suggérées depuis le début pouvaient laisser imaginer que cet homme parlait peu; la place presque envahissante de la voix off trahirait sans doute ce besoin de s'exprimer loin d'elle, sans les paralysantes règles de la communication amoureuse... Cette phrase ( «j'aurais dû me taire ») est aussi le signe verbal de tout le dispositif du film : Raymond Depardon a choisi de ne jamais se faire entendre in ou horschamp; de privilégier ainsi la pensée à la parole, le réfléchi à l'instinctif - ce que son " propre personnage » aurait sans doute dû faire, tant ses mots sont jugés inadéquats... Depardon, en fait, ne cesse de rechercher et reprendre sa place de photographe, d'observateur, d'enregistreur des événements et des émotions. Mais le sentiment amoureux ne peut guère se contenter d'une telle place, d'où ce porte-à-faux qui participera au déséquilibre de cette relation par la suite. Le personnage féminin est foncièrement dans l'instant, l'acte, la parole libre ; alors que lui est irrémédiablement en retrait, dans la pensée, proprement invisible. Cette « absence » est le véritable révélateur de son être amoureux : il est face à elle, mais sa réaction n'existe pas dans l'instant, et la voix off amplifie monstrueusement la difficulté d'«être ", d'exister face à elle, puisque cette voix préfère être écoutée par un spectateur anonyme... 


\section{Qui regarde ? Qui écoute?}

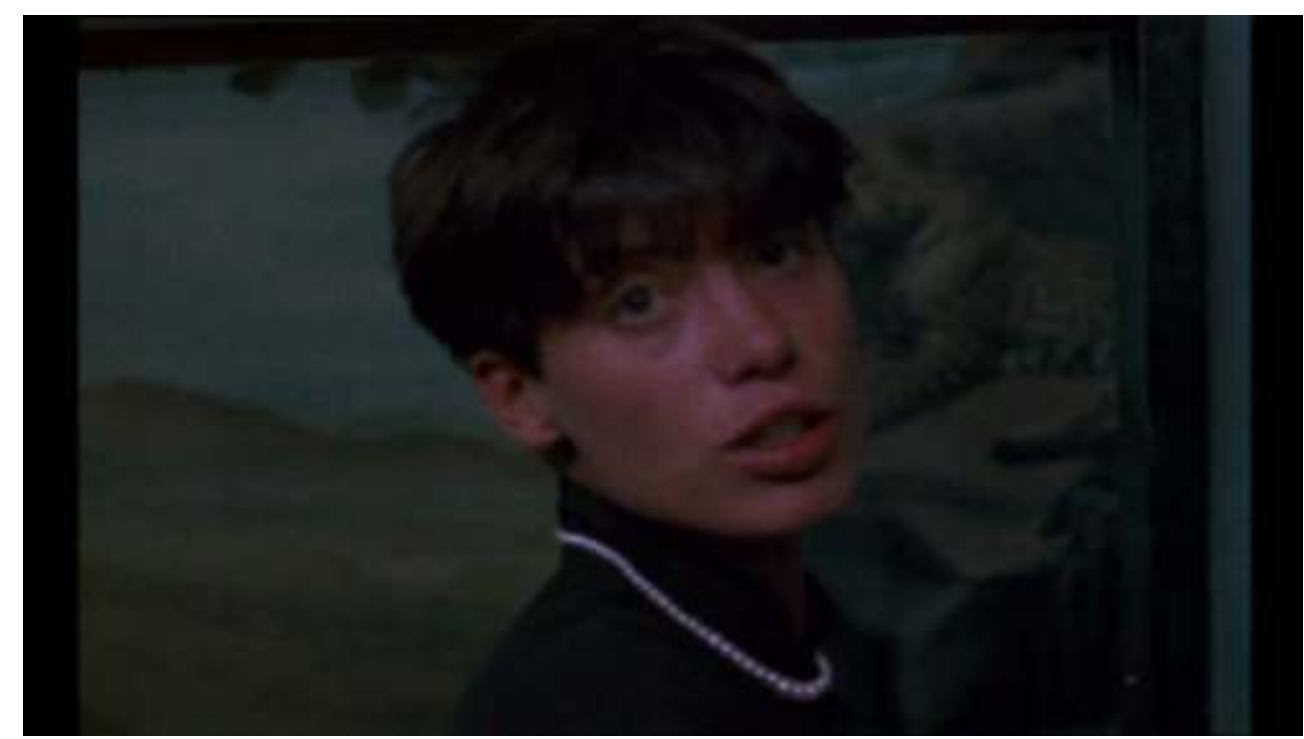

Plan 73 - 37 min 17/38 $\min 13$

[«Empty Quarter (Une Femme en Afrique)», production : Double D Copyright Films / FR3 films production. Tous droits réservés.]

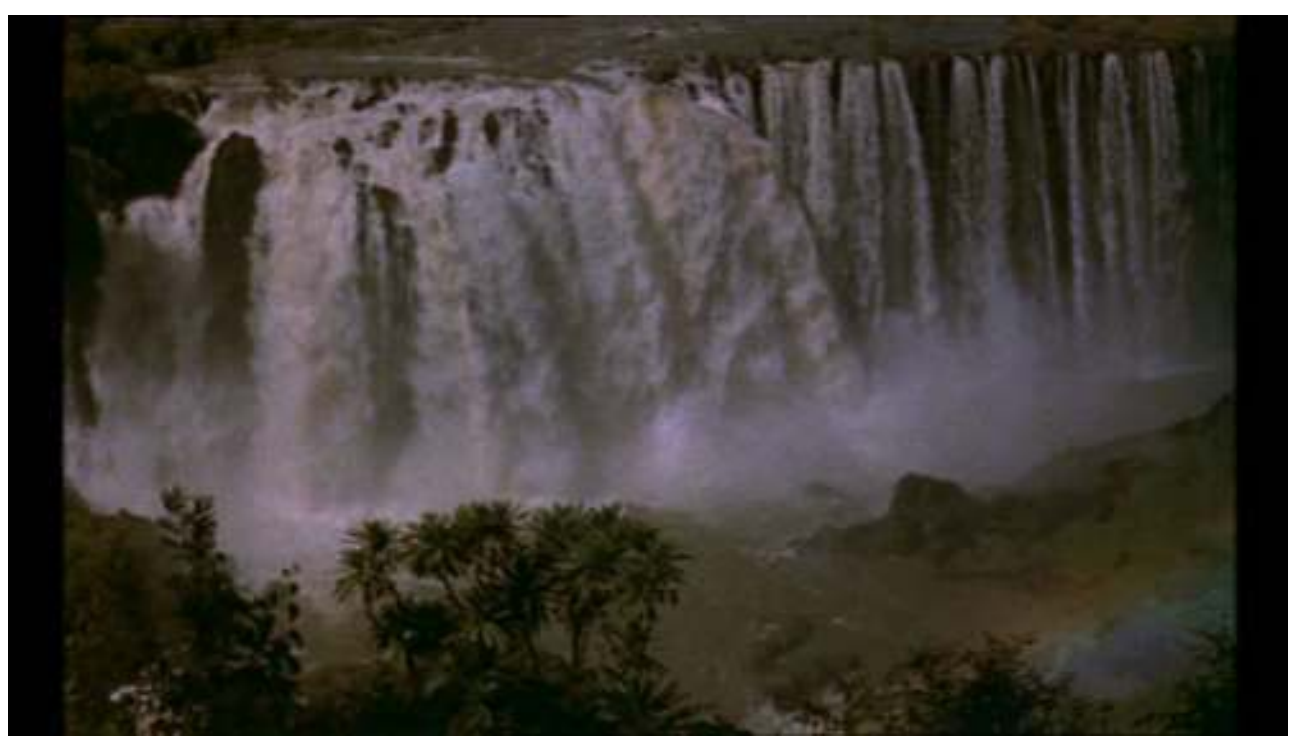

Plan $74-38 \min 13 / 38 \min 20$

["Empty Quarter (Une Femme en Afrique)», production : Double D Copyright Films / FR3 films production. Tous droits réservés.] 


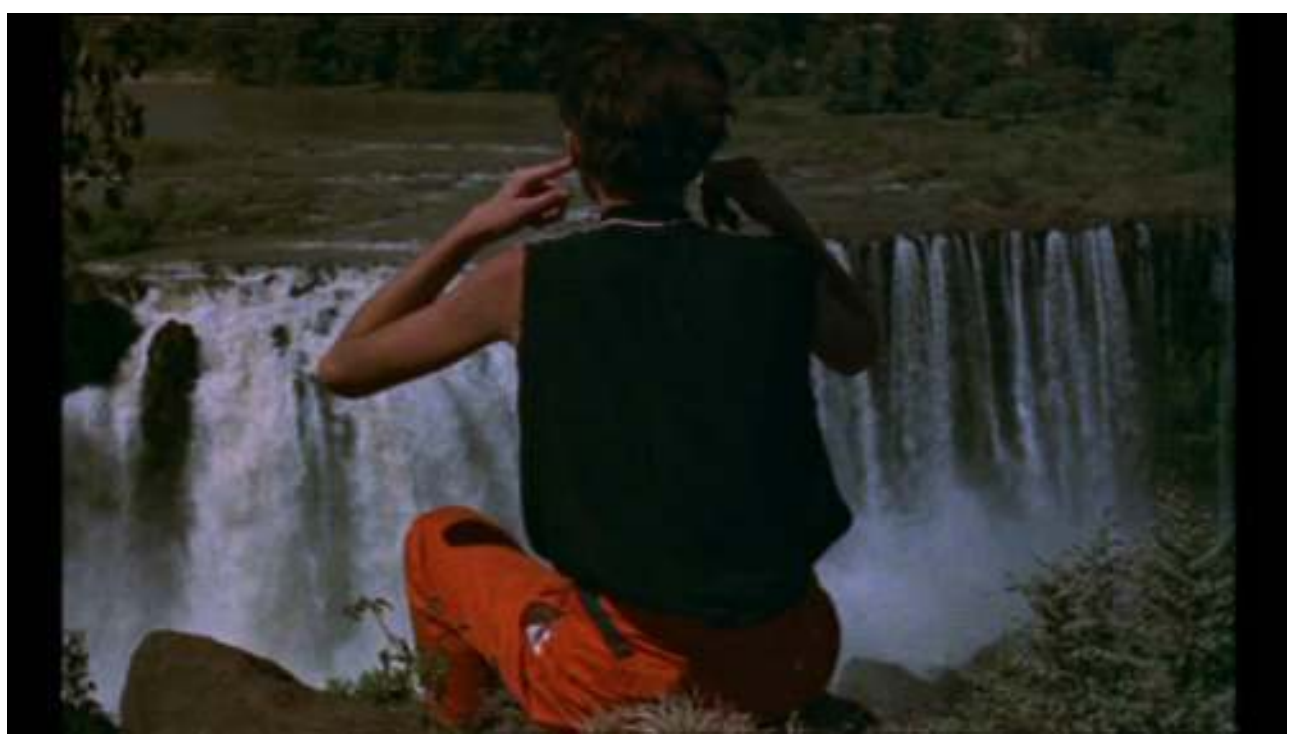

Plan $75-38 \min 20 / 38 \min 36$

[«Empty Quarter (Une Femme en Afrique) », production : Double D Copyright Films / FR3 films production. Tous droits réservés.]

41 Ces trois plans, tour à tour, précisent et perturbent le point de vue. Le plan 73 propose le seul mouvement de caméra-épaule aussi marqué du film ${ }^{20}$ : d'amples et rapides panoramiques traduisent le point de vue subjectif du personnage regardant les vitrines d'un musée d'histoire naturelle, se tournant, se déplaçant plusieurs fois vers le personnage féminin qui le regarde et lui parle (regard-caméra). Ce mouvement de caméra achève enfin la nature du point de vue subjectif: le plan vit. Pour autant, alors que l'action ainsi filmée rend compte d'une ballade à deux, la voix off évoque les décalages qui se sont opérés et qui persistent entre eux :

(en repensant à leur rencontre) (...) Je crois qu'elle ne m'écoutait pas. Elle n'a commencé à m'écouter que plus tard ; et maintenant c'est moi qui ne l'écoute plus (...)

42 Le chevauchement de cette voix off avec les dialogues de la jeune femme accuse plus encore la problématique de l'écoute: qui écoute et, surtout, quand l'écoute est-elle opérationnelle? Incontestablement, la caméra portée est le point de vue subjectif de l'homme, donc le son est censé être le point d'écoute subjectif de celui-ci. Les phrases prononcées en voix off commentent alors les disjonctions qui s'opèrent entre le perçu et le compris, l'audible et l'assimilé. Celui qui regarde "n'écoute " pas forcément; de même pour celle qui est regardée. L'absence de la voix masculine in ou hors-champ anesthésie toute faculté d'écoute. Le spectateur est ainsi pris au piège de ce dispositif qui claironne un hiatus autant verbal que visuel entre ces deux êtres.

Après un plan « simple » où une cascade en plan d'ensemble est vue et entendue, le plan 75 présente une incongruité concernant le point d'écoute. Alors que la jeune femme est face à cette cascade, elle s'amuse à se boucher les oreilles et la bande son accompagne ce jeu par un étouffement du son de la cascade. Le plan 74 est alors particulièrement utile pour imposer une qualité sonore identifiable qui contrastera avec celle du plan 75 . Ainsi, le film semble offrir pour la première et unique fois un son interne objectif ${ }^{21} \mathrm{du}$ personnage féminin, ce qui perturbe totalement le dispositif jusque-là, et par la suite, si intransigeant $^{22}$. Certes, Depardon peut traduire ici un transfert mental de l'impression sonore donnée (elle est censée entendre de cette manière-là); mais il jette tout d'un coup 
un doute sur ce qu'il donne à entendre depuis le début : et si tous les sons perçus jusqu'ici étaient en définitive ceux entendus par elle et non par lui ? Il y aurait de la sorte une déconnexion totale entre point de vue et point d'écoute : l'image pour lui, le son pour elle. De plus, la voix off, présente sur ce plan 75 , continue son discours sans changement particulier tout en entretenant le fantasme d'un destin qui les unirait :

Nous partons vers le Nord. Elle aussi ne veut pas qu'on se sépare. Elle va peut-être

finir par penser, comme moi, que nous ne nous sommes pas rencontrés par hasard.

\section{Déphasage sentimental}

44 Le voyage les emmène sereinement des chutes du lac Tana (Ethiopie) aux hauts plateaux du Kenya. La voix off est plus rare ${ }^{23}$ et évoque une entente complice ( On a beaucoup ri tous les deux depuis quelques temps. » plan 90)

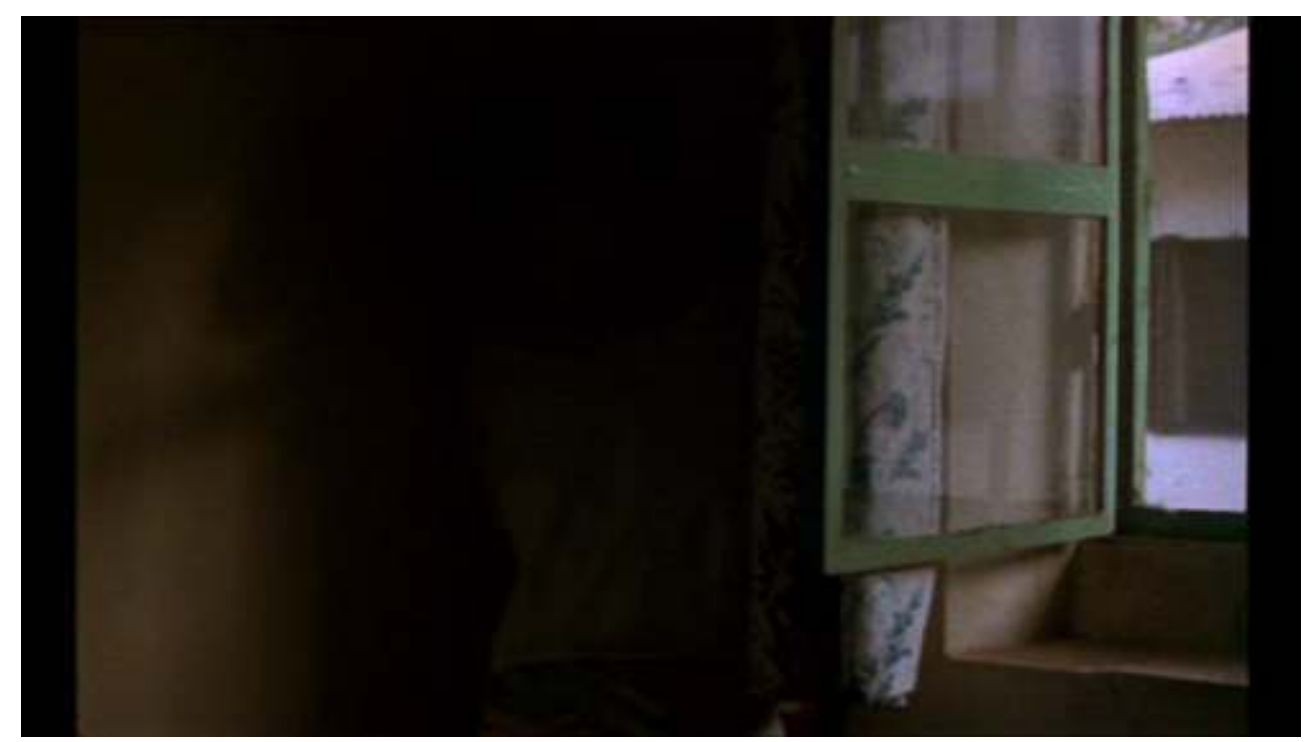

Plan 98 - $46 \min$ 32/46 min 57

[«Empty Quarter (Une Femme en Afrique) », production : Double D Copyright Films / FR3 films production. Tous droits réservés.] 


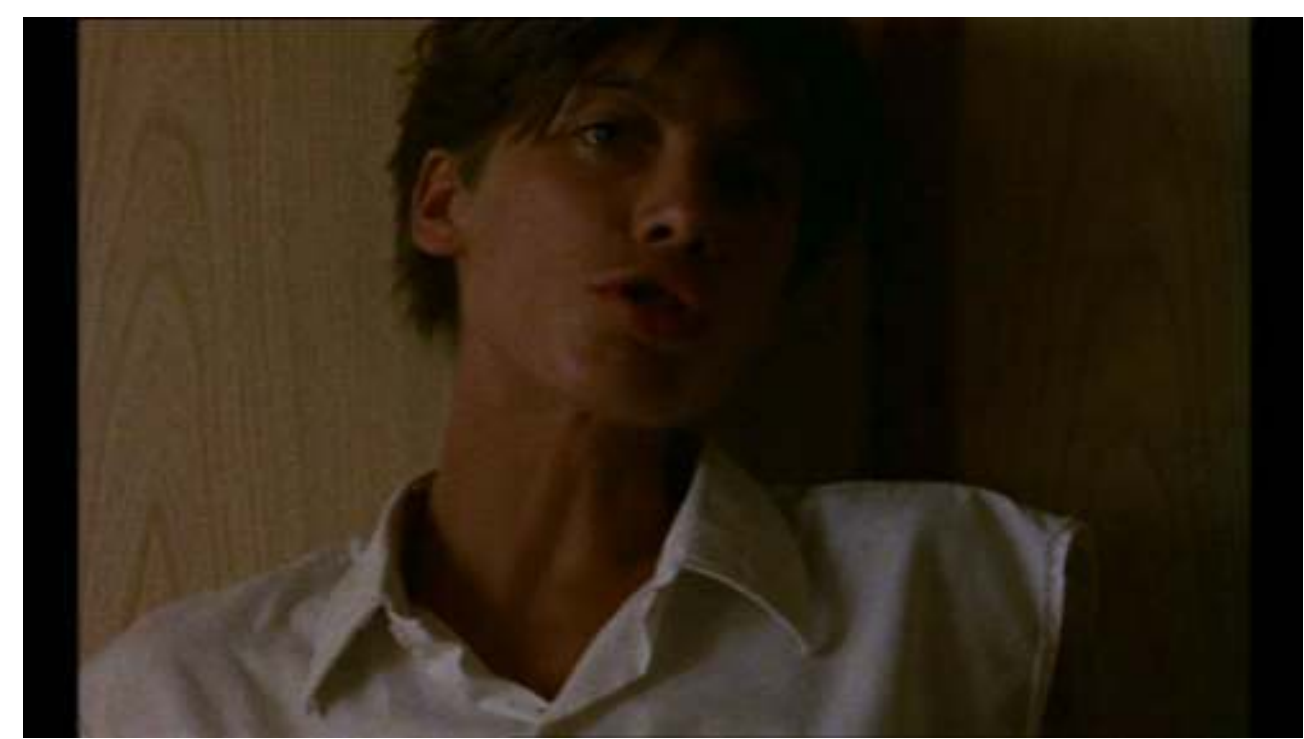

Plan 102 - 49 min 51/50 min 44

[«Empty Quarter (Une Femme en Afrique)», production : Double D Copyright Films / FR3 films production. Tous droits réservés.]

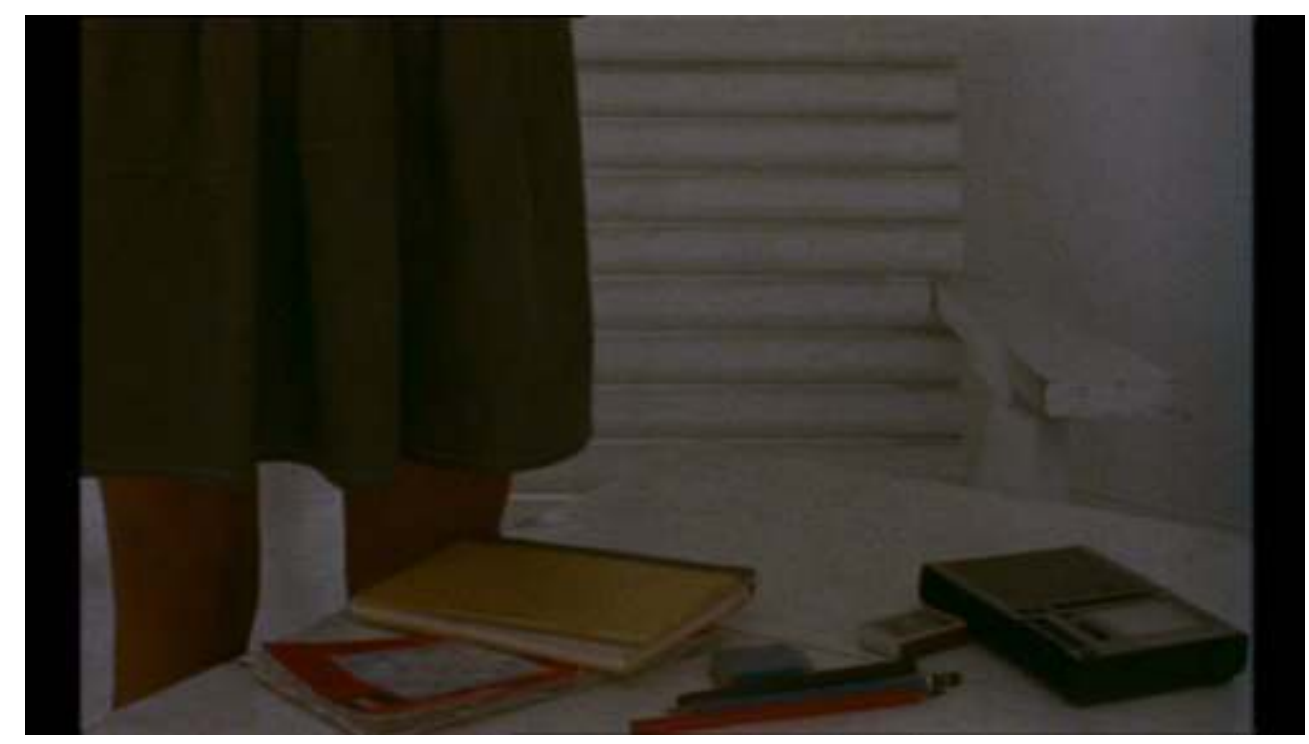

Plan 103 - 50 min 44/51 $\min 19$

[«Empty Quarter (Une Femme en Afrique)», production : Double D Copyright Films / FR3 films production. Tous droits réservés.]

Cette complicité bienvenue engage le personnage masculin à plus d'audace :

J'ai l'impression d'être détraqué à cause du désir. Il fait une chaleur énervante. Elle me parle moins qu'avant. On aurait dû aller ailleurs, ne jamais s'arrêter ici. Si je lui demande de faire l'amour maintenant, ça va tout détruire. Mais j'ai envie de coucher avec elle. Je n'arrive pas à dominer ça. C'est plus fort que moi, plus fort que n'importe quoi.

Les craintes exprimées ici sont instantanément confirmées par la jeune femme alors qu'elle se situe dans l'obscurité d'une encoignure, quasiment invisible :

J'veux pas. J'en ai pas envie. J'trouve que faire l'amour c'est un mot vulgaire. T'es en train de tout gâcher. Tu comprends rien à rien. Tu m'fatigues. 
Le chevauchement des voix off et in est thématiquement synchrone : "J'veux pas. J'en ai pas envie » arrive exactement au moment où il dit «Si je lui demande de faire l'amour (...) » Le déphasage est total. Ici, la pensée qui passe par la voix off est décalée et « trop synchrone » par rapport à l'action; elle est donc dans un autre temps, celui d'une pensée a posteriori qui reconstitue violemment les erreurs passées en faisant ainsi s'entrechoquer voix off et voix in. La voix off semble ainsi vouloir dialoguer (maladroitement) avec la voix in; elle acquiert une définition presque inédite pour laquelle la frontière entre in et off devient poreuse et temporellement instable. La voix off, comme depuis le début et jusqu'à la fin du film, se substitue, d'une certaine manière, à la voix in (ou hors-champ) du personnage masculin, mais cette substitution ne paraît pas conserver strictement le même statut. La définition physique du "déphasage » est appropriée et insuffisante : c'est la mesure entre deux ondes différentes (ici «les ondes masculine et féminine »); mais, pour un phénomène non périodique, il faut utiliser la notion de "décalage", ce qui est de plus en plus le cas à ce moment de la situation amoureuse.

Les plans suivants témoignent de ce décalage et l'accusent encore plus. Le monologue de la jeune femme pendant le plan 102, alors que la caméra la suit en panoramique, est parfaitement clair :

(...) T'as fait plein de choses dans ta vie, et t'es tellement aveugle avec les gens, tellement empoté avec les choses. Et puis t'es maladroit avec moi. T'es un bébé. Et puis, de toute façon, t'es un con, t'es un emmerdeur, t'es un abruti, t'es un moins que rien, t'es un ras du sol.

La voix off se tait, accuse le coup. Dans le plan suivant, elle reprend la parole :

On peut pas aimer et voyager en même temps. C'est comme ça. Elle est là. Elle me persécute. Je garde la tête baissée. J'essaye de sourire.

51 Ce plan montre effectivement un regard baissé. Le décalage (ou la désunion) semble consommé(e). Pourtant, dix plans plus tard, la voix off annonce : «J'ai couché avec elle. Je suis devenu son amant (...) nous avons fait l'amour et ça a été moins bien que prévu (...) J'ai eu l'impression qu'elle acceptait de coucher avec moi de guerre lasse, comme si elle me faisait la charité de ça (...)»

L'« onde » du désir ne répond décidément pas à un profil périodique régulier. Ce discours s'effectue sur un plan du désert qui défile à travers la fenêtre de leur voiture, juste après le plan du désir (mal) assouvi : elle est accroupie, recroquevillée, dénudée et regarde plusieurs fois la caméra avec un air songeur. La voix off reprend alors son mode de réflexion sur un événement passé. 


\section{Concordance/discordance}

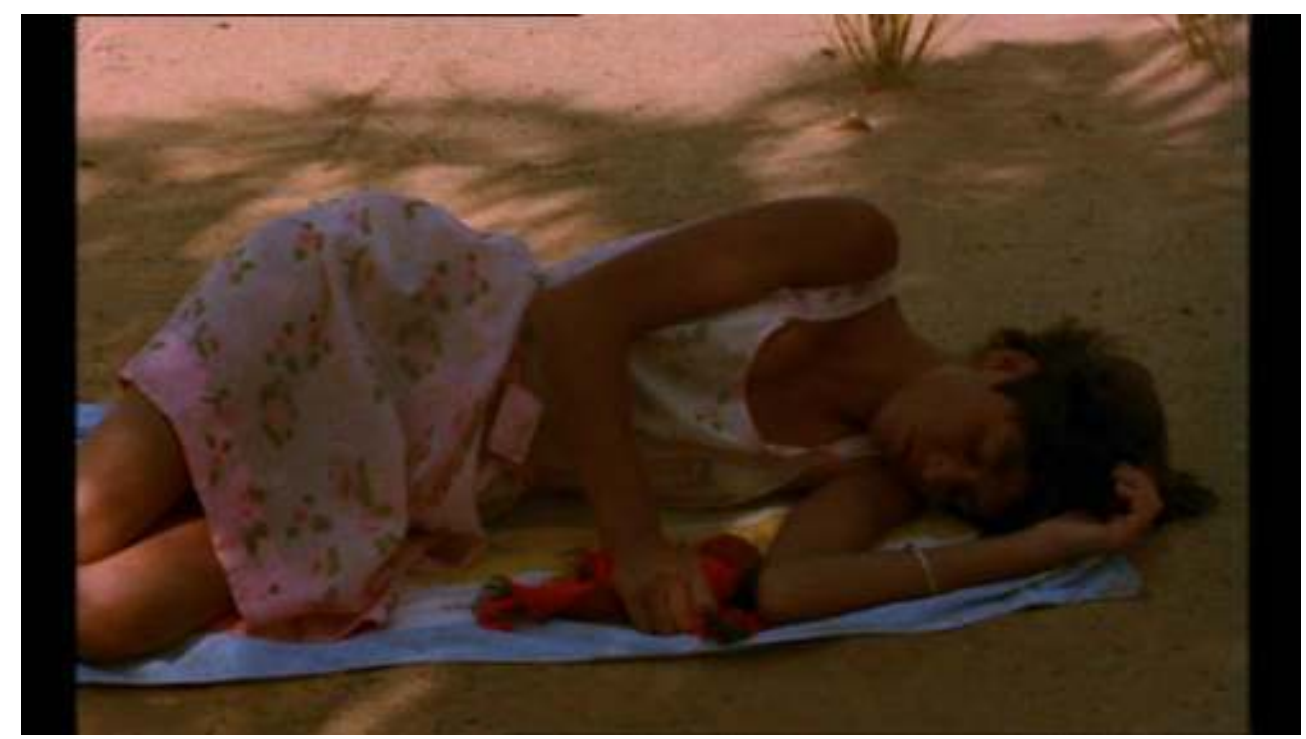

Plan $127-58 \min 25 / 58 \min 48$

["Empty Quarter (Une Femme en Afrique) », production : Double D Copyright Films / FR3 films production. Tous droits réservés.]

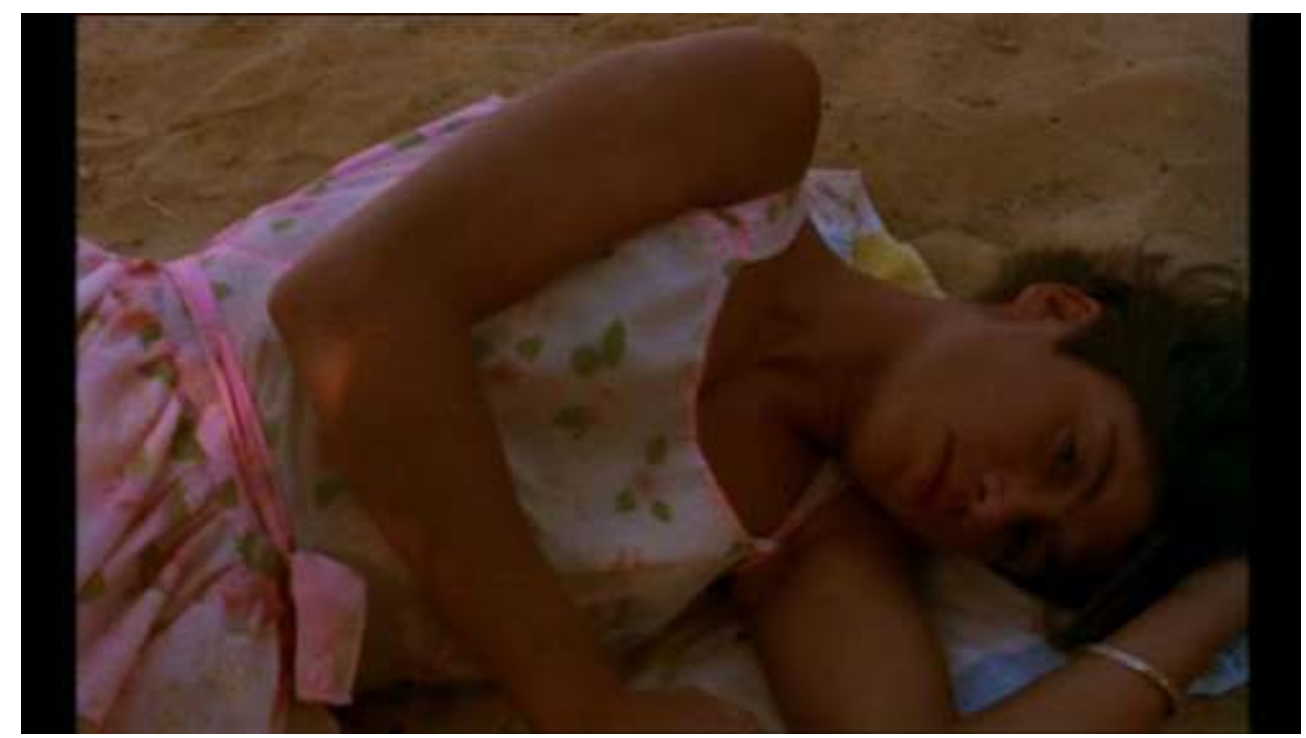

Plan 128 - 58 min 48/59 min 26

["Empty Quarter (Une Femme en Afrique)», production : Double D Copyright Films / FR3 films production. Tous droits réservés.]

Comme lors du voyage, une certaine sérénité est retrouvée lors de cette séquence dans le désert égyptien entre Luxor et Kharga. La voix off révèle à quel point le personnage masculin est en phase avec l'espace, le désert :

J'ai voulu l'emmener ici. J'y ai pensé dès que je l'ai vue la première fois à Djibouti. J'ai su qu'un jour nous serions dans le désert. J'aime le désert. Je suis mille fois plus amoureux du désert que d'elle. Il faudrait que j'apprenne à être content ; j'ai tout là avec moi, et je la regarde qui dort et je suis insatisfait.

54 Ce discours se poursuit sur le plan suivant qui, avec un quasi raccord dans l'axe avant, atteste du voyeurisme et de la contemplation renouvelés. Comme pour marquer la phase 
harmonieuse du moment, la jeune femme se redresse face à la caméra et dit en parfait synchronisme avec la voix off:

Faut partir? Pourquoi faut-il toujours qu'on parte? pendant que la voix off déclare :

Il faut qu'on parte.

Les deux personnages offrent des états d'âme en partie concordants. Voix in et voix off semblent "dialoguer" à nouveau; le chevauchement des deux voix marque cette connivence, cette union, ce temps partagé, plutôt qu'une distance réflexive comme ce fut le cas précédemment lorsque la voix off proposait des réflexions personnelles pendant que la jeune femme parlait de choses anodines - en tout cas rendues anodines par la présence envahissante de ces commentaires off, justement.

Leur voyage se poursuit. Les voix se taisent pendant plusieurs minutes. Le désert prend toute la place : vent, train au loin, enlisement, contemplation diurne et nocturne,... Le retour en ville n'en est que plus agressif tant au son qu'à l'image.

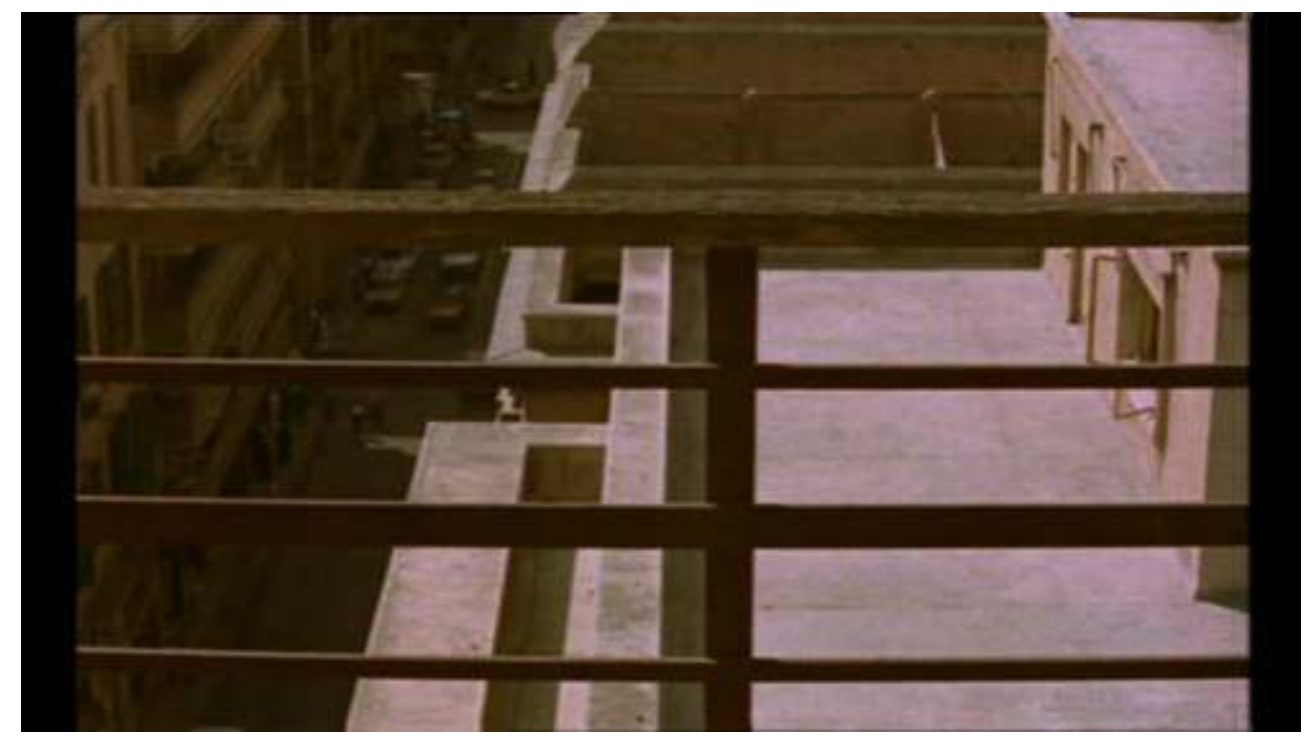

Plan 145 - 63 min 37/63 min 58

[«Empty Quarter (Une Femme en Afrique)», production : Double D Copyright Films / FR3 films production. Tous droits réservés.] 


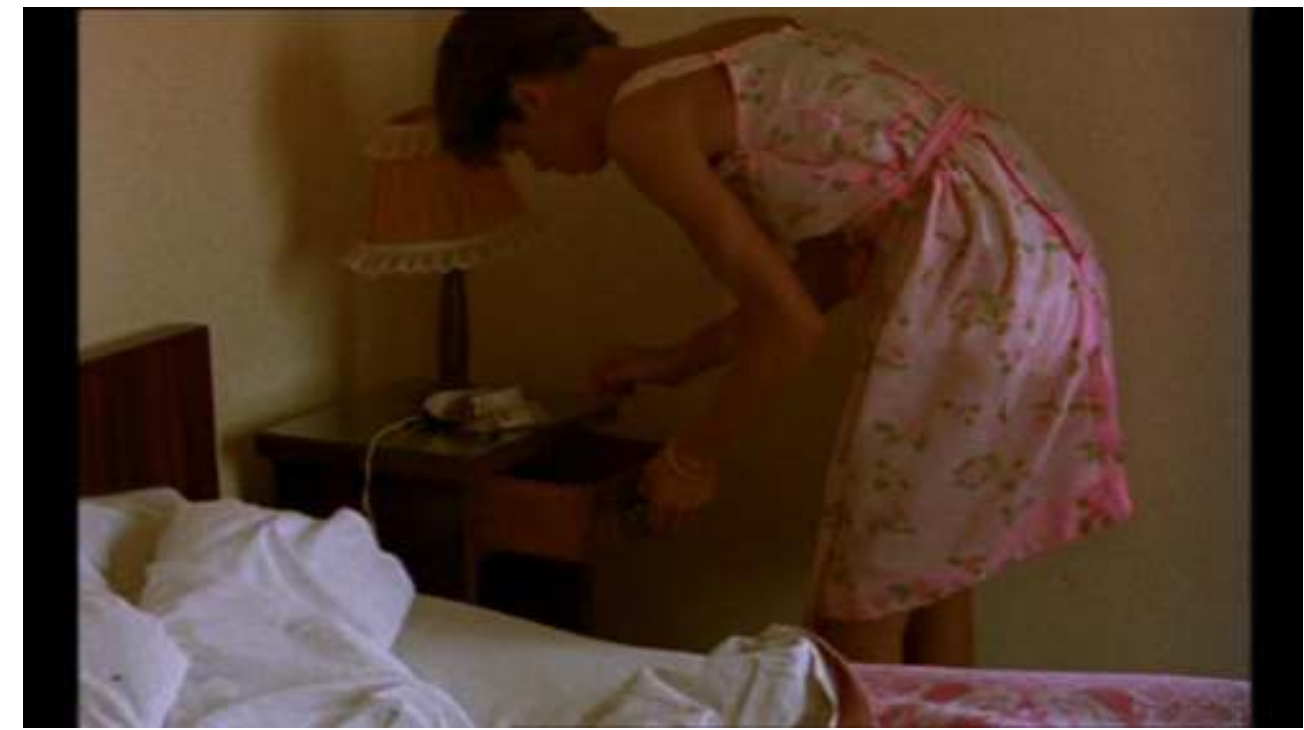

Plan 146 - $63 \min 58 / 64 \min 7$

[«Empty Quarter (Une Femme en Afrique)», production : Double D Copyright Films / FR3 films production. Tous droits réservés.]

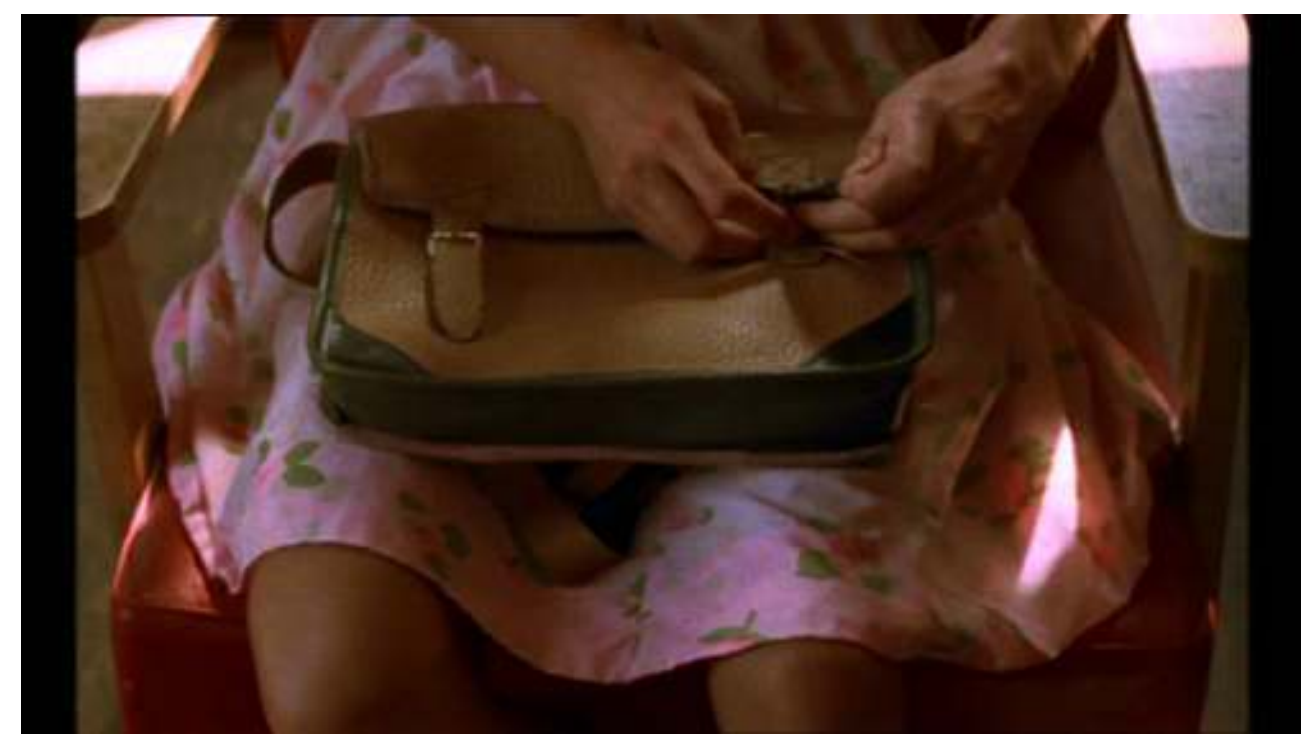

Plan $147-64 \min 7 / 64 \min 18$

[«Empty Quarter (Une Femme en Afrique)», production : Double D Copyright Films / FR3 films production. Tous droits réservés.] 


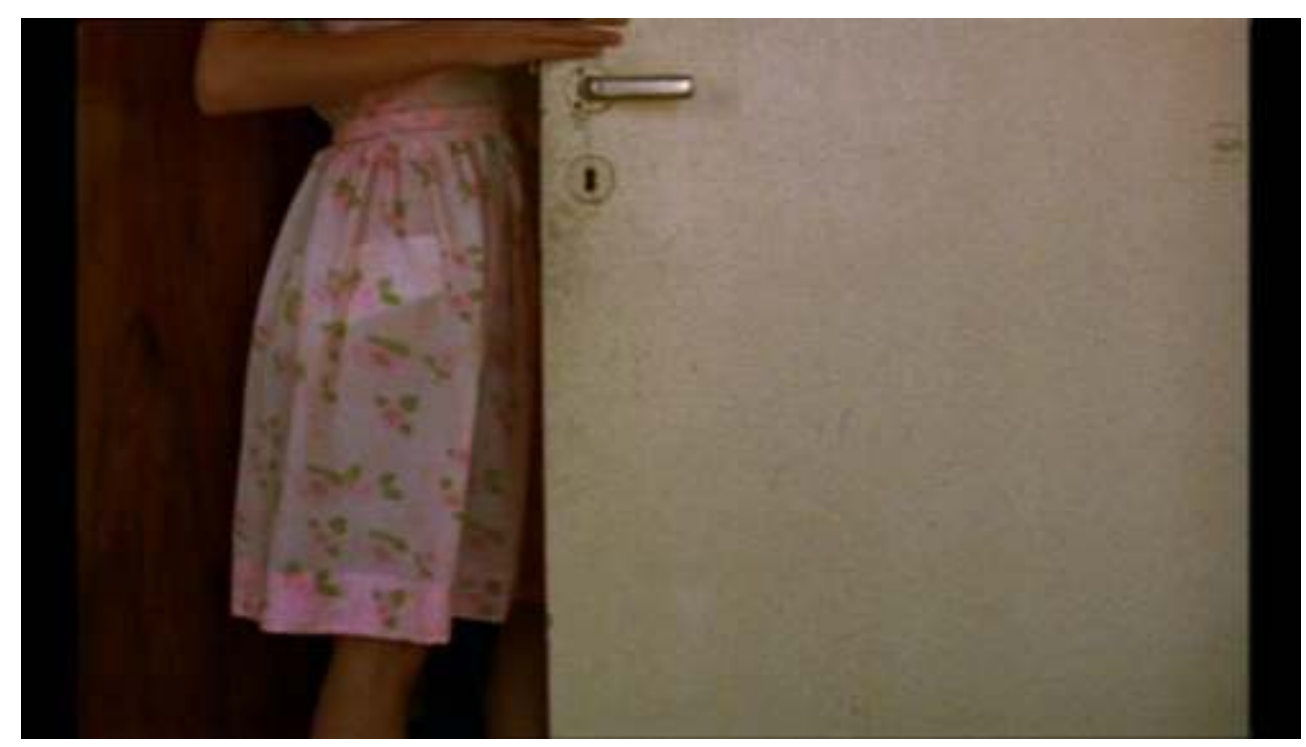

Plan 148 - $64 \min 18 / 64 \min 29$

[«Empty Quarter (Une Femme en Afrique)», production : Double D Copyright Films / FR3 films production. Tous droits réservés.]

58 L'espace visuel se referme : les plans sont plus serrés, les arrière-plans sont bouchés, le rectiligne et l'orthogonal règnent, une balustrade cisaille le premier plan, le personnage est coupé par le cadre. L'espace sonore est à nouveau urbain: brouhaha de la ville, klaxons ; sans être nullement assourdissante, cette ambiance sonore surgit après un plan nocturne du désert à l'ambiance sonore parfaitement calme. La ville modifie tout, semble happer les personnages dans un autre réel, totalement disjoint du réel sentimental. La rupture à tous niveaux semble avérée : le changement radical de lieu les propulse dans un quotidien qu'ils avaient oublié.

Voix off du plan 145 :

Depuis qu'on est arrivé à Alexandrie, elle a changé. Je vais m'occuper de mon travail. Il faut que je leur dise où je suis à Paris.

Voix in du plan 147 :

Je sors et j'sais pas quand j'reviens

61 Voix off du plan 148 :

Il va falloir que j'invente une histoire. Je n'peux tout de même pas leur dire que j'ai tout laissé tomber pour une fille.

62 La discordance entre eux est manifeste. Le retour dans une ville est l'alibi de cette désunion, et chacun la légitime à sa façon (s'occuper de son travail/sortir en ville). Alors que le quasi raccord dans l'axe et le chevauchement des voix établissaient une concordance entre les personnages durant les plans 127-128, ici, les décadrages et la disjonction des voix marquent cette discordance.

63 Les cinq minutes suivantes (22 plans) laissent le personnage masculin dans une solitude qu'il vit difficilement :

Elle est partie, elle a disparu (...) J'attends la femme que j'aime (...) j'ai passé la journée tout seul (...) 


\section{Désir d'être absent au regard des autres}

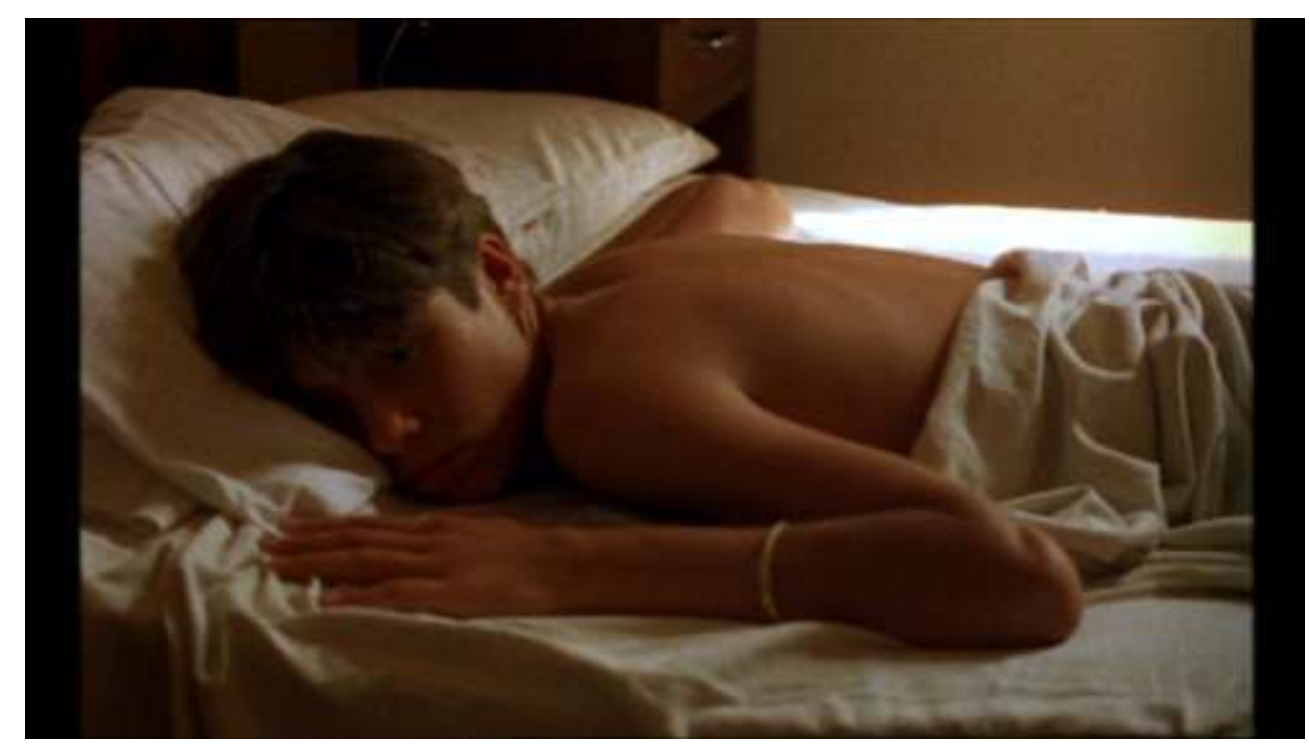

Plan 171 - 69 min 56/70 min 30

["Empty Quarter (Une Femme en Afrique) », production : Double D Copyright Films / FR3 films production. Tous droits réservés.]

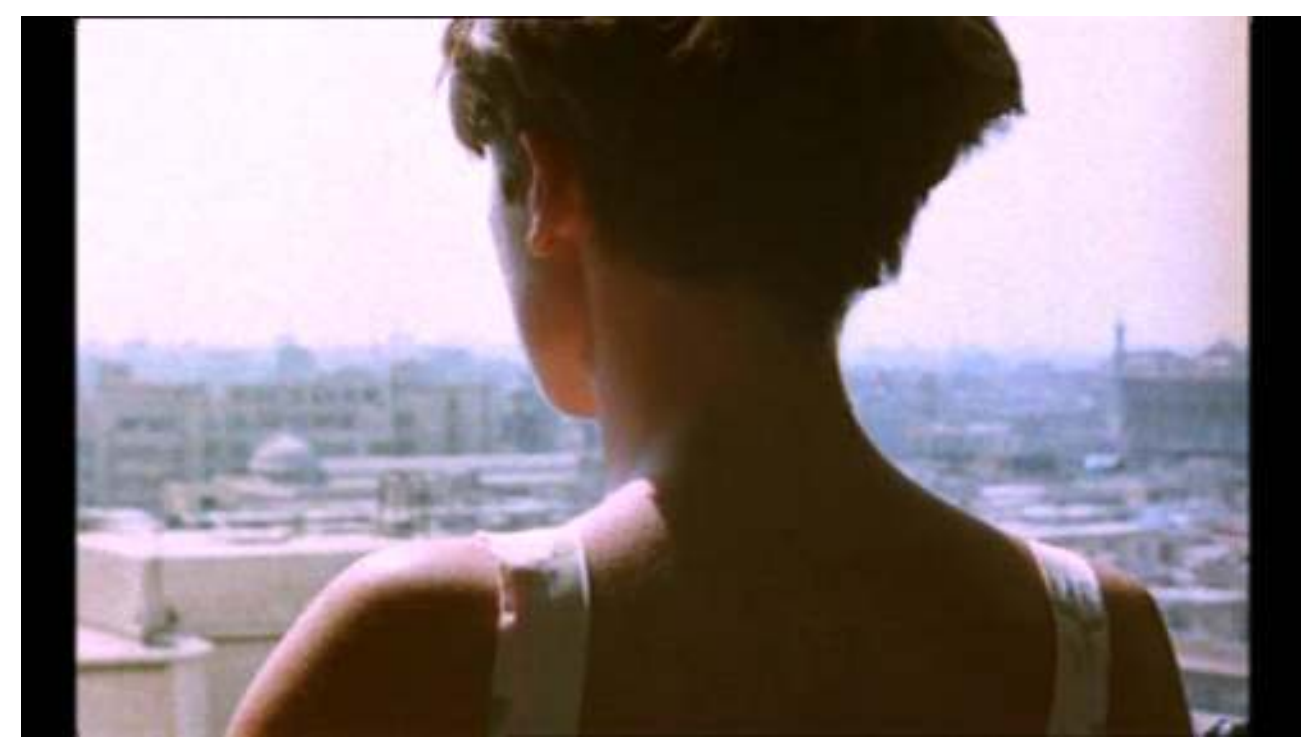

Plan 172 - $70 \min 30 / 70 \min 38$

[«Empty Quarter (Une Femme en Afrique)», production : Double D Copyright Films / FR3 films production. Tous droits réservés.]

Le retour à l'image et au son de la jeune femme n'est pas apaisé, bien au contraire. Elle se plaint de l'omniprésence du regard de l'homme :

Arrête de m'regarder comme ça. T'es toujours là devant moi comme si tu m'voyais pour la première fois. C'est une torture de dormir dans la même chambre.

Le plan suivant la montre de dos en plan rapproché épaule en train de regarder par une fenêtre ; puis elle se retourne, fixe la caméra un instant et quitte le champ sans un mot. Après la problématique de l'écoute (plan 73), celle du regard. Son regard et sa présence donc la caméra - lui deviennent insupportables. Cette problématique du regard va 
s'amplifier par la suite, matérialisant ainsi les fins, celle de leur histoire et celle du film (une dizaine de minutes plus tard) : le désir de ne plus être regardés de la part des deux protagonistes va être clairement exprimé, ce qui, en extrapolant, congédie le spectateur.

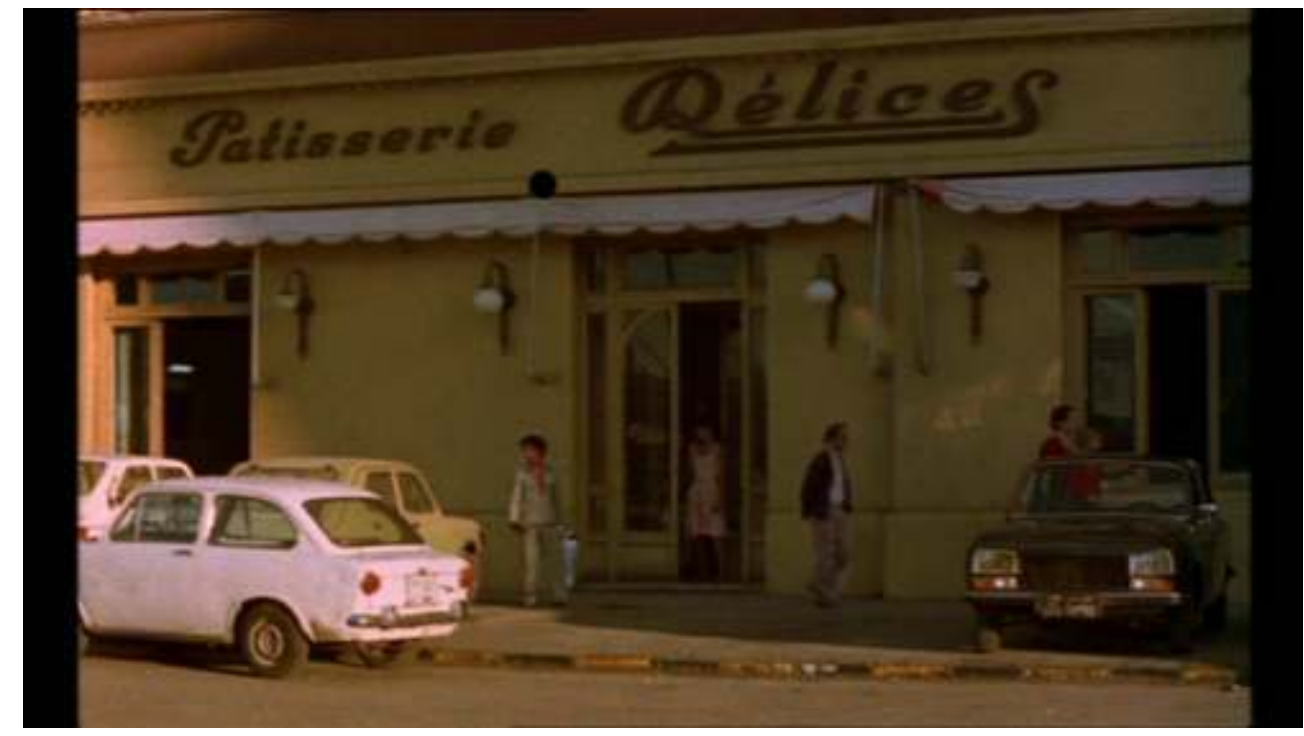

Plan $179-72 \min 57 / 73 \min 3$

["Empty Quarter (Une Femme en Afrique)», production : Double D Copyright Films / FR3 films production. Tous droits réservés.]

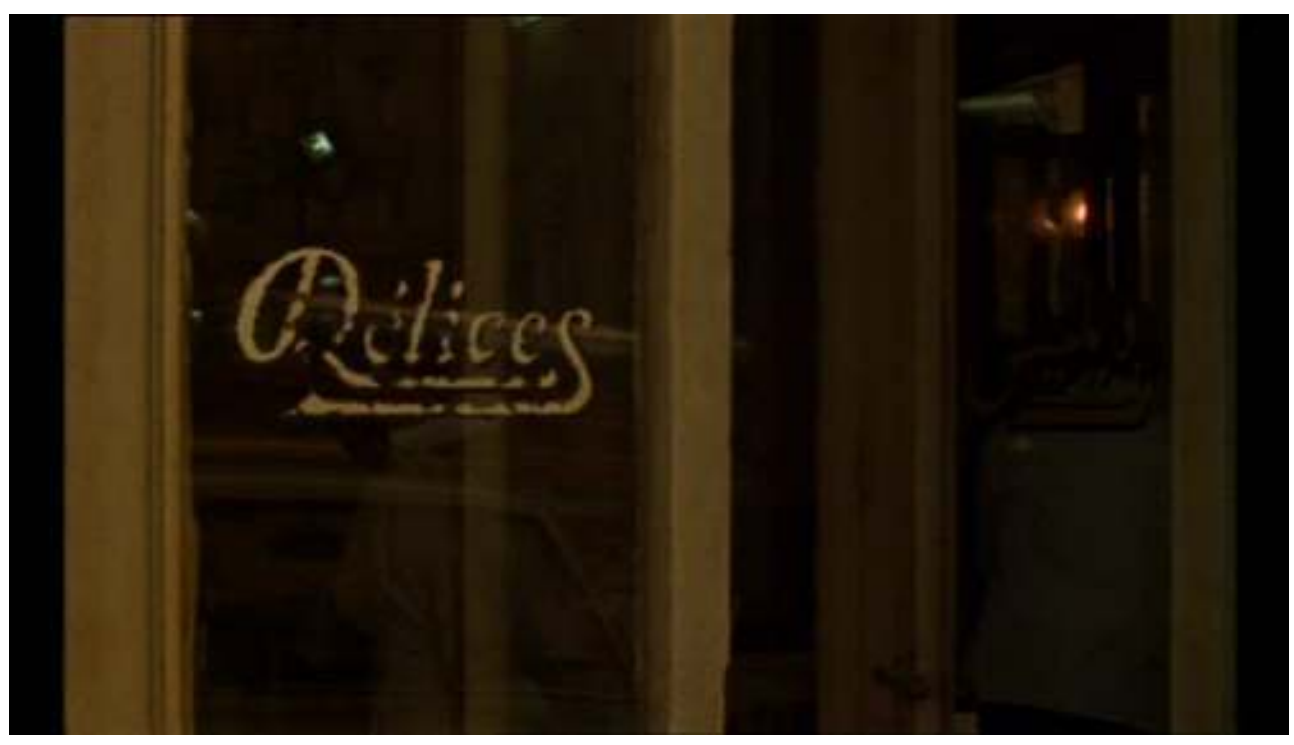

Plan $180-73 \min 3 / 73 \min 7$

[«Empty Quarter (Une Femme en Afrique)», production : Double D Copyright Films / FR3 films production. Tous droits réservés.] 


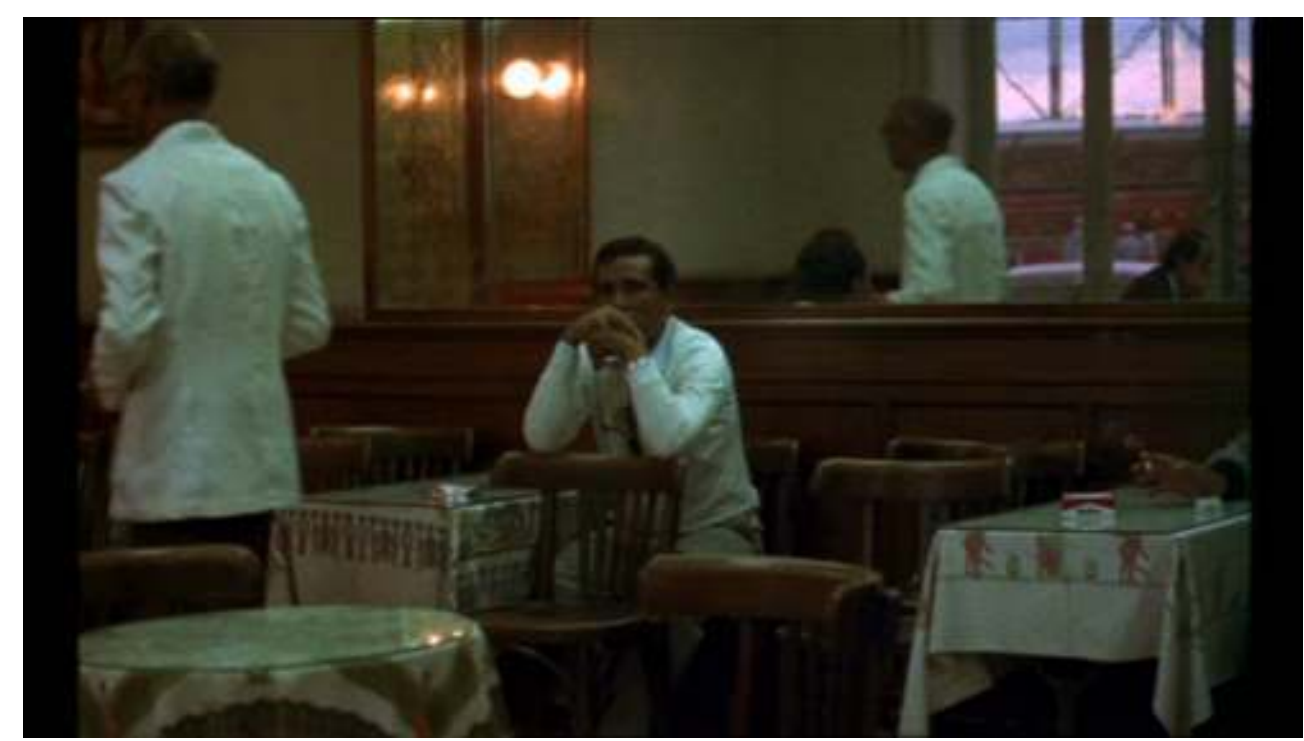

Plan $181-73 \min 7 / 73 \min 18$

[«Empty Quarter (Une Femme en Afrique)», production : Double D Copyright Films / FR3 films production. Tous droits réservés.]

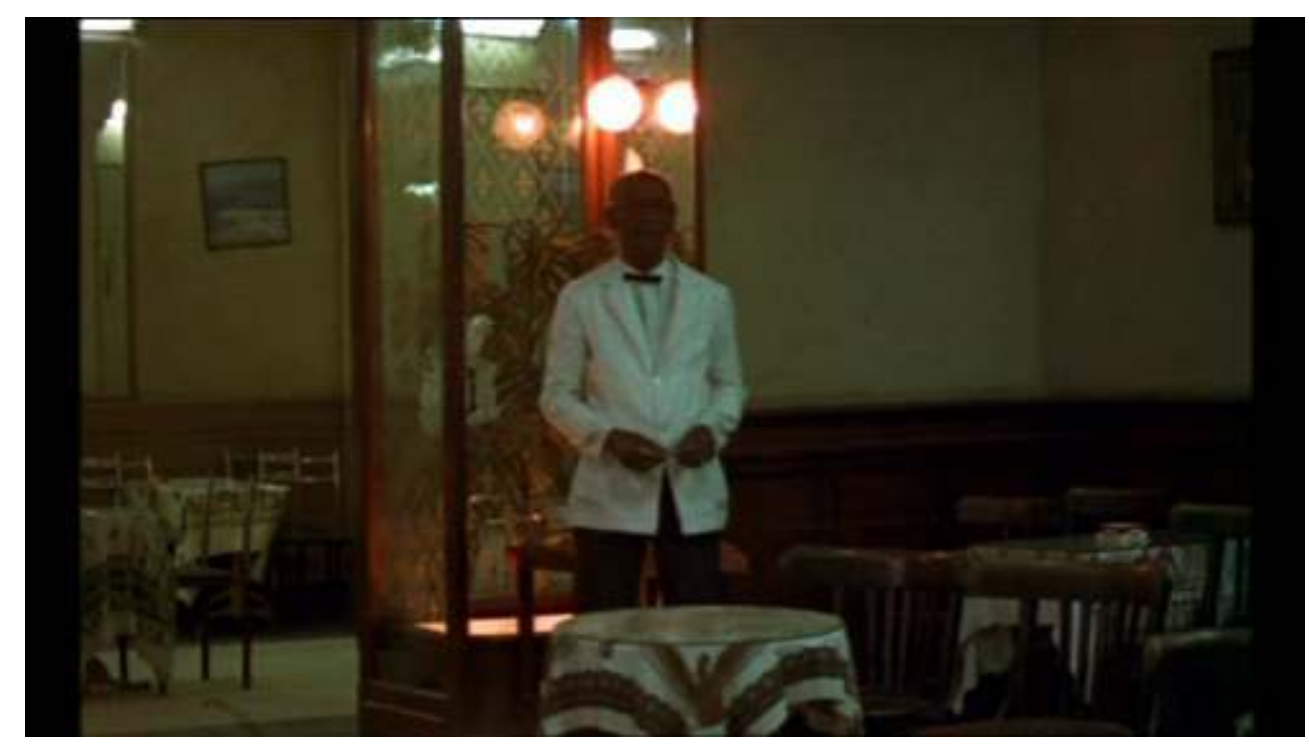

Plan 182 - 73 min 18/73 $\min 27$

[«Empty Quarter (Une Femme en Afrique)», production : Double D Copyright Films / FR3 films production. Tous droits réservés.]

66 Ces quatre plans concluent ce désir de disparition aux yeux des autres. Le plan 179 introduit le regard inquisiteur de l'amoureux transi (elle sort du magasin accompagnée par un homme). Les plans 181 et 182 présentent les regards-caméra insistants inédits ${ }^{24}$ de deux inconnus. Quant à la voix off des plans 180-182, elle exprime le malaise du personnage masculin :

Qui peut bien être l'homme avec qui je l'ai vue sortir d'ici? " (plan 180) «Je n'sais plus où aller. Elle m'oblige à rentrer dans cet endroit sinistre; le seul endroit où je suis sûr de ne pas la rencontrer. » (plan 181) «Je veux que personne ne s'occupe de moi... que personne me regarde. (plan 182)

67 Le regard-caméra était jusqu'ici dévolu au seul personnage féminin. Ces deux regards d'inconnus deviennent ainsi particulièrement gênants. Il désire qu'on ne le regarde pas, 
mais la caméra " résiste ", ce désir ne se « réalise " pas. La voix off se retrouve à nouveau synchrone avec l'action filmée, ce qui augmente ici l'incapacité de ce désir d'être comblé, puisque ce désir n'est effectivement pas suivi d'effets en ce qui concerne les actions (les regards ne se détournent pas).

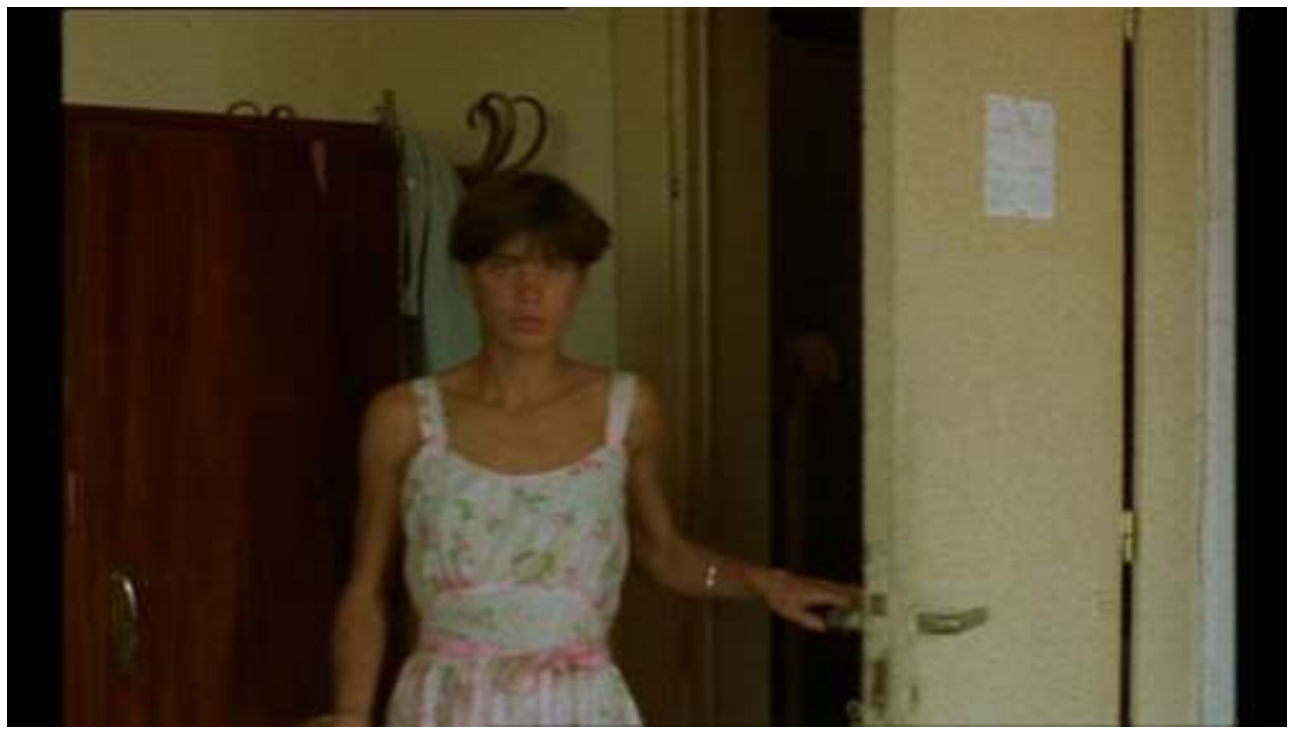

[«Empty Quarter (Une Femme en Afrique)», production : Double D Copyright Films / FR3 films production. Tous droits réservés.]

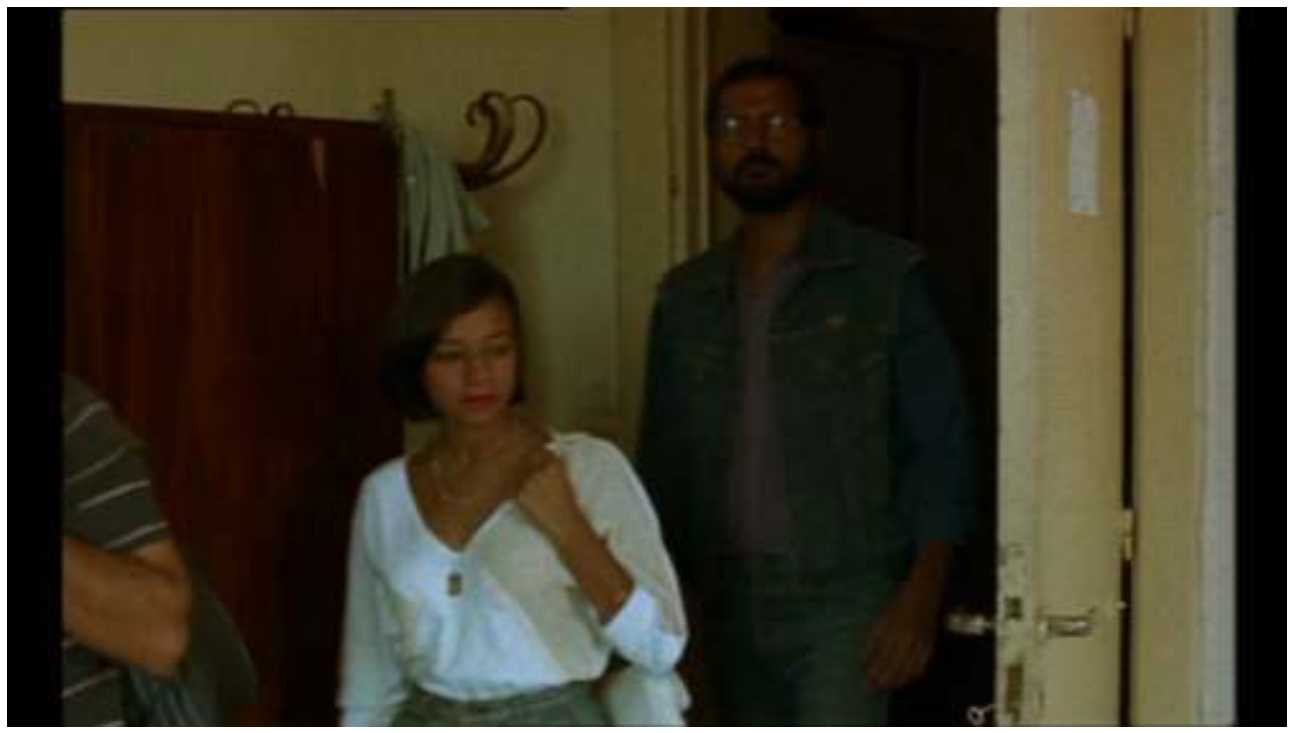

Plan 194 - 77 min 04/77 $\min 19$

[«Empty Quarter (Une Femme en Afrique)», production : Double D Copyright Films / FR3 films production. Tous droits réservés.] 


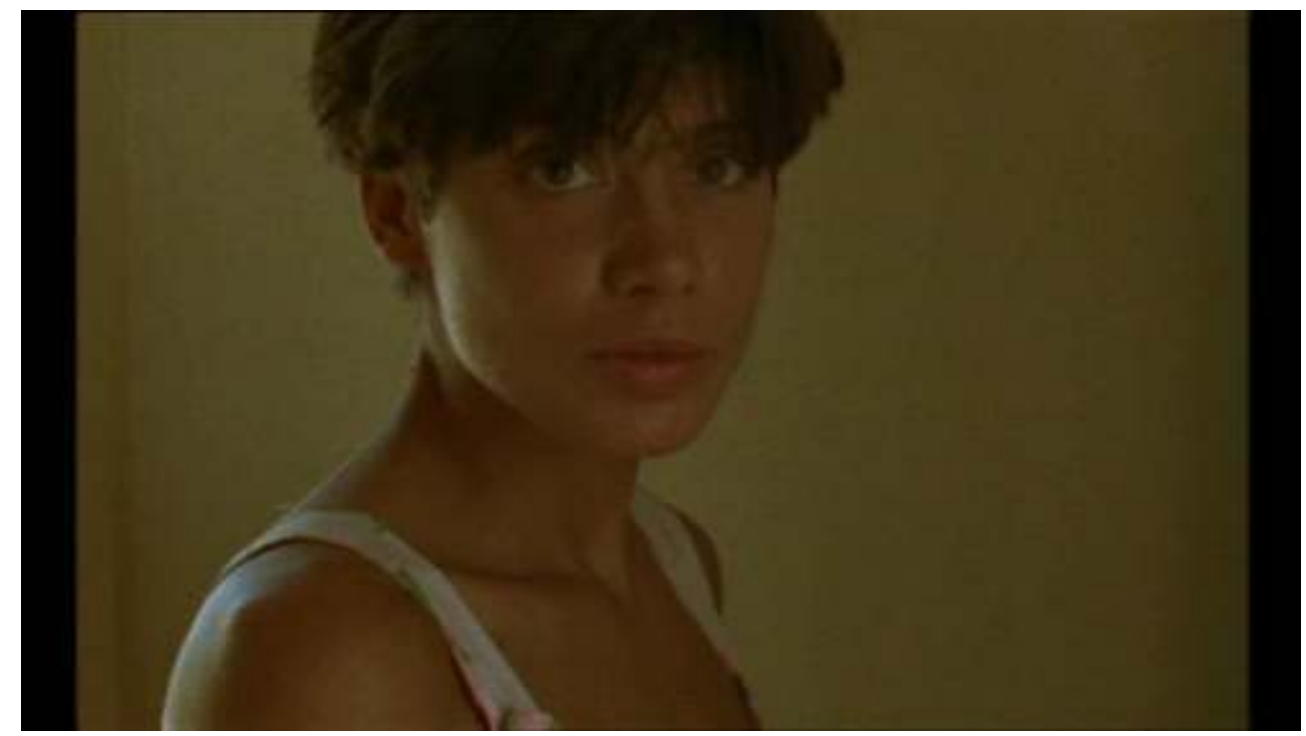

Plan 195 - 77 min 19/77 $\min 26$

[« Empty Quarter (Une Femme en Afrique) », production : Double D Copyright Films / FR3 films production. Tous droits réservés.]

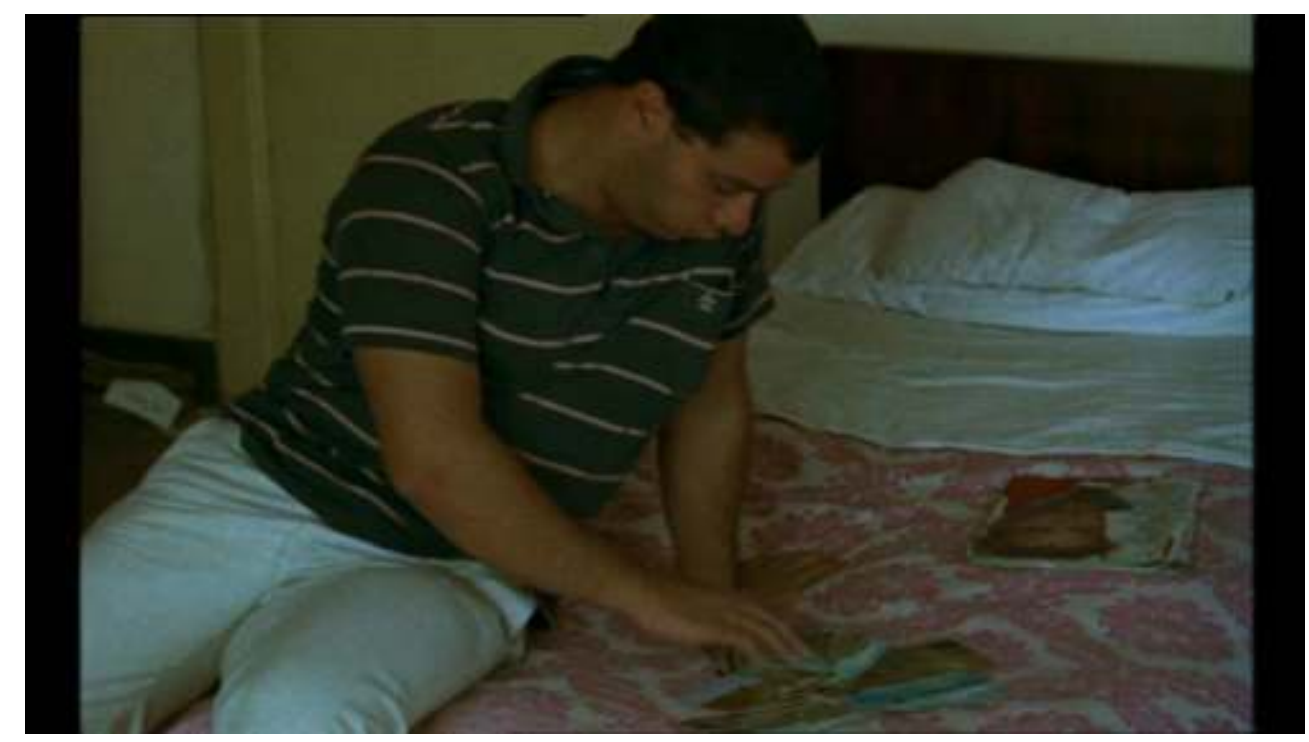

Plan 196 - 77 min 26/77 $\min 31$

[«Empty Quarter (Une Femme en Afrique)», production : Double D Copyright Films / FR3 films production. Tous droits réservés.] 


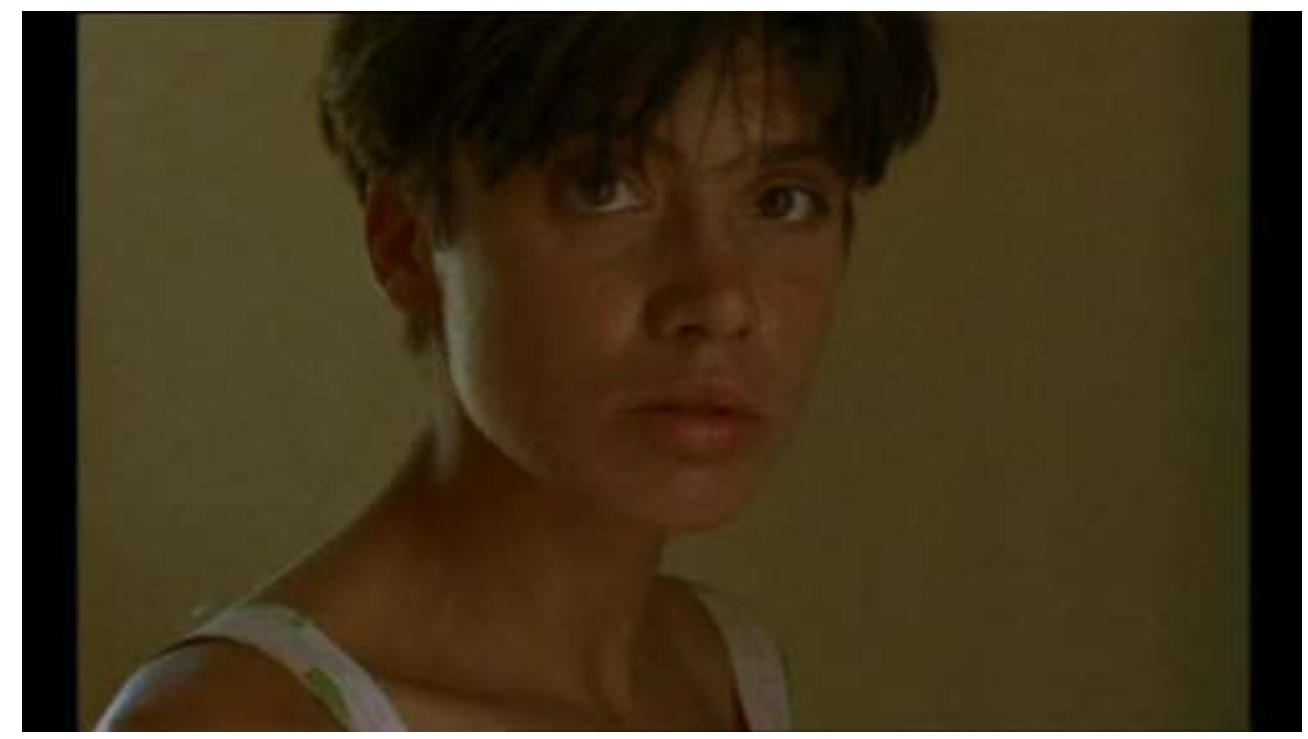

Plan 197 - 77 min 26/77 $\min 31$

[«Empty Quarter (Une Femme en Afrique)», production : Double D Copyright Films / FR3 films production. Tous droits réservés.]

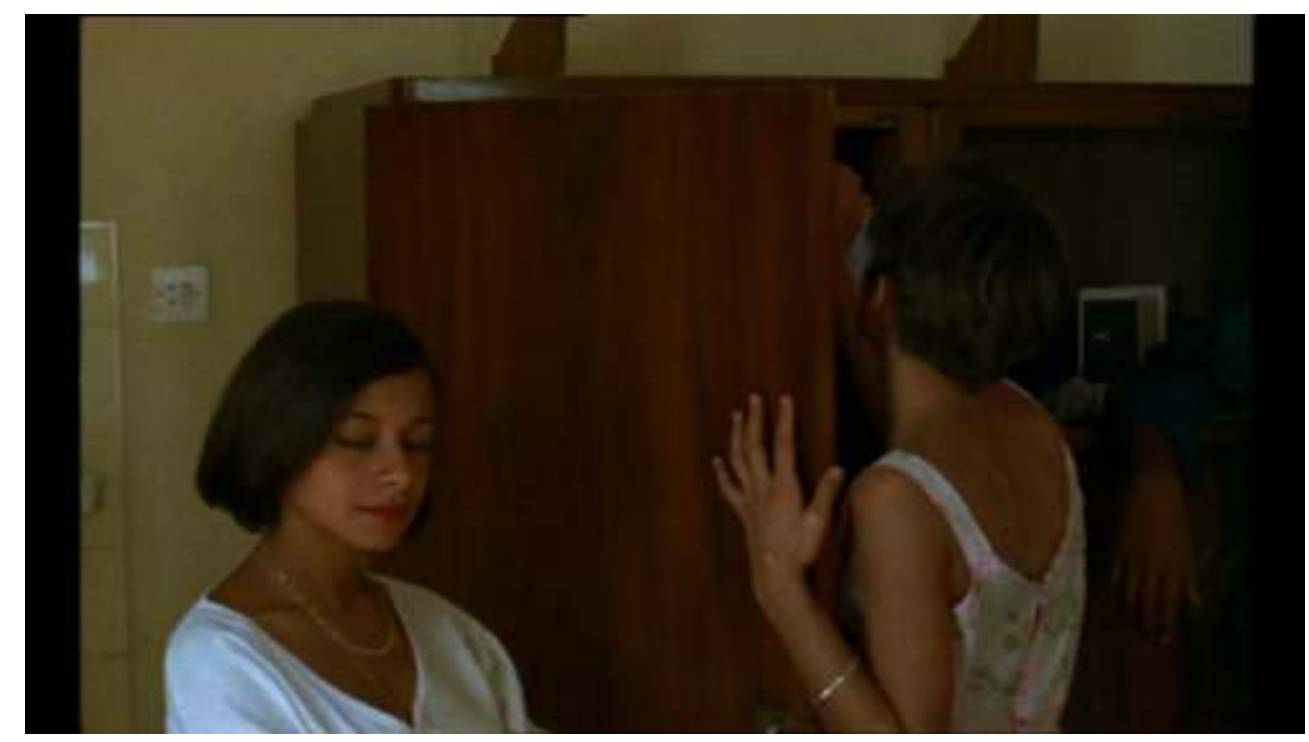

Plan $198-77 \min 42 / 77 \min 57$

[«Empty Quarter (Une Femme en Afrique)», production : Double D Copyright Films / FR3 films production. Tous droits réservés.] 


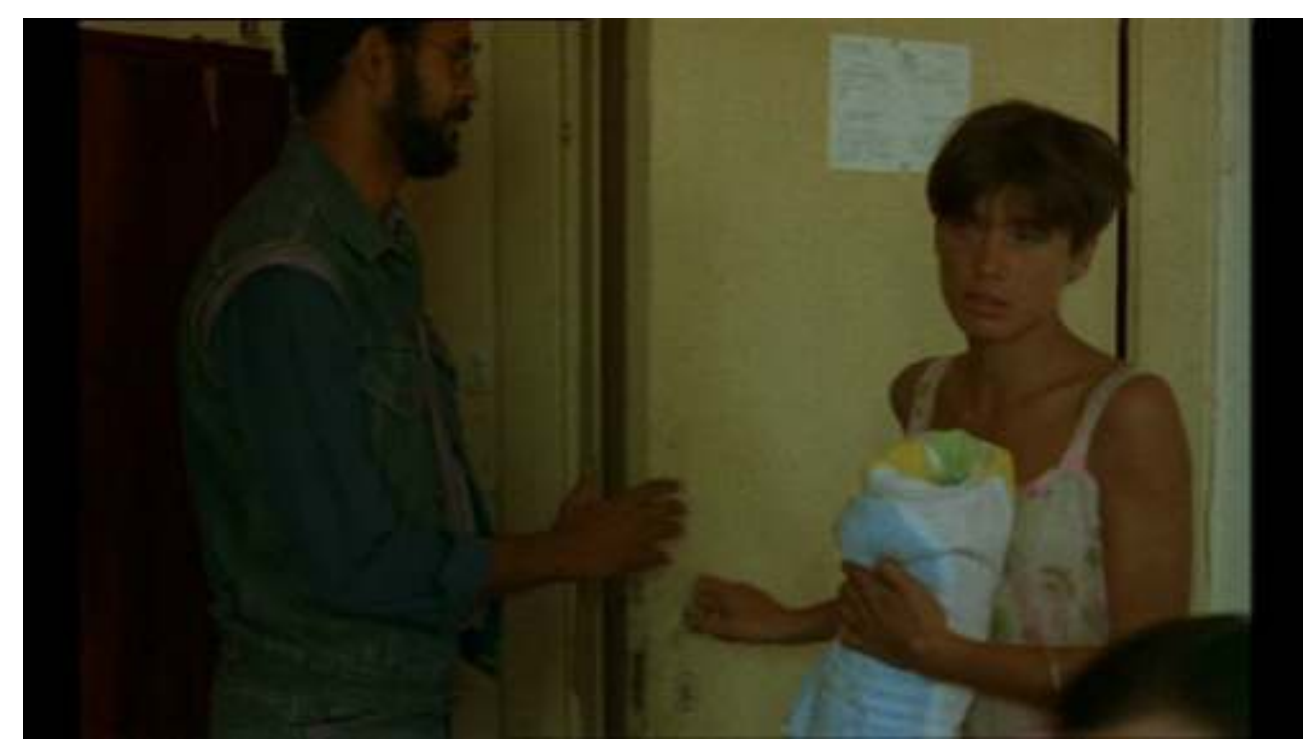

[«Empty Quarter (Une Femme en Afrique)», production : Double D Copyright Films / FR3 films production. Tous droits réservés.]

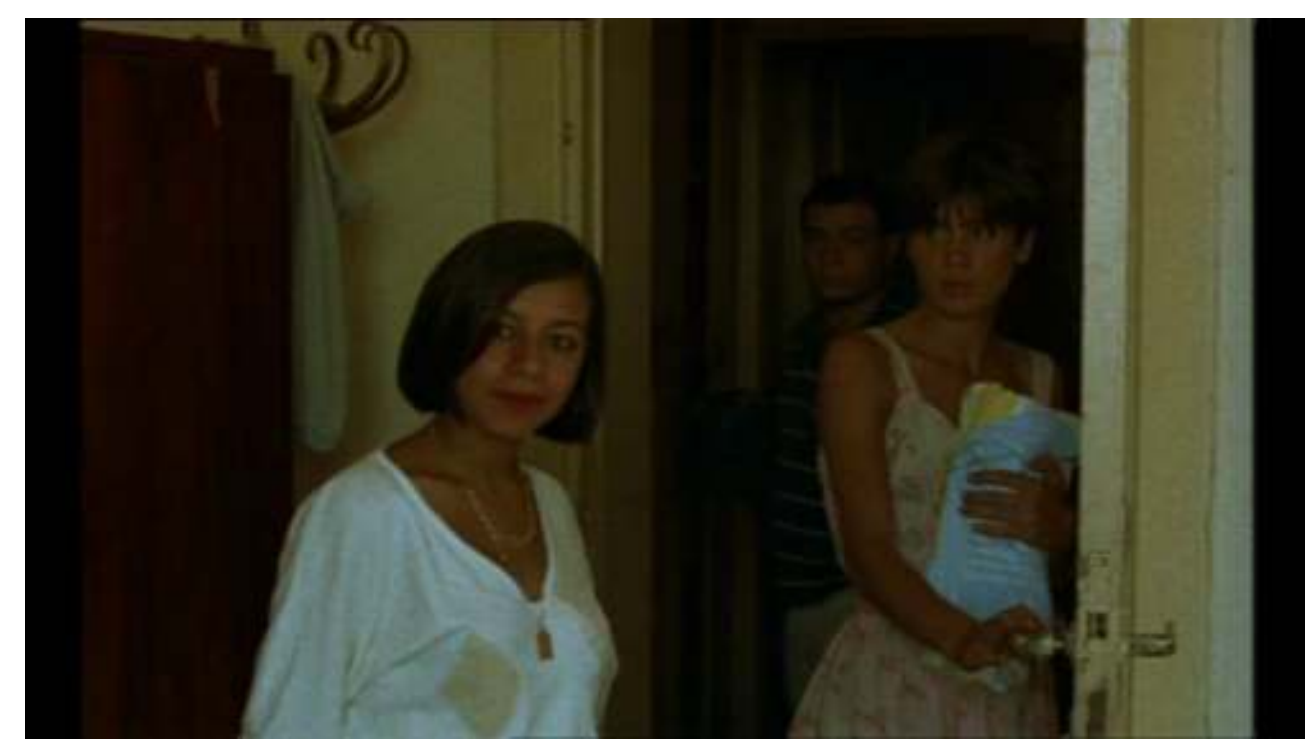

Plan 199 - 77 min 57/78 min 17

[«Empty Quarter (Une Femme en Afrique)», production : Double D Copyright Films / FR3 films production. Tous droits réservés.]

68 Sur ces six plans, pas de voix off. L'irruption de personnages secondaires dans l'intimité de cette chambre d'hôtel où se trouve le personnage masculin, quasiment cloîtré dans son désespoir amoureux, peut être ressentie comme très incongrue. C'est la première, et unique, intervention de personnages secondaires (hormis quelques serveurs); elle brise définitivement l'intimité tant convoitée, surtout qu'elle est initiée par la jeune femme elle-même qui montre ainsi ostensiblement sa volonté de vivre non seulement autre chose, mais, surtout, de vivre sans lui,... bref, de s'émanciper. La place est au dialogue :

Plan 194 : visiteuse (à lui)

$$
\text { - Bonjour }
$$

Plan 195 : elle (à lui)

- Tu peux m'prêter l'camion? La clef est où? 

systématique, mais elles restent obstinément sans réponses audibles. Que fait-il ? Ses réponses ne sont-elles pas rendues audibles par la mise en scène? Répond-il par de simples hochements de tête et des gestes? Mais rien, dans l'attitude de la jeune femme, ne laisse supposer qu'elle suit du regard un geste hors-champ ou qu'elle a obtenu une réponse muette. L'«absence» du personnage masculin est donc particulièrement manifeste ici. Absence voulue: il ne veut plus être regardé, perturbé, comme dit précédemment. Absence subie : elle ne veut plus être avec lui. Pourtant, il serait tout aussi logique de remplacer ce terme « absence » par celui de " présence », tant cet homme n'a cessé de s'imposer tout au long du film par le point de vue subjectif presque omniprésent. Cette rafale d'interrogations sans réponses questionne l'interaction entre le champ et le hors-champ. Le visuel ne suffit plus ici, la lacune de la voix de cet homme est manifeste et transcrit sans doute le véritable point de vue de ce film: les actions vues jusqu'à présent ont-elles réellement été vécues telles quelles ou «seulement" partialement reconstituées par lui, donc transfigurées par sa sensibilité ? Ces questions sont encore plus pertinentes avec l'ultime interrogation, celle posée par la visiteuse qui clôt définitivement l'interaction champ/hors-champ. C'est une inconnue - mais une femme tout de même - qui conclut ce rapport aux autres. Ces questions sans réponses sont donc bien représentatives du point de non retour de leur relation : il existe (regardscaméra, on s'adresse à lui) mais n'est matérialisé que par les autres ; son état est une sorte de béance de laquelle, par définition, ne peut émerger aucun son. L'absence de sa voix off renforce cette perception. Dans le plan suivant, sur une vue d'un carrefour en plongée verticale, il se contente de dire: «Nous devons terminer ce voyage ensemble, comme nous l'avons commencé." La fin de leur histoire semble consommée. Ici, la voix off reprend place dans une certaine contemporanéité avec l'action car, après l'intrusion des inconnus, le personnage masculin paraît être affecté et en tirer les conclusions nécessaires : revenir au point de départ, comme pour effacer, exorciser cette aventure,... voire, dans un espoir chimérique, la recommencer fort des enseignements tirés.

Après, les dernières paroles de la jeune femme sont symptomatiques d'une rupture presque oubliée :

78 Plan 202 (78 $\min 44 / 79 \min 11)$ :

J'aime bien cette ville. J'reviendrai un jour. C'est à quelle heure le départ du bateau demain ? (avec un regard-caméra) T'as réussi à avoir une cabine? 
Ici, pas de rancœur (Alexandrie ne sera pas entachée d'un mauvais souvenir) et les questions sont non seulement encore purement formelles, mais aussi portées sur l'avenir et un départ qui matérialisera leur séparation une fois arrivés en Europe.

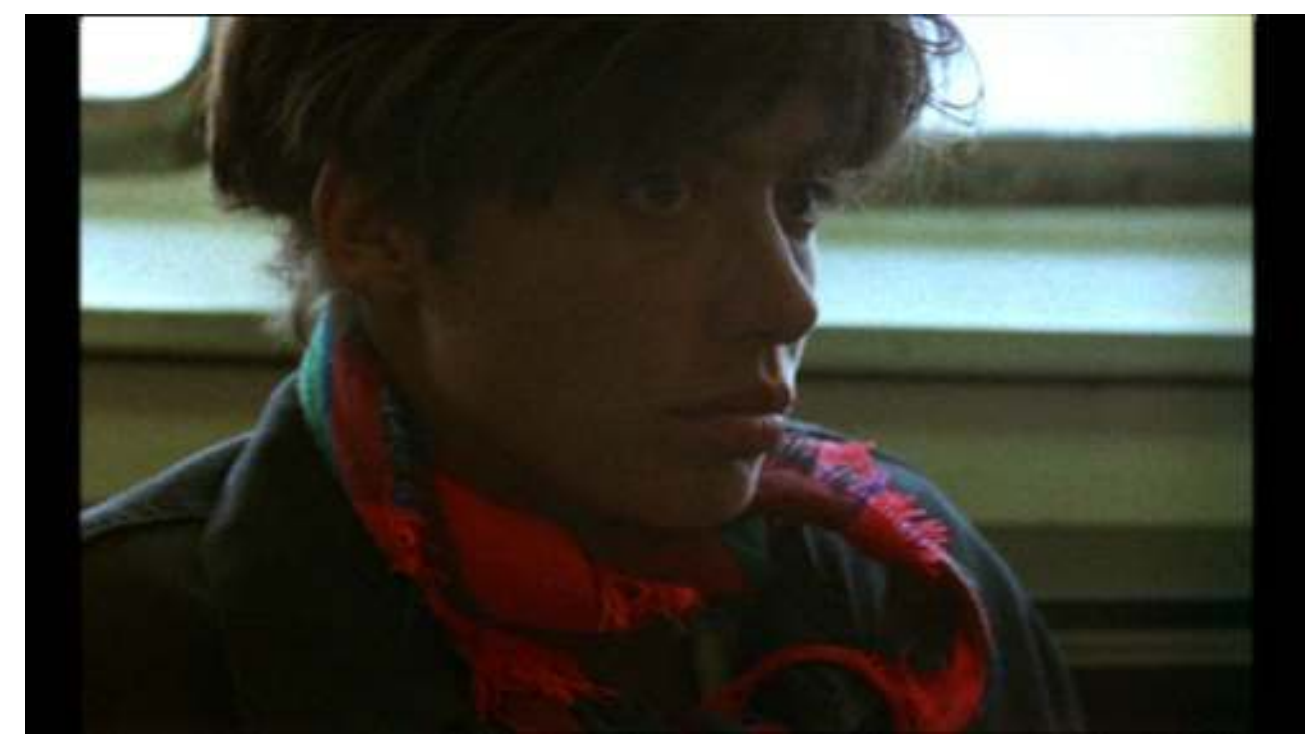

Plan 207 - 80 min 3/80 min 31

[«Empty Quarter (Une Femme en Afrique)», production : Double D Copyright Films / FR3 films production. Tous droits réservés.]

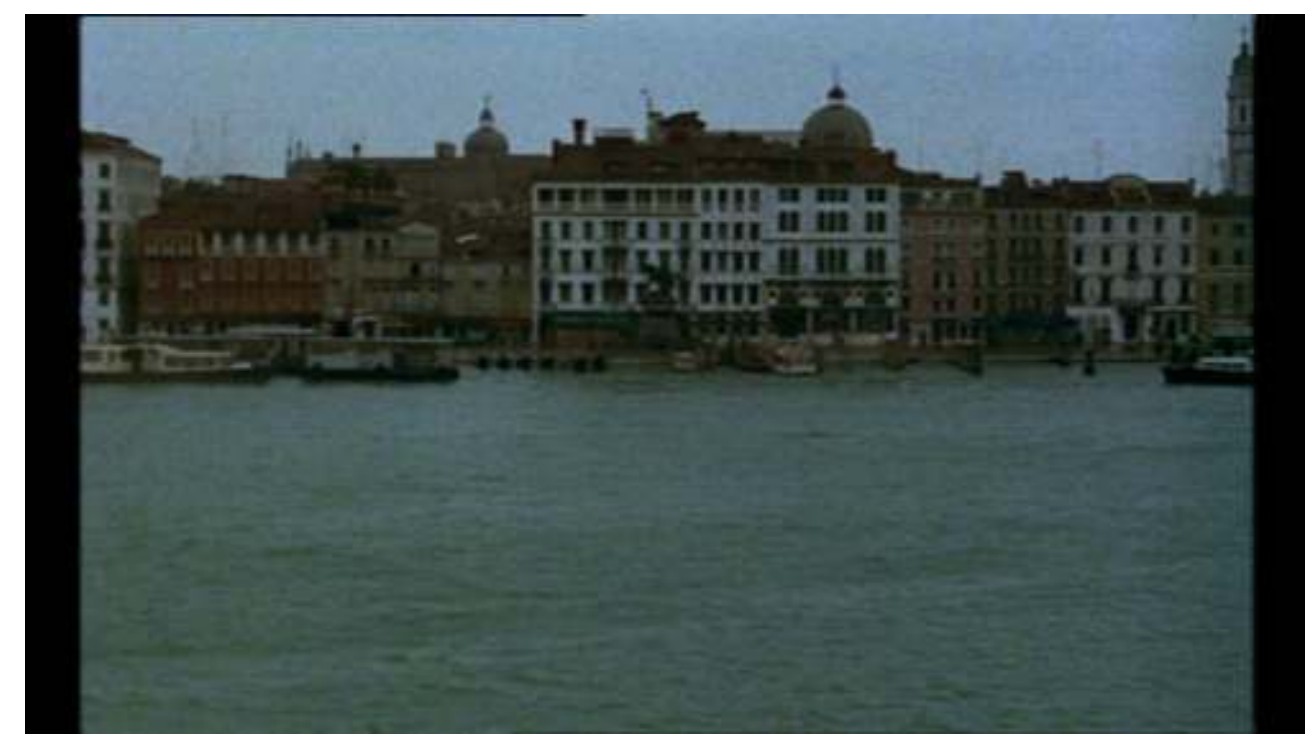

Plan 208 (dernier) - $80 \min 31 / 81 \min 26$

[«Empty Quarter (Une Femme en Afrique)», production : Double D Copyright Films / FR3 films production. Tous droits réservés.]

80 Plan 207: «Le peu qu'il nous reste, nous devons le préserver. J'aimerai lui dire que je ne suis plus le même. Elle m'a changé. Je sais que les souvenirs de ce voyage reviendront me poursuivre pour que cela recommence avec une autre femme. Je n'pourrai plus voyager comme avant. "

81 Sur le regard dans le vague de la jeune femme, ce texte ultime termine le discours intérieur. Cette conclusion lie profondément les deux passions de cet homme : la femme et le voyage, ce dernier prenant d'ailleurs plus de place. Le dernier plan marque le retour 
en Europe. La voix off est inutile ici, le lieu et l'atmosphère visuelle parlent d'eux-mêmes : Venise par temps gris. La " cité des voyages de noces " est bien terne, comme ce retour à la réalité sur le Vieux Continent de ce couple qui n'a jamais vraiment existé. L'ambiance sonore, de même, est étouffée, sans relief. Tout semble s'achever et les cartons noirs du générique de fin défilent sans un son.

\section{L'image d'une voix-off}

Empty Quarter n'est ni le premier, ni le dernier film totalement en point de vue subjectif. Ce choix d'une totale immersion permet, ici, de transcrire une certaine vision des événements, et non, "simplement ", une volonté de créer une totale identification du spectateur avec le personnage - identification évidemment sujette à caution du fait qu'aucun visage ne permette de la matérialiser, de la magnifier. Il n'est d'ailleurs pas anodin de remarquer que les films utilisant un tel procédé font souvent intervenir les mains ou le reflet du personnage concerné, comme pour " raccrocher » le spectateur à une identification non virtuelle ${ }^{25}$. Raymond Depardon refuse totalement cela et propose ainsi un point de vue subjectif moins "confortable»; quasiment aucune excroissance visuelle ou sonore du personnage ${ }^{26}$ n'est détectable, bien que sa présence hors-champ soit revendiquée par les regards-caméra. De plus, mis à part pour quelques rares spectateurs de l'époque, l'identification de la voix de Raymond Depardon n'est ni évidente, ni nécessairement recherchée ${ }^{27}$. Donc, aucun visage n'est concrètement attribuable à ce personnage irrémédiablement hors-champ, et le processus d'identification visuelle n'est ainsi pas réellement souhaité. Le propos est ailleurs et cette absence totale de reconnaissance visuelle contribue bien sûr à la portée sensible de ce film, à sa réflexion sur un point de vue masculin des rapports amoureux.

La particularité d'Empty Quarter est d'utiliser uniquement la voix off pour le personnage principal dont le spectateur partage le point de vue. Cet alliage visuel et sonore particulier s'est combiné en plusieurs étapes et a fluctué légèrement selon les séquences, au gré des sentiments. Cette voix off a, tour à tour, rempli plusieurs rôles dévolus habituellement à celle-ci, principalement donner des informations diverses (situationnelles, personnelles, émotionnelles...) Cependant, elle s'est aussi chargée d'entretenir un lien parfois étrange avec l'univers présenté en général, et la voix in de la femme en particulier : parfois synchrone, parfois distanciée par rapport aux actions. De la sorte, cette voix off, véritable personnage, a nourri certains paradoxes: à la fois "personnage-voix off» sans corps ni voix, "personnage-voix off» regardant/regardé, " personnage-voix off» écoutant/non entendu/muet. Quelques éléments sonores ont en effet pu être jugés, si ce n'est contradictoires, tout du moins ambigus, et ont ainsi jeté un doute sur le point de vue lui-même. D'où l'interrogation légitime quant à la véritable nature de ce point de vue née lors de l'intervention du son interne objectif (séquence où elle se bouche les oreilles face à la cascade), et redoublée lorsqu'aucune réponse aux questions posées face à la caméra n'est entendue. Ces éléments sont d'autant plus singuliers que le film avait pris soin de définir par étapes successives le point de vue subjectif. L'irruption de ces éléments inattendus peut, bien sûr, être interprétée comme un facteur symbolisant la vie sensible de cet homme : il se met à la place de l'être aimé lors du jeu auditif ; l'absence de réponses audibles matérialise sa gêne et son désespoir. En fait, il faut constater que la temporalité de cette voix off n'est pas irrévocablement stable. Un schéma des rapports de cette voix off avec l'espace visuel et sonore montrerait une 
fluctuation. En matérialisant en une ligne droite les actions vues et entendues, et en une autre ligne la voix off, celle-ci se développerait en se rapprochant et s'éloignant plus ou moins de la droite en fonction du quasi synchronisme observé ou de la distanciation trahissant une réflexion a posteriori. Le jeu de cette voix off est donc bien le jeu d'un vécu repensé, voire au-delà, d'un vécu fantasmé. En effet, d'une certaine manière, le film tend à un point de vue purement mental : la dématérialisation totale du personnage masculin et le rôle de sa voix off invitent le spectateur à se plonger dans une pensée qui nous livre des sentiments et des impressions stimulés par le désir, celui-ci pouvant prendre un caractère plus universel que concret.

Le cinéma est, par essence, regard et écoute. Dans ce film, regard et écoute semblent à la fois univoques (ceux de l'homme) et, à certains moments, équivoques. L'étrange (dés)équilibre engendré par le mixage des voix in, off et des sons d'ambiance, déstabilise discrètement le spectateur qui ne peut pas totalement croire au systématisme du point de vue subjectif ouvertement offert ; mais ce n'est pas grave, bien au contraire. Raymond Depardon fissure le champ convenu de la voix off en lui donnant la possibilité de « dialoguer » autant avec le personnage féminin qu'avec le spectateur. Cette voix off n'a donc pas d'image proprement dite car tous les plans la matérialisent d'une certaine manière. Un peu comme le personnage interprété par Ingrid Bergman dans Europe 51 qui se voit folle dans les regards-caméra des pensionnaires de l'hôpital psychiatrique où elle est finalement internée, le personnage masculin d'Empty Quarter n'existe que par le regard de la jeune femme désirée; et rarement désir n'a été autant incarné par le « regard de la caméra » de Raymond Depardon.

\section{ANNEXES}

\section{Annexe : Prolongation écrite}

En 1986, Raymond Depardon publie les Fiancées de Saïgon (Cahiers du cinéma). Il s'agit d'un livre, contenant textes et photos, entremêlant des souvenirs amoureux autobiographiques vécus à Saïgon qui sont à l'origine du projet d'Empty Quarter, et le récit de son tournage ${ }^{28}$. 


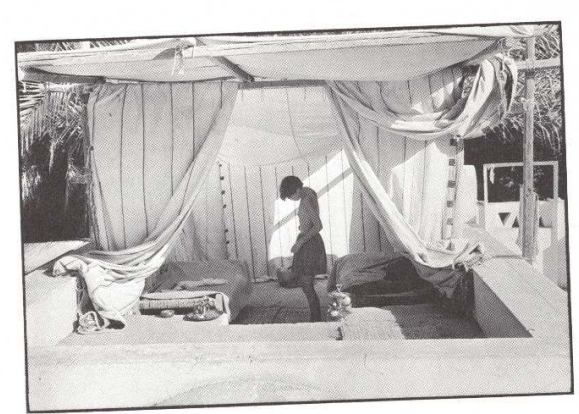

Il y a longtemps que j'avais envie de l'embrasser.

J'aurais dû l'embrasser, la caresser.

J'aurais dù m'approcher d'

J'aurais du luz parler.

J'aurais dû me taire.

Je me souviens qu'il y avait encore du soleil dans la chare rait.

J'étais bien. Ce jour-là,
Nous n'avions rien à faire.

Je n'ai même pas pensé à faire un geste.

96

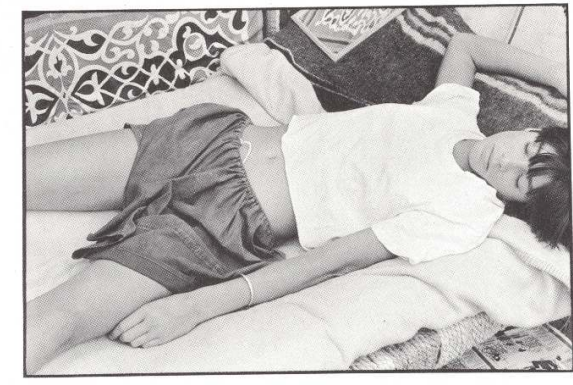

Il y a deux histoires

la vraie et la fausse.
La fausse est parfois vraie.

La vraic n'est pas racontée, elle n'a pas de voix.

La vraie n' est pas racontee, elle n'a pas de

à moins qu'elle ne soit déjà finie avant d'avoir commencé

à tourner le film.

Pages 96, 97

[Tous droits réservés]

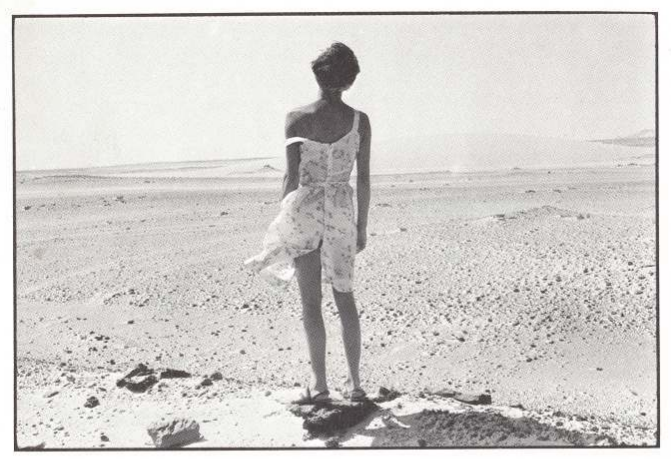

Nous ne faisons plus le même voyage.

J'ai été mal.

Je veux filmer ça,

mais je ne veux pas le revivre.

Si j'ai de nouveau mal,

je ne l'ai pas fait exprès !

Western Desert (Egypte)

105

Page 105

[Tous droits réservés]

Les textes sont sous deux graphies différentes : italique et police romaine. La première est utilisée pour le texte qui se rapproche de la voix off $\mathrm{du}_{\mathrm{film}}^{29}$, la seconde pour les réflexions de Depardon sur ce projet de film et ses impressions de tournage. Sans prendre le temps ici d'entrer dans l'analyse des textes et leurs rapports avec les photos, il est 
intéressant de relever quelques détails significatifs en résonnance avec l'usage de la voix off.

Page 97 : « Il y a deux histoires, la vraie et la fausse. La fausse est parfois vraie. La vraie n'est pas racontée, elle n'a pas de voix. C'est elle qu'on devine, qui est encore libre, à moins qu'elle ne soit déjà finie avant d'avoir commencé à tourner le film... »

Ce texte plonge au centre de la problématique soulevée ici : le vécu et le fantasmé, le dit et le non-dit.

Page 105 : « Nous ne faisons plus le même voyage. J'ai été mal. Je veux filmer ça, mais je ne veux pas le revivre. Si j'ai de nouveau mal, je ne l'ai pas fait exprès ! »

Les textes en italique et en police romaine se superposent. Cette association appelle à ce que ces deux textes se complètent, se nourrissent l'un l'autre; ce qui ressemble au dispositif voix off - voix in.

A d'autres endroits, des réflexions techniques de tournage apparaissent :

Page 67 : « Pour ne pas me disperser... Je garde un seul objectif, le $25 \mathrm{~mm}$. Cela m’oblige à trouver la bonne place, la bonne distance, et ne pas fuir devant les faux problèmes. »

Page 111 : «Comment sortir des plans fixes? Je crois que je ne suis pas doué pour les panoramiques, à moins que je n'aime pas ça. »

Ces réflexions renvoient d'une certaine façon à la dernière phrase du film : « Je n'pourrai plus voyager comme avant » que l'on pourrait transformer en « je ne pourrai plus filmer comme avant » tant Empty Quarter est un film singulier dans l'œuvre de Raymond Depardon. Son second long métrage de fiction, la Captive du désert (1990), est d'ailleurs assez symptomatique : aucune voix off, très peu de dialogues et, de mémoire, uniquement des plans fixes ! La très forte présence de la voix off a d'ailleurs été souvent commentée, à commencer par l'une des premières intéressées, Françoise Prenant :

« Il n'y avait pas de texte off sur la première partie ; la femme avait l'air plus heureuse, plus vivante. C'est aussi pour cette raison que je n'aime pas ce texte (de la voix-off, NDLR): il enterre tout, il plonge tout dans un climat je ne dirai pas malsain, mais complaisant, étriqué, banal, enfin sans fantaisie, sans vie. Je sais que le type n'était pas comme ça au début. Ce n'était pas seulement quelqu'un qui pense du début à la fin, «Cette fille il faudrait que je la baise, ça y est je l'ai fait, il faut que je recommence ». Et moi je trouve que c'est assez réduit à ça. J'exagère toujours quand j'en parle, parce que je me suis battue sans arrêt pour que ce soit autre chose quand on a monté cette voix off. Et j'ai perdu ${ }^{30}$.»

\section{NOTES}

1. les Années Déclic (1985), son long métrage précédent (65 min), n'est déjà plus vraiment un documentaire, mais un film autobiographique sur son expérience photographique. A la grande différence d'Empty Quarter, Depardon se montre. Il s'agit d'un documentaire sur lui-même. Empty Quarter est son septième long métrage. Raymond Depardon a tourné un second long métrage de fiction inspiré par la prise d'otage de Françoise Claustre au Tchad au milieu des années 1970 : la Captive du désert (1990). Il a réalisé à ce jour 17 longs métrages et 25 courts métrages.

2. Le titre entre parenthèses ne figure pas au générique du film; ce complément n'apparaît qu'à partir de son exploitation (dossier de presse, affiche, articles,...)

3. Raymond Depardon in Dossier de presse d'Une Femme en Afrique (Empty Quarter) 
4. Françoise Prenant avait déjà participé au montage d'un film de Raymond Depardon : Faits divers (1983) ; actrice dans trois films seulement, elle tient notamment le rôle principal du film de Romain Goupil Lettre pour L. (1994)

5. Il paraît tentant, par uniformisation langagière, d'opter pour la terminologie « out » à la place de « hors-champ ».

6. Comptage fiable à quelques secondes près.

7. Un premier carton pour les sociétés de production, un deuxième carton pour le titre («EMPTY QUARTER »), un troisième pour le nom du réalisateur ( " un film de raymond depardon »)

8. Il est d'ailleurs intéressant de relever dès à présent l'ambiance sonore récurrente dans ce film et dans d'autres films de Depardon situés dans les villes de cette partie du monde (le nord-est du continent africain). Dans Cinéma d'été, court métrage qui débute le film choral Chacun son cinéma (2007), une ambiance sonore proche de celle de ce plan, ainsi que des plans nocturnes propices à un cinéma de plein air d'Alexandrie, suffisent là aussi à planter instantanément le décor.

9. Les photogrammes reproduits ici n'ont qu'une valeur de repère visuel ; c'est pourquoi sont indiqués le début et la fin du plan concerné afin de permettre de repérer la durée du plan et sa place dans le film (indications temporelles relativement fiables à la seconde près).

10. Selon la définition qu'en donne Michel Chion dans : la Voix au cinéma, Cahiers du Cinéma/ Éditions de l'Étoile, coll. «Essais ", Paris, 1982, p. 48.

11. Il pourrait s'agir d'un employé de l'hôtel, mais les modalités de la présence de cette femme dans la chambre de l'homme ne plaident pas pour cette hypothèse (il l'invite dans sa chambre, donc aucun employé n'est censé l'accompagner).

12. Les klaxons sont très présents dans toutes les séquences urbaines et ont quasiment toujours la même tonalité. Bien sûr, ils n'ont plus nécessairement la même portée métaphorique par la suite.

13. Une vingtaine de plans seront le lieu de regard-caméra jusqu'à la fin du film.

14. "Nous étions plutôt intimidés tous les deux. »

15. La diffusion s'arrête au milieu d'un air chanté ; il ne peut donc pas s'agir d'un enregistrement avec un tel fondu. Un quelconque problème technique est tout autant exclu (arrêt de la batterie...). Il ne s'agit pas non plus de l'éloignement de l'appareil puisqu'elle ne le transporte pas quand elle quitte le champ.

16. Le plan suivant également est en mouvement ; mais il ne s'agit que d'un léger recadrage.

17. Elle évoque être allée à une fête, avoir discuté avec un certain «Manuella» (sic), etc. Il ne s'agit ostensiblement plus de leur premier jour ensemble.

18. Citation extraite des commentaires de Raymond Depardon dans les bonus de l'édition DVD.

19. Ce son d'une radio arabe apparaît sur le plan 66 montrant un carrefour en plongée (point de vue de la chambre d'hôtel sans doute) et s'achève au cut entre les plans 69 (plan serré sur une petite table de la chambre) et 70 .

20. Seul véritable plan cadré ainsi, les six autres plans en caméra portée bougent très peu.

21. Selon la définition de Michel Chion, notamment celle présente dans le glossaire d'Un art sonore, le cinéma - histoire, esthétique, poétique, Cahiers du cinéma, coll. Essais, 2003, p. 425.

22. Bien sûr, il serait à peine envisageable d'imaginer que le personnage masculin regardant cette action effectue le même jeu dans un synchronisme parfait! Il ne peut donc pas s'agir du point d'écoute de celui-ci.

23. Notamment 12 plans sans voix off pendant 3 min 14 au gré d'un voyage en avion et bateau.

24. Un très furtif regard-caméra d'un serveur apportant le petit-déjeuner apparaît au plan 173, mais il n'a pas le même statut que ceux-ci.

25. Dans la Dame du lac (Lady in the Lake, USA, 1947) de Robert Montgomery, censé être «le premier film totalement en point de vue subjectif ", l'acteur-réalisateur se présente face à la caméra pour introduire le film pendant deux minutes environ, puis réapparaît plusieurs fois de la même manière, ainsi que quatre fois grâce à des miroirs ; de plus, Robert Montgomery étant une 
grande vedette de l'époque, le processus d'identification est facilité et réclamé. Dans le Dossier 51 (France, 1978) de Michel Deville, le procédé est attribué à plusieurs personnages, dont certains sont vus grâce à des miroirs. Dans la Femme défendue (France, 1997) de Philippe Harel, comme pour Empty Quarter, le réalisateur interprète le rôle masculin principal ; mais, à la différence d' Empty Quarter, sa voix est hors-champ et ses bras et ses mains entrent plusieurs fois dans le champ.

26. A l'exception à peine perceptible de l'interrupteur entendu hors-champ dans le plan 3 .

27. D'ailleurs, aucun prénom ou nom ne sont prononcés en ce qui concerne ce personnage. Au plan 89, la jeune femme lit la rubrique horoscope dans un journal ; elle lui demande quel est son signe et lit alors la notule de celui du lion, alors que Raymond Depardon est du signe du cancer.

28. "Je voulais le tourner au Vietnam, mais il était difficile d'y travailler, c'est pourquoi j'ai pensé à l'Afrique que je connaissais bien, j'ai donc transposé cette histoire. » Raymond Depardon in Dossier de presse d'Une Femme en Afrique (Empty Quarter)

29. Certaines phrases sont quasiment les mêmes.

30. Extrait de l'article paru dans Sophie $\left(n^{\circ} 2-1986\right)$ : «Le Bel Eté» de Françoise Prenant, entretien réalisé par Claude Schmitt le 28 décembre 1985 ; in Depardon/Cinéma, par Raymond Depardon et Frédéric Sabouraud, Cahiers du cinéma/Ministère des Affaires étrangères, 1993, p. 103. Note : les graphies originales sont reproduites ici, notamment les différences concernant le terme voix off...

\section{RÉSUMÉS}

Pour son premier long métrage de fiction, Raymond Depardon choisit un dispositif radical pour mettre en scène la passion amoureuse d'un homme pour une femme: ne jamais le voir ni l'entendre ; il est présent uniquement par sa voix off et les regards-caméra de cette femme. Une certaine forme de point de vue subjectif s'ancre dans les premières séquences. Pourtant, malgré une séquence en caméra portée épaule, des indices sonores et visuels troublent étrangement ce point de vue subjectif : un inattendu son interne objectif associé au personnage féminin et des questions posées au personnage-voix off restant sans réponse. Le spectateur est ainsi insensiblement amené à s'interroger sur le statut de cette voix off: temporalité variable, «dialogue improbable » entre voix off et voix in, existence même de ce personnage-voix off... Dans Empty Quarter, la voix off devient un véritable personnage relatant une histoire tout autant vécue que fantasmée.

For his first fiction feature, Raymond Depardon chooses a radical device to direct the passionate love of a man for a woman: never see him never hear him; he is only present thanks to his voiceover and the camera-glances of this woman. Kind of a shape of a subjective point of view is anchored in the first sequences. Yet, despite a hand-held shot, sound and visual clues strangely disturb this subjective point of view; an unexpected objective internal sound linked to the female character and the questions asked to the voice-over-character remain unanswered. The audience is imperceptibly led to ask itself questions on the status of this voice-over: varying time-scale, « improbable dialogue» between voice-over and voice-in, mere existence of this voice over character... In Empty Quarter, the voice-over becomes a real character telling a story which is both lived and fantasized. 


\section{INDEX}

Index chronologique : 1985

Index géographique : Afrique, Djibouti, Egypte, France, Kenya

Mots-clés : Depardon Raymond, point de vue subjectif, regard-caméra, voix-in, voix-off

\section{AUTEUR}

\section{CYRIL LAVERGER}

Cyril Laverger est Docteur en Art et Sciences de l'Art : Cinéma, Télévision, Audiovisuel (thèse sur la représentation de la société française dans le cinéma français de 1975 à 1985, soutenue en 1999 à l'Université Panthéon-Sorbonne). Il est enseignant d'histoire du cinéma, d'esthétique de l'image et de mise en scène à l'ESRA Côte d'Azur et a été chargé de cours d'histoire du cinéma à l'Université de Nice. 